\title{
Technological Extinctions of Industrial Firms: An Inquiry into their Nature and Causes
}

\author{
Steven Klepper and Kenneth L. Simons
}

This is a working paper version of a paper later published. For the newest version, please consult the published paper.

Please cite:

Steven Klepper and Kenneth L. Simons. "Technological Extinctions of Industrial Firms: An Inquiry into their Nature and Causes." Industrial and Corporate Change vol. 6 no. 2, March 1997, pp. 379-460.

The published paper has also been reprinted in a volume titled Innovation, Evolution of Industry and Economic Growth, edited by David B. Audretsch and Steven Klepper and published in 2002 by Edward Elgar.

For other papers by Kenneth L. Simons, see: http://www.rpi.edu/ simonk 


\title{
Technological Extinctions of Industrial Firms: An Inquiry into their Nature and Causes
}

\author{
Steven Klepper and Kenneth L. Simons \\ Carnegie Mellon University and Royal Holloway, University of London
}

February 1997

We thank David Hounshell, John Miller, Richard Rosenbloom, and two anonymous referees for helpful comments. Klepper gratefully acknowledges support from the Economics Program of the National Science Foundation, Grant No. SBR-9600041. 
Technological Extinctions of Industrial Firms: An Inquiry into their Nature and Causes

Steven Klepper and Kenneth L. Simons

\begin{abstract}
After a buildup in the number of firms, new industries commonly experience a "shakeout" in which the number of firms declines sharply. Three theoretical perspectives on how technological change contributes to industry shakeouts are analyzed. The theories are used to synthesize predictions concerning technological change and industry evolution. The predictions inform an analysis of four U.S. industries that experienced sharp shakeouts: automobiles, tires, televisions, and penicillin. Using data on firm participation and innovation from the commercial inception of the four products through their formative eras, we uncover regularities in how the products evolved. The regularities suggest that shakeouts are not triggered by particular technological innovations nor by dominant designs, but by an evolutionary process in which technological innovation contributes to a mounting dominance by some early-entering firms.
\end{abstract}

\title{
1. Introduction
}

Many manufacturing industries, such as automobiles and aircraft, have long been composed of a few dominant firms and a small fringe of competitors. While it is customary to think of these industries as tight oligopolies, they were not always this way. During their early years, these industries were typically composed of a much larger number of firms vying for leadership. They took on a structure closer to their modern form only after passing through a period in which there was a sharp drop or shakeout in the number of producers. For example, Thomas' Register of American Manufacturers lists almost 400 automobile manufacturers in 1910, nearly 15 years after the start of the automobile industry. By 1925 there were only about 80 automobile manufacturers listed in the Register, an $80 \%$ decline in 15 years. Judging from the 46 major new products studied by Gort and Klepper [1982] and Klepper and Graddy [1990], a majority of new products pass through periods in which there is a pronounced decline in the number of producers. While the shakeouts of the 46 products were not generally as severe as in automobiles, products often sustained a decline of $50 \%$ or more in the number of producers during their shakeouts.

What could cause these dramatic shifts in market structure? A leading candidate is technological change. A growing number of theories portray technological change 
and market structure as either coevolving (e.g., Nelson and Winter [1978], Flaherty [1980], Metcalfe and Gibbons [1988]) or simultaneously determined (e.g., Dasgupta and Stiglitz [1980], Shaked and Sutton [1987]). Indeed, recently three models featuring technological change have been proposed to explain industry shakeouts. In Jovanovic and MacDonald [1994], a major innovation triggers a shakeout by forcing out of the industry those firms unable to develop the follow-on innovations to the major innovation. In Utterback and Suarez [1993], a coalescence of producers around a de facto product standard triggers a shakeout by forcing out of the industry those firms less proficient at producing the standard. Last, in Klepper [1996] increasing returns from R\&D precipitates a shakeout by causing entry eventually to dry up and continually forcing the smallest firms to exit. To date, tests of these theories and others that link market structure to technological change have been limited. The primary purpose of this paper is to develop detailed evidence about the evolution of products that experienced shakeouts in order to evaluate the three shakeout theories and more generally to assess the role of technological change in industry shakeouts.

We consider four products that experienced sharp shakeouts and a great deal of technological change, automobiles, tires, televisions, and penicillin. Automobiles and televisions are analyzed in Utterback and Suarez [1993] and tires in Jovanovic and MacDonald [1994]. Penicillin is considered because it represents a quite different technology from the other three products. We collect detailed information for each product concerning the evolution of the industry that developed to produce it and how the product and its production process were improved over time. We rely heavily on lists of product and process innovations developed by others and supplemented by our own efforts, quantitative series on productivity, and qualitative information regarding innovation culled from various sources to reconstruct the history of technological change for each product. The evolution of the market and the technology of each product is compared to the predictions of the theories, and the findings for the four products are used together to reflect on the key premises and predictions of the theories. By concentrating on multiple products that experienced sharp shakeouts and that span various technologies and eras, we anticipated that any general patterns in the way the products evolved would be revealing about the technological determinants of 
shakeouts. Our findings suggest that shakeouts are not triggered by particular technological developments but are part of an evolutionary process that is driven by continual technological change. Technological innovation apparently contributes to a mounting dominance by some of an industry's early-entering firms, which eventually makes entry untenable and steadily drives out smaller firms with relatively high costs and low quality.

The paper is organized as follows. In Section II, we review the three theories and their implications for entry, exit, and technological change. In Sections III, IV, V, and VI we analyze respectively the history of autos, tires, televisions, and penicillin. Each of these sections is composed of three subsections: an overview of the evolution of the industry, including entry and exit patterns and brief histories of the leading producers; an analysis of product innovation; and an analysis of process innovation. In each subsection the evidence is used to reflect on the theories. In Section VII, the findings for the four products are synthesized to evaluate the key premises and predictions of the theories and the role of technological change in industry shakeouts. In Section VIII, we conclude.

\section{Theories of Industry Shakeouts}

The three theories we consider feature technological change as the prime driver of industry shakeouts. The theories developed by Jovanovic and MacDonald [1994] and Utterback and Suarez [1993] emphasize a particular technological development that triggers a shakeout. They have similar implications regarding entry, exit, and firm survival, but differ in their predictions about technological change. The third theory, developed by Klepper [1996], describes a gradual evolutionary process with contrasting implications regarding entry, exit, firm survival, and technological change.

Jovanovic and MacDonald's model, which we refer to as the innovative gamble model, builds on ideas dating back at least as far as Schumpeter [1911]. While numerous formal models embodying Schumpeter's ideas about industry evolution have been proposed (cf. Nelson and Winter [1978], Futia [1980], Metcalfe and Gibbons [1988]), to our knowledge Jovanovic and MacDonald's is the first explicitly to address a 
rise and shakeout in the number of firms. They posit that a new industry is created by a basic invention and a shakeout is triggered later by a refinement invention. The basic invention leads to a new product, and firms enter to develop it. All firms produce the same (optimal) level of output, which is determined by the shape of the average cost curve. Entry is assumed at all times to be sufficient to drive expected economic profits to zero, and the industry demand curve is assumed to remain fixed over time to focus on supply-side factors. With the demand curve fixed, entry ceases after the basic invention and the number of firms remains constant until the refinement invention.

The refinement opens up challenging opportunities for profitable innovation that only some firms will succeed at developing. ${ }^{1}$ If the innovative gamble opened up by the refinement is sufficiently attractive, entry occurs. Incumbents are assumed to have a greater probability than entrants of developing the innovations opened up by the refinement by dint of their prerefinement experience. Immediate entry is more profitable than later entry because it gives entrants the maximum chance of innovating before it is no longer profitable to be in the industry. Coupled with entry driving economic profits of entrants to zero, this insures that all entry occurs immediately as the expected profits of later entry are negative.

After entry is completed, the gamble plays out. The refinement is assumed to increase the optimal firm level of output, so that firms that innovate expand their output. This causes price to fall, which induces exit among noninnovators, giving rise to the shakeout. Incumbents have a lower probability of exit than entrants since they have a higher probability of innovating. Over time, unsuccessful innovators either innovate or exit, and eventually the number of firms stabilizes once price is driven down sufficiently that no unsuccessful innovators survive. All firms that do survive produce the same level of output.

Utterback and Suarez's theory emphasizes the role of a dominant design. The

\footnotetext{
${ }^{1}$ The notion of innovative opportunities opened up by a refinement is consistent with the idea that technologies follow trajectories initiated by major technological developments (Nelson and Winter [1977], Sahal [1981], and Dosi [1982]).
} 
notion that dominant designs directly influence corporate evolution and industrial competition has gained increasing attention over the past two decades (cf. Murmann and Tushman [1996]). The concept of the dominant design was developed by William Abernathy and James Utterback in 1975 to 1978 (Utterback and Abernathy [1975], Abernathy [1978], Abernathy and Utterback [1978]). In their original conception, a dominant design was held to be a collection of enduring product standards to which the bulk of industry output eventually conformed. Abernathy and Utterback used the concept of a dominant design to help interpret the evolution of the U.S. automobile industry.

Many industries have since been labeled as having dominant designs, under a proliferating range of definitions. Standardization of one or two individual features of a product or sometimes even a process technology was taken to constitute a dominant design in some cases, such as cement and minicomputers in Anderson and Tushman [1990], automobiles, picture tubes, and calculators in Utterback and Suarez [1993], and facsimile transmission in Baum et al. [1995]. In other cases, a whole product architecture, rather than individual features, was seen as essential to a dominant design (Abernathy and Utterback [1978], Henderson and Clark [1990, p. 14], Anderson and Tushman [1990, p. 613]). ${ }^{2}$ Some conceptions of dominant designs allow for the repeated displacement of existing dominant designs with new designs; such periodic replacement is central to Anderson and Tushman's concept of cyclic technological discontinuities. Others, including Abernathy and Utterback [1978], posit only a single dominant design for a product.

In all these views, dominant designs represent watersheds for technological change and organizational survival. Their formation is typically seen as defining new technological eras. After the appearance of a dominant design, product innovation becomes more incremental, focusing on refining the existing design, and greater effort and investment is devoted to improving the production process for the product. These

\footnotetext{
${ }^{2}$ Although Anderson and Tushman conceptualize a dominant design as an overall architecture of interacting characteristics, in practice they often resort to individual features as indicators of dominant designs.
} 
changes in innovation coincide with changes in competition. To remain competitive, organizations must keep to incremental product improvements and focus on managing their production processes. New firms, with their lesser experience and lack of an existing customer base, have less chance to break into the market than prior to the emergence of the dominant design. Conversely, innovations that disrupt a dominant design are typically portrayed as opening new opportunities for major product innovation and entry (Anderson and Tushman [1990], Henderson and Clark [1990], lansiti and Khanna [1995]), .

Utterback and Suarez [1993] exploit these ideas to fashion a theory of shakeouts. ${ }^{3}$ They focus on a single, lasting, widely-adopted dominant design in the product. The design need not be technologically optimal, as they acknowledge for cases such as the QWERTY typewriter keyboard (David [1985]). The dominant design is at the architectural level of how components are combined into an overall design, representing a "creative synthesis of the available technology and the existing knowledge about customer preferences" (Utterback and Suarez [1993, p. 7]). ${ }^{4}$ A design may become a de facto standard because of network externalities (as with the development of gas stations to service gasoline-powered cars) or preferred technological traits, or possibly a de jure standard because of industry-wide standard setting (as with television transmission regulation). Utterback [1994, p. 48] restricts the occurrence of dominant designs to complex assembled products such as automobiles.

In Utterback and Suarez's theory, a shakeout is triggered by convergence on the dominant design. When a new product is introduced, buyer preferences for possible features of the product and the technological means of satisfying these preferences are uncertain. As a result, producers enter offering different varieties of the product and

\footnotetext{
${ }^{3}$ Hopenhayn [1993] presents a related mathematical model. In his model, firms innovate relatively little until a dominant technology is established, since a new dominant technology is assumed to limit the value of previous innovations. In the model, a shakeout occurs solely from decreased entry, but this prediction results from assuming a constant exit rate, which leaves open the question whether exit would increase for the reasons argued by Utterback and Suarez.

${ }^{4}$ In practice, however, Utterback and Suarez sometimes resort to individual product features to identify a dominant design.
} 
compete based on product innovation. Experimentation by buyers and sellers leads to a resolution of uncertainty over time, contributing to the emergence of a dominant design.

After the emergence of the dominant design, product innovation slows as producers and users are reluctant to adopt innovations that upset the benefits conferred by the dominant design. This makes entry more difficult. It also reduces producer fears that investments in the production process will be rendered obsolete by major product innovations. Consequently, process innovation rises and a greater amount is invested in capital intensive methods of production. Firms less able to manage the production process exit. Coupled with the decline in entry, the wave of exit contributes to the shakeout. Suarez and Utterback [1995, pp. 420-421] hypothesize that incumbents will have lower rates of exit than post-dominant design entrants due to collateral assets and economies of scale. Christensen et al. [1996, pp. 9-10] elaborate this hypothesis. They conjecture that among pre-dominant design entrants, the later entrants will have lower exit rates because they have sufficient time to duplicate the strength of incumbents regarding collateral assets and scale economies without becoming attached to older technologies that will soon be rendered obsolete by the dominant design. ${ }^{5}$ With the onset of the dominant design era, the firms least able to survive exit. Eventually, only the firms that have adapted to the dominant design survive, so that after the emergence of the dominant design presumably firm exit rates should decline and the number of firms stabilize over time.

The innovative gamble and dominant design theories have similar implications regarding entry and exit. Both predict that entry will be concentrated early and then decline after the start of the shakeout. In Jovanovic and MacDonald, the number of firms stabilizes before the shakeout, with a possible rise in entry and thus the number of firms just prior to the shakeout. Neither of these patterns is addressed by Utterback and

\footnotetext{
${ }^{5}$ Consistent with their assumptions about effects of entry time on exit rates, Suarez and Utterback [1995] find that pre-dominant design entrants had statistically significant higher rates of survival than post-dominant design entrants in typewriters, automobiles, televisions, picture tubes, and calculators, and Christensen et al. [1996] find evidence that disk drive producers entering within the four years leading up to the time of a dominant design had statistically significant higher survival rates than other firms.
} 
Suarez. Both theories predict that the fall in the number of firms during the shakeout eventually subsides as the firms least able to adapt to the forces triggering the shakeout exit. In both theories, the firms entering during the shakeout are more vulnerable to exit than the preshakeout incumbents, but both theories allow for the long-term survival of firms that entered during the shakeout. In the innovative gamble theory, the shakeout entrants that survive have the same output and thus market share as the preshakeout incumbents; Utterback and Suarez do not address relative market shares.

The theories differ principally regarding technological change. The innovative gamble theory posits the existence of a milestone innovation just before the start of the shakeout, with no comparable breakthrough earlier in the industry's history. This innovation is posited to increase the optimum firm size. In contrast, the dominant design theory posits the emergence of a dominant design just prior to the shakeout, which need not correspond to a major innovation. The vagueness of the dominant design concept makes it difficult to test directly. A more testable implication of the theory is that the emergence of the dominant design leads to a fall in product innovation and a pronounced rise in process innovation. Assuming the dominant design induces the shakeout, this shift from product to process innovation should occur around the start of the shakeout. Nothing comparable is predicted by Jovanovic and MacDonald.

Klepper [1996] develops an alternative model of shakeouts featuring continuous opportunities for product and process innovation. The model builds on another theme emphasized by Schumpeter [1950], the advantages of large firm size for R\&D. Such advantages can lead to a rich-get-richer, self-reinforcing dynamic that Phillips [1971] used to describe how a technologically progressive industry could become dominanted by a few firms. Dasgupta and Stiglitz [1980] have formalized this idea to explain intraindustry regularities in R\&D and firm size, and Sutton [1991] has used a similar process to explain how marketing-intensive industries can become highly concentrated. Following recent growth models (e.g., Romer [1986]), Klepper's model features increasing returns from $R \& D$, which imparts an advantage to size that contributes to a shakeout. Firms are assumed to conduct both process and product $R \& D$, where $R \& D$ refers broadly to all of a firm's technological efforts, not just formally designated R\&D. 
Process R\&D reduces the firm's average cost of production. Since the value of a reduction in average cost is proportional to the firm's level of output, larger firms earn greater returns from process $R \& D$, giving rise to increasing returns. In contrast, product $R \& D$ is assumed to create new product features which open up new submarkets, so that the returns to product R\&D are independent of the firm's pre-innovation level of output. Costs of expansion are assumed to limit firm growth. This allows for initial entry and a buildup in the number of firms. As incumbents firms grow and industry price is pushed down, however, the increasing returns from process R\&D impart an advantage to the earliest entrants, which eventually renders entry unprofitable and forces the smallest and least capable product innovators out of the industry, contributing to a shakeout. The number of firms does not stabilize over time but continues to decline as the earliest entrants take over an increasing share of the market.

New opportunities for product and process innovation are assumed to arise at a constant rate over time. All innovations can be imitated, so firms must continually innovate to maintain an advantage over rivals. As incumbent firms grow, their incentive to engage in process $R \& D$ increases, leading to a rise over time in process innovation. Such innovation is concentrated among the leading firms. In contrast, firm growth has no effects on the amount of product R\&D undertaken by each firm. Firms are assumed to undertake different types of product innovations. Consequently, as the number of firms falls during the shakeout, the diversity of product innovation declines. This reduces the range of product innovations to be imitated, leading to a decline over time in the overall rate of product innovation.

This theory has a number of implications which contrast with those of the innovative gamble and dominant design theories. Similar to these theories, it predicts that entry falls off after the start of the shakeout, but it does not address the potential rise in entry just prior to the shakeout predicted by the innovative gamble theory. However, it predicts that the number of firms does not stabilize but declines steadily once the shakeout starts, in contrast to both the innovative gamble and dominant design theories. It predicts that later entrants during the shakeout will be at a disadvantage and eventually will all be forced to exit as the earliest entrants take over an increasing 
share of the market. In contrast, both the innovative gamble and dominant design theories allow for the long-term survival of firms entering during the shakeout, with these firms achieving a comparable market share to preshakeout incumbents in the innovative gamble theory. Regarding technological change, the increasing returns theory does not predict any technological milestone or coalescence around a set of product features around the start of the shakeout. It does, however, predict that product innovation declines after the start of the shakeout, similar to the dominant design theory. It also predicts that as industry output rises and firms grow process innovation rises, but this rise is not keyed to the start of the shakeout as in the dominant design theory. Last, it predicts that the largest firms will account for a disproportionate number of process innovations, which is not addressed in the other two theories.

\section{Automobiles}

The analysis of the automobile industry focuses exclusively on U.S. producers, reflecting the low level of U.S. automobile imports through the formative era of the industry.

\subsection{Industry Evolution 6}

The production of autos in the United States for the period 1899-1937 based on Census data is presented in FTC [1939, p. 7]. Only 3,720 autos were produced in 1899, and the industry was still small in 1904 when around 23,000 cars were produced. After 1904 output grew rapidly, especially from 1909 to 1919 when the annual production of autos increased from approximately 127,000 to 1.7 million, a $25.8 \%$ annual rate of growth. In the following decade, the growth rate slowed to a still impressive 11.5\%, with 5.3 million autos produced in 1929. The Great Depression hit the industry hard; by 1937 annual production was still below its 1929 level. Growth in demand was fueled by cost reductions and product improvements. Automobiles went from unreliable buggy-like vehicles with tiller steering, chain transmission, hand-cranked starting, and varying engine types to streamlined gasoline-powered cars with steering

\footnotetext{
${ }^{6}$ This section largely draws from Doolittle [1916], Epstein [1928], and Rae [1959], with other sources cited where used.
} 
wheels, shaft-driven transmissions, automatic starters, and a host of other improvements such as safety windshields and four-wheel brakes.

A large number of firms entered the industry, by some counts well over a thousand by 1920. Figure 1 shows the number of automobile producers and the annual amounts of entry and exit from 1895 to 1966. The data are based on Smith [1968], which appears to be the most reliable of several available sources at including even very small producers while excluding firms that never reached commercial production. ${ }^{7}$ Entry of automobile producers was concentrated early. In 1895-1898, 14 firms entered, followed by 19,37 , and 27 firms in 1899, 1900, and 1901, and then an average of 48 firms per year from 1902-1910, with entry peaking at 81 firms in 1907. In the next eleven years from 1911 to 1921 entry dropped sharply to an average of 16 firms per year and thereafter was negligible. With the decline in entry, the number of firms reached its zenith in 1909 at 274 firms and then began to drop off, with the dropoff accelerating in the 1920s. We date the shakeout as beginning after the peak number of firms in 1909. Exit continued to drive down the number of firms until only seven firms remained in the late 1950 s and early 1960 s.

The leaders of the industry at various times are presented in Table 1, which lists the number of cars produced in the selected years 1904, 1908, 1916, 1925, and 1936 for the top ten makes. When the industry was poised to take off in 1904, the number one producer was the Olds Motor Works, the firm generally credited with the first massproduced car, the Oldsmobile curved-dash runabout. Olds subsequently declined after its founder, R.E. Olds, left to start another firm. It was taken over by General Motors when GM was formed in 1908. The number two producer in 1904 was the Cadillac

\footnotetext{
${ }^{7}$ The timing of the shakeout and the general patterns of entry and exit are confirmed by data compiled by Thomas [1965] and Carroll and Hannan [1995]; a count of firms catalogued annually in Thomas' Register of American Manufacturers also roughly confirms the timing of the shakeout. However, a list published by Epstein [1928], as well as a much more selective list published by Thomas [1965], indicate a shakeout beginning in 1921 or 1922. A comparison with Kimes and Clark's [1985] Standard Catalog of American Automobiles, a comprehensive reference providing information about would-be and actual producers, shows, however, that these lists exclude large numbers of small producers which tended to be among the earliest firms to exit. The 1915 year-end article by the auto journalist Hatch [1915] also confirms that the number of producers was already declining (sharply) by 1911. All the lists indicate an eventual decline in entry and a continuation of the shakeout until the mid-1950s.
} 
Motor Car Company, famous for its high quality, precision-engineered cars. It too was taken over by GM soon after its formation. Buick, the nucleus of GM, was started in 1903 and was the number two producer when it was taken over by GM in 1908. Later GM acquired Chevrolet, which had been started by William Durant, the founder of GM, after his initial ouster from GM in 1910. In the 1920s GM rode the low-priced Chevrolet to become the number one auto producer, surpassing Ford. Ford Motor Company was started in 1903 and was the number one producer by 1908. Ford pioneered the mass produced Model T, which dominated auto sales until the mid-1920s when it became increasingly obsolete due to Ford's unwillingness to adopt the latest technological advances.

Two other companies of note in the top ten in 1904 were Overland and MaxwellBriscoe, producer of the Maxwell. The former rose to the number two spot in the industry by 1916 after it was taken over by John North Willys and its name changed to Willys-Overland, only to decline subsequently after Willys withdrew from active management and the company encountered engineering problems. Maxwell-Briscoe also fell on hard times after it merged with a number of firms into U.S. Motors, which was later reorganized as Maxwell Motors. Both Willys-Overland and Maxwell hired Walter Chrysler, who had left the presidency of GM due to a clash with Durant's management style, to reorganize them. Chrysler began development at WillysOverland of a new car which he later used at Maxwell as the new product for what became Chrysler Motors. In 1928 Chrysler acquired Dodge, a leading producer that had been started by the Dodge brothers in 1914 after a long association supplying Ford with engines and transmissions, and in the 1930s Chrysler grew to be the number three producer. Two other long-lived firms not in the top ten in 1904 that rose to prominence in the 1910s and 1920s were Studebaker, the leading carriage maker that began producing electric automobiles in 1902, and Hudson, a new company formed in 1909 by alumni of Olds Motor Works.

Over time, the market structure of the automobile industry became increasingly concentrated. In 1911, Ford and GM, the top two firms, accounted for $38 \%$ of the total number of automobiles sold (FTC [1939, p. 20]). In the 1920s their combined share 
generally exceeded $60 \%$. Along with Chrysler, in the 1930s they accounted for over $80 \%$ of total sales (FTC [1939, p. 20]). Their combined share continued to increase subsequently as the number of producers dwindled.

The time paths in entry and the number of firms and the timing of entry of the market leaders can be used to reflect on the theories. The concentration of entry early and the decline in entry after the start of the shakeout is consistent with all the theories. The continued decline in the number of firms for over fifty years after the start of the shakeout and the increasing market share of the leaders, however, are consistent only with the increasing returns theory. Nearly all the leaders of the industry after the start of the shakeout were firms that had entered prior to the shakeout, most prior to 1905 . The only exception was Chrysler, but even Chrysler was not a true new entrant but a continuation of a firm whose heritage dated to 1904 .

\subsection{Product Innovation}

In this subsection, we analyze the history of product innovation in automobiles. We focus on both innovation and the diffusion of innovations across producers. This provides a sense of the technical challenges facing auto producers on the product side and also whether a dominant design or a major product innovation might have triggered the shakeout. We rely centrally on a comprehensive list of 631 U.S. auto innovations for the period 1893 to 1981 developed by Abernathy et al. [1983]. Innovations were divided into product and process categories and ranked on a seven-point "transilience" scale in terms of their impact on the production process. ${ }^{8}$ We use other sources to assess the extent and pace with which innovations diffused across producers. We focus particularly on innovations through 1940, after which only twelve firms were left in the industry.

To begin, we consider the pattern of innovation over time. The number of product innovations and the sum of the squared transilience scores of product innovations were

\footnotetext{
${ }^{8}$ This is one measure of the significance of an innovation. Judging from other lists of major auto innovations, such as in Pound [1934, pp. 435-47] and FTC [1939, pp. 893-919], the major auto innovations generally received higher transilience ratings.
} 
computed in each year. Figure 2 plots the five-year moving average of each index to smooth out year-to-year variations. Both curves show a similar pattern. Product innovation is greatest from about 1899 to 1905 . After 1905, it peaks in 1912-1915, then again at a higher level in 1922-1925, and is higher again in the early 1930s based on the transilience-weighted index.

Product innovations ranked 4 or higher by Abernathy et al. are listed in Table $2 .^{9}$ The early innovations through about 1905, including the front-mounted four-cylinder engine, shaft-driven transmission, and pressed steel frame, reflect the evolution of the automobile from its carriage and bicycle origins to the design of cars pioneered in France. Such autos were large and expensive and provided a great opportunity for a car with the benefits of the French design at the low price of the popular Olds runabout (Langlois and Robertson [1991, p. 366]). Ford's Model T seized that opportunity in 1908. The Model T employed a simple four-cylinder engine with integrally cast cylinder block and crankcase, detachable cylinder heads, three-point suspension, and steel alloys and heat treatments to achieve strength in lightness. Its planetary transmission was simple to operate and rugged for demanding country roads. The magneto integrated into the flywheel provided efficient ignition and lighting. Most importantly, it was priced right at $\$ 850$, with subsequent process and product innovations reducing its price to $\$ 360$ by 1916 (Hounshell [1984, p. 224]). Subsequent innovations in the 1910s and 1920s improved every aspect of the French design, making the novel features of the Model T obsolete well before it was retired in 1927. Innovations after the mid-1920s largely refined the characteristics of the auto rather than broke new ground (cf. Rae [1959, p. 154]).

Many firms contributed major product innovations. The two leading firms, Ford and GM, accounted for only $33.7 \%$ of the 52 product innovations in Table 2, considerably less than their share of the market after the start of the shakeout. Relatively minor producers contributed a disproportionate share of innovation not only

\footnotetext{
${ }^{9}$ An exception is the Synchromesh transmission introduced by Cadillac in 1924. Although it was only rated a three in terms of its impact on production, it was included because of its significance.
} 
during the early years of the industry, but also after the start of the shakeout.

Diffusion of major product innovations generally occurred rapidly. Bigger engines, improved sliding gear transmissions, the closed body, the electric self starter, and fourwheel brakes were all quickly adopted by manufacturers. For example, by 1926 over $70 \%$ of cars produced had closed bodies, following Hudson's 1922 inexpensive closedbody design; within two years of the development of the electric starter, over $90 \%$ of manufacturers offered it as standard equipment; and over $90 \%$ of manufacturers had adopted four-wheel hydraulic brakes within five years of their introduction (Epstein [1928], pp. 110-112). This was partly a reflection of the cross-licensing agreement in force in the industry since 1915. It provided free licensing of all but radical patents to members of the National Automobile Chamber of Commerce, which included all the bigger firms except Ford. ${ }^{10}$ Other major innovations such as the electric self starter and the closed body diffused rapidly through suppliers.

The historical record thus suggests that there were many significant product innovations through the mid 1920s from a broad range of firms. Their rapid diffusion suggests that it was important to keep up with them to remain competitive. Can a credible case be made from the historical record for the emergence of a dominant design or a major product innovation a la the innovative gamble theory that might have caused the shakeout? Focusing first on the innovative gamble hypothesis, there does not seem to be a product innovation with sufficient competitive implications to have caused the shakeout. The highest rated product innovations in terms of their transilience scores through 1940 are Cadillac's V-8 engine in 1914, the inexpensive closed body pioneered by Hudson in 1922, and the automatic transmission by Oldsmobile in 1940. Certainly another major innovation was the electric self starter, developed by Dayton Engineering Laboratories for the 1912 Cadillac. Only the self

\footnotetext{
${ }^{10}$ Despite applications for exemptions for major patents such as Hudson's 1916 balanced crankshaft, in the first ten years of the agreement no patent was granted such an exemption (FTC [1939, p. 58]), and innovations such as Cadillac's synchromesh transmission were widely licensed (Renner [1973, p. 411]). Prior to 1915, the most significant patent was the Selden patent, which claimed to cover the basic design of the modern automobile. Although royalties were collected on this patent for many years until it was successfully challenged by Ford on behalf of many manufacturers, the royalty rate was quite modest and it was licensed to all comers.
} 
starter and V-8 are close to the start of the shakeout. Yet the self starter was widely purchased from its supplier, Dayton Engineering Laboratories, and the V-8 was not a major competitive force until the 1930s. Ultimately, the closed body may have had significant competitive implications in terms of the dies and presses required to produce it (cf. Katz [1971, pp. 295-302]), but it came too late to trigger the shakeout. ${ }^{11}$

In terms of a dominant design triggering the shakeout, a case would have to be made for a dominant design emerging around 1909. The only possible candidate is the Model T. Abernathy [1978, p. 78] notes how the Model T solidified a number of features of the automobile and Langlois and Robertson [1991, pp. 366-7] discuss how the development of the Model $\mathrm{T}$ caused radical product innovation to give way to incremental product changes and how the focus of innovation began to shift toward process innovation, characteristic of a dominant design. Yet it is hard to see the Model $\mathrm{T}$ as defining a design that would not change much in future years, nor as defining a design that would make it safe to invest in process innovation without fear of obsolesence of the investment. By the early 1920s, product innovation had largely rendered obsolete the novel features of the Model $\mathrm{T}$, which itself had undergone significant changes since 1908. Its magneto integrated into the flywheel, planetary transmission, and brakes were all targets for criticism when it was finally retired. Furthermore, four-cylinder engines had largely been replaced by six-cylinder ones, and closed bodies, which had been incorporated into the Model $T$ in the 1920s, were widespread. Indeed, the Model A that replaced the Model T bore little resemblance to its famous forebear, embodying many of the advances that had made the Model $T$ obsolete. Although identifying a dominant design requires considerable subjectivity, in their article on innovation and industry structure Utterback and Suarez [1993, p. 8] identify the all-steel closed body of 1923 as dating the emergence of a dominant design in autos. If it makes sense to single out a dominant design in the face of continual innovation, this seems a reasonable choice, but it comes too late to have triggered the shakeout. Moreover, as we relate in the next subsection, it comes well after the

\footnotetext{
${ }^{11}$ Moreover, when it was introduced there were a number of major, independent body manufacturers supplying it, including the firm that produced it for Hudson.
} 
enormous rise in process innovation that ushered in the industry's era of "mass production" and thus could not have had the influence on innovation required of a dominant design.

The timing and nature of product innovations is broadly consistent with the increasing returns theory. The theory predicts a decline in product innovation after the start of the shakeout, with product innovations dispersed widely. The former prediction is consistent with the finding of product innovation peaking around 1905, with later innovations largely refining the characteristics of the automobile rather than breaking new ground. The latter prediction is consistent with the large number of firms that contributed major product innovations and the fact that the two leading firms accounted for a smaller share of major innovations than their share of the market. Last, the theory assumes that innovations are imitated quickly and do not provide lasting competitive advantage, which is consistent with the widespread and rapid diffusion of product innovations.

\subsection{Process Innovation}

We begin the analysis of process innovation by examining the pattern of innovation over time, using the Abernathy et al. list of process innovations supplemented with series on labor productivity and capital per wage earner. The five-year moving averages of process innovation, including both transilience weighted and unweighted indexes, are presented in Figure 3. In contrast to product innovation, the trend in process innovation is clearly upward from the start of the industry through 1915 or so. It then drops but reaches a new high around 1923 and an even greater high in the early 1930s, after which it drops sharply. Two measures of labor productivity, number of cars per wage earner and value added per wage earner, are presented for Census years in the period 1899-1937 in Table 3. Also presented are figures on capital per wage earner from 1904 through 1927. These series are crude indicators of process innovation, but they reflect a pattern similar to the process innovation counts. There was little change in productivity and capital per wage earner until 1909, then rapid growth in the period 1909 to 1921 at an annual rate of $12.5 \%$ for output per wage earner, $6.9 \%$ for value added per wage earner, and $13.3 \%$ for capital per wage earner. Between 1921 and 
1929 growth in the three measures is more modest, after which the Great Depression depressed both output and labor productivity. Coupled with the Abernathy et al. list, it appears that process innovation was low until 1909, thereafter increased through roughly 1923 , and then decreased to a lower but still high level in the early 1930 s, after which it declined sharply.

Process innovations ranked 4 or higher by Abernathy et al. are listed in Table 4. The innovations through 1902 established standardized designs and the first interchangeable automobile parts, making mass production of automobiles feasible. The most dramatic improvement in manufacturing, however, occurred when Ford pioneered the mass market automobile with the Model N and T cars. From 1907 to 1920, an array of new production techniques at Ford helped define the company's new system of production. In the 1920s, the majority of innovations involved new methods of body production, finishing, or welding, reflecting the advent of the cheap closed body and the progressive substitution of steel for wood in closed bodies, while innovations in the 1930s reflect efforts by Ford to compete with new models from GM and Chrysler.

Ford's 1907 to 1920 innovations can be divided into five types. First, specialpurpose machine tools were developed to perform multiple operations on parts simultaneously, such as drilling forty holes in an engine block. These tools not only economized on labor, but with improved gauges and indicators also facilitated the precision manufacturing required for interchangeable parts. Second, production methods for new metal alloys such as vanadium steel made possible lighter and stronger components. Third, new methods were developed to manufacture major components, such as casting the cylinder block and crankcase as one unit. Fourth, branch assembly plants economized on freight costs by eliminating shipping of bulky, finished automobiles. And fifth, the famous moving assembly line dramatically reduced labor requirements.

The industry's major process innovations were dominated by Ford and GM. From 1907 to 1920, all but two of the innovations listed in Table 4 were developed by Ford. In the 1920s, the majority of process innovations were introduced by GM, and then in the 1930s all the innovations were from Ford. This pattern contrasts sharply with the major 
product innovations listed in Table 2, for which Ford and GM's share together was only $35 \%$ for $1910-1919$, 39\% for $1920-1929$, and $29 \%$ for $1930-1939$, with Ford accounting for only two out of thirty-five major product innovations over all these years.

Similar production methods to those developed at Ford and GM spread rapidly, but by no means costlessly, to other firms. Walter Flanders, who had been instrumental in a number of the early process innovations at Ford before he moved to the EverittMetzger-Flanders Company (E-M-F) in 1908, installed many machine tools new to the industry at E-M-F, which was later acquired by Studebaker (Doolittle [1916, p. 155]). Similarly, machine tool builders developed many novel machine tools for Buick in response to insistent and sometimes imperious demands that in some instances took months or even years to satisfy (Chrysler [1937, p. 137]). When it built its engine plant in 1916, Hudson equipped it with highly specialized milling, drilling, and grinding machines capable of multiple operations such as boring a series of holes in a cylinder block from several angles (Renner [1973, p. 113]). Many firms also established foundries and metal labs following Ford. For example, Studebaker had a lab headed by a top metallurgist to test materials. It also had an efficiency department to study all aspects of production and a factory devoted to experimentation (Smallzreid and Roberts [1942, p. 235]). Judging from a Bureau of Labor Statistics study of the productivity effects of changes in methods and machinery in the auto industry based on twenty-five establishments (La Fever [1924]), the use of numerous special-purpose machine tools, specialty metals, and new heat treating and forging methods was widespread and afforded tremendous reductions in man-hours per car in the 1910s and 1920s. The moving assembly line was also widely imitated soon after its implementation at Ford, no doubt spurred by Ford's openness about his methods. A March 1916 article in Motor Age (Spencer [1916]) recounts in some detail the moving assembly line at the Maxwell plant in Detroit and cites similar assembly lines at a number of other leading firms, including Hudson, Packard, Overland, Studebaker, Dodge, Reo, Paige, and Saxon. Not all firms caught up quickly, and Hudson (cf. Renner [1991, pp. 113-4]) and other leading firms long relied in part on hand work and fitters (Raff [1991, pp. 729, 731]). Moving assembly-line methods at least at Studebaker, however, were compared favorably with 
Ford's methods (Colvin [1915]). ${ }^{12}$

What can we learn from the early process innovations at Ford and the subsequent process innovations in the 1920 s and 1930s concerning the determinants of the shakeout in autos? Can the process innovations at Ford qualify as the triggering innovation in the innovative gamble theory? Together, the five key types of process innovations at Ford have many of the defining attributes of the triggering innovation. Their timing corresponds with the start of the shakeout. They collectively led to tremendous growth in labor productivity and brought about decreases in cost of immense competitive significance. Judging by the experience of Hudson, they were challenging to master. Finally, they no doubt increased the minimum efficient scale of operations, a requisite feature of the triggering innovation in the innovative gamble theory. On the negative side, however, the innovative gamble theory stresses the importance of a distinctive innovation based on developments outside the industry, yet the Ford system was based on an interrelated set of innovations developed by Ford with little outside influence. If one innovation had to be singled out, it would be the moving chassis assembly line, yet that came too late to trigger the shakeout. Indeed, it seems awkward to distinguish one particular innovation at Ford, for what emerged was truly a system composed of a number of innovations that evolved over a span of at least seven years beginning prior to the model T (Sorensen [1956, pp. 113-28], Nevins [1954, pp. 324-27, 349]). It is also awkward to speak about the Ford system as if process innovation did not subsequently continue in the industry. Both the Abernathy et al. series and the productivity measures suggest that process innovation remained at an extremely high rate through at least the middle 1920s if not beyond. Furthermore, the 1920s ushered in a new era of "flexible mass production" which required new production methods to avoid such debacles as Ford's switchover from the Model $\mathrm{T}$ to the Model A (cf. Hounshell [1984, pp. 263-301]).

Regarding the dominant design theory, we have already seen that the shakeout

\footnotetext{
${ }^{12}$ Assembly lines at other firms, though, may not have fully embraced Fordist principles, particularly the centralized control of workers afforded by the assembly-line pacing of work (Raff [1991, pp. 727-31]).
} 
preceded the development of a legitimate candidate for a dominant design by fifteen years. Perhaps more interesting is the great rise in process innovation and investment in new machinery and methods at Ford and elsewhere that occurred well before product innovation slowed significantly and equipment stabilized. Indeed, the start of process innovation at Ford even predated the Model T, and machine tools turned over at a rapid rate throughout the production of the Model T (Sorensen [1956, p. 123]), culminating in the $\$ 18$ million cost of refurbishing and replacing machine tools when Ford switched from the Model T to the Model A in 1927 (Hounshell [1984, p. 288]). Ford's success with the Model T drew heavily from his willingness to innovate on the process side even in the face of significant product innovation and rapid obsolescence of process investments. The success of other leading companies such as Buick, Studebaker, and Hudson also stemmed from their early commitment to process innovation. Indeed, companies that floundered in their management of the production process in the 1910s, such as Willys-Overland, squandered much of their early lead.

Process innovation in general and at Ford in particular in the 1907-1914 period has all the earmarks of the increasing returns to $R \& D$ hypothesis. First, it involved a great amount of resources to pull off. For example, Nevins [1954, p. 504] described the large labor force at Ford devoted in 1914 to what he called creative preparations for mass production--fifty-nine men making drawings for machine tools and fixtures, forty making patterns for tools, and nearly five hundred at Highland Park and three-hundred in outside machine shops building machine tools. Four years earlier, Flanders noted how to be competitive, auto makers had to invest in experimental laboratories for analyzing and testing materials whose cost, "with its necessary adjunct, the machine shop for tool and jig making, would amount to more than the earlier makers had ever invested in factories."13 The working out at Ford of the moving chassis assembly line alone involved eight months of no doubt costly experimentation. Second, the surge in process innovation occurred when the industry's output started to grow rapidly and firms developed a much larger output over which they could reap the returns from process innovation. Ford epitomized the self-reinforcing process inherent in increasing returns

\footnotetext{
${ }^{13}$ Quoted in Nevins [1954, p. 476].
} 
to $R \& D$, with each success contributing to lower prices and greater output that spurred further efforts to lower cost. Third, the largest firms were clearly in the vanguard of process innovation. Process innovation was far more concentrated in the biggest firms than product innovation throughout the formative era of the industry, and the largest firms were the first to imitate Ford's innovations. Fourth, the immense and continuous competitive significance of process innovation is attested to by the rapid labor productivity growth after 1909 and by the continuation of major process innovation throughout the industry's shakeout. In light of all of these factors, it is not hard to envision how process innovation a la the increasing returns to R\&D theory could have contributed to the eventual drying up of entry and the protracted shakeout of producers.

\section{Automobile Tires}

As with automobiles, we focus exclusively on U.S. producers of automobile tires given the small level of imports through the formative era of the industry.

\subsection{Industry Evolution ${ }^{14}$}

Automobiles have used pneumatic tires almost exclusively from their inception, and the U.S. automobile tire industry grew along with the U.S. automobile industry. Sales of pneumatic tires broken down into original equipment $(\mathrm{OE})$ sales to automobile manufacturers and renewal sales are reported by French [1991, p.16] for 1901-1909 and Gaffey [1940, p. 55] for 1910-1936, with OE sales accounting for approximately $30 \%$ of all sales. The market for tires was still quite small in 1905 , with 334,000 tires sold, but it was about to be propelled to new levels by the growth of the automobile industry. In the decade 1909-1919, unit sales of pneumatic tires grew by an average of $29 \%$ per year to over 30 million in 1919. Sales declined in 1920 and 1921 during the national recession, then resumed their growth, yielding an average $8 \%$ annual growth from 1919 to 1929 to over 67 million in 1929. The industry was hit hard by the Great Depression, and by 1936 sales had still not recovered their 1929 level.

\footnotetext{
${ }^{14}$ This section draws from French [1991], Allen [1949], O’Reilly [1983], Lief [1951], and Babcock [1966].
} 
Entry into tire production was initially modest, but eventually the number of producers reached heights similar to those in the automobile industry. Figure 4 indicates the number of firms and annual entry and exit from 1905 to 1980 . These data are compiled from annual editions of Thomas' Register of American Manufacturers. ${ }^{15}$ From 1906 to 1911 the average annual number of entrants was approximately 15 and then doubled to 30 from 1911-1922, with entry peaking at 115 firms in 1922 when the number of producers also peaked at 274 . We date the shakeout as beginning around 1922, after the peak number of firms. ${ }^{16}$ Thereafter, entry dropped to negligible levels. Continuing exit steadily drove down the number of firms through the 1960 s to a low of 23 producers in 1970.

The industry was dominated by five firms, which early were reduced to the "big four" by a merger of two of the leaders. The big four firms were, in order of their entry, B.F. Goodrich Company, Goodyear Tire and Rubber Company, Firestone Tire and Rubber Company, and the United States Rubber Company. Comprehensive early market share data are not available for the firms, but their market shares for selected years in 1921-1933 are presented in Table 5. Goodrich was a leading producer of rubber products in Akron, Ohio when it produced the first pneumatic tires used on a commercially produced U.S. automobile in 1896. In 1912, Goodrich merged with its local rival, Diamond Rubber Company, with the two firms having a combined market share of between $20 \%$ and $25 \%$, which subsequently declined sharply under weak management. Goodyear Tire and Rubber also started in Akron in 1898. It overcame early patent roadblocks through innovation and aggressive legal action and by 1916 was the leading producer of tires, with GM its major OE customer. In the 1910s Goodyear integrated backward into rubber and cotton growing and production of its own cotton cords. In 1926 it secured the private label business of Sears Roebuck, and as

\footnotetext{
${ }^{15}$ The time path in the number of tire manufacturers and the general pattern of entry and exit, though not the precise number of firms, coincide with counts of firms based on the Census of Manufactures presented by Gaffey [1940, p. 88] and with counts of entry, exit and the number of firms pieced together by French [1986, p. 33] for the years 1914-1937.

${ }^{16}$ Judging from French's series and other sources, Thomas' Register may have been delayed by a few years in its listings of a number of tire entrants and the shakeout may actually have begun one to three years earlier than is reflected in the data from Thomas' Register.
} 
Table 5 indicates, by 1933 it had increased its leading market share to $30.1 \%$. Firestone was the other member of the big four to locate in Akron in 1900. When its entry into the pneumatic tire market was blocked by patents, Firestone followed Goodyear's lead by developing a new tire. In the 1920s Firestone acquired textile mills to produce its own cotton cord and took out a long-term lease on a Liberian rubber plantation. Although Firestone's market share in Table 5 was only $8.2 \%$ in 1921, it had been and would again be higher, rising to $19 \%$ in 1929 . U.S. Rubber, the last of the big four, was a trust formed from nine companies in 1892 to control the rubber footwear business. In 1905 it acquired the Rubber Goods Manufacturing (RGM) Company, which had four subsidiaries producing tires. RGM controlled important patents that enabled U.S. Rubber to become the number one automobile tire producer in 1912, but it was slow to recognize the superiority of new tire designs and failed to rationalize production among its various tire plants. As a consequence, Table 5 indicates that by 1921 its market share had declined to $8.5 \%$. In the 1930s its market share rose dramatically after the Du Ponts, major shareholders in GM, gained control of the company, and it acquired a large portion of GM's business and secured with Goodrich the private label business of Montgomery Ward and three other major chains. Together, the big four increased their joint market share to $72.1 \%$ by 1933 , after which their share of the market remained steady as automobile manufacturers spread their OE business among the industry leaders to preserve competition.

In terms of the theories, the sharp drop in entry after the start of the shakeout is consistent with all the theories. The tremendous surge in entry around the start of the shakeout, though, is predicted only by the innovative gamble theory. The steady decline in the number of producers for over fifty years after the start of the shakeout is consistent only with the increasing returns theory. Although the failure of the leading firms to increase their market share after the 1930s is not consistent with the increasing returns theory, this seems largely attributable to the auto companies spreading their business among the leading firms to maintain competition. Last, the total dominance of the industry after the shakeout by four of the earliest entrants is predicted only by the increasing returns theory. 


\subsection{Product Innovation}

To analyze product innovation in tires, we rely on a list of major tire product innovations for 1895-1965 compiled by Warner [1966] in his doctoral dissertation on tire product innovation. The list includes innovations developed by the tire manufacturers and non-tire, principally chemical, firms. Focusing on the innovations credited to tire manufacturers (shared innovations are split), the number of innovations per decade was 6 in 1901-1910, 1.5 in 1911-1920, 5 in 1921-1930, and 3.5 in 1931-1940. These counts suggest product innovation was concentrated early and then rose again in the first decade of the shakeout, declining somewhat in the 1930s as the shakeout continued.

A closer look at the character of the innovations reinforces this impression. Table 6 reports the innovations listed by Warner for the period 1895-1940, which covers the brunt of the shakeout. ${ }^{17}$ Innovations through 1930 predominantly involved the design of the tire and new chemicals. The design innovations, most prominent up to 1910 and in the 1920s, defined the basic character of the tire and along with new fabrics and additives yielded a large improvement in tire performance. The innovations in the 1930s predominantly involved the development of substitute materials for cotton cord and natural rubber and had less effect on performance. The lifetime mileage of tires reflects these patterns. Using figures assembled from various sources by Warner [1966, pp. 306-307], the annual growth in average tire mileage per decade was $5.1 \%$ in $1910-1920,11 \%$ in $1920-1930,3.8 \%$ in $1930-1940,2 \%$ in $1940-1950$, and $1.7 \%$ in $1950-1960 .^{18}$ This reinforces the impression from the simple counts of product innovation that the rate of product innovation increased in the 1910s to reach a peak in the 1920s and declined steadily thereafter.

The cord and balloon tire designs were the most outstanding changes around the time of the shakeout, and given their competitive importance, it is worthwhile to review their interdependent history. The gradual switch from fabric to cord and then balloon

\footnotetext{
${ }^{17}$ The innovations listed agree closely with two other lists of major tire innovations presented in Dick [1981, p. 25] and Tire Business [1988, pp. 26-29].

${ }^{18}$ The same pattern holds after adjusting for the effect on mileage of changes in the average driving speed and tire pressure (cf. Warner [1966, p. 319]).
} 
tires is documented in Table 7. The cord tire innovation removed the cross threads from cotton fabric used in the plies of tires. This eliminated the abrasion of cotton cord against cord, which was a major factor limiting tire mileage. ${ }^{19}$ Although they significantly increased mileage, cords were initially two to three times as expensive as fabric tires, which as Table 7 indicates greatly limited their initial rate of adoption. Innovations by Goodyear and later Firestone in cord thickness, methods of impregnating the cords with rubber, machinery to cut the cord plies, and vulcanization processes gradually made cords more competitive and spurred their adoption, as reflected in Table 7. As a result, Goodyear and Firestone captured a substantial share of the market for cords (Allen [1949, pp. 37-39], Lief [1951, pp. 103-5]), which helped Goodyear to become the number one producer in the industry by 1916 (Allen [1949, pp. 39-40]).

The balloon tire was an outgrowth of gum dipping, a new method of impregnating cords with rubber developed by Firestone. ${ }^{20}$ Gum dipping contributed to a more resilient and flexible tire that enabled Firestone to widen the cross section of the tire. Firestone engineers discovered that with greater air capacity, the pressure in the tire could be greatly reduced, making it possible to lighten the tire through less plies and a lighter tread. The result was a smaller, squatter, softer tire resembling a balloon. While it was designed for a more comfortable ride, unexpectedly the balloon tire also greatly increased tire mileage. Firestone began selling balloon tires in late 1923. The tire's requirement for new wheels and rims and modifications of new automobiles slowed adoption (Lief [1951, pp. 139-40]), but by 1925 Ford and other major manufacturers adopted it, and the tire caught on rapidly.

Table 6 indicates that tire product innovation was dominated by the big four plus

\footnotetext{
${ }^{19}$ Diamond Rubber, followed quickly by Goodrich, introduced cord tires in the U.S. in 1910 based on a license from Palmer Cord Tyre Company, the developer of the Palmer Cord tire in England. The Palmer patent did not block the development of alternative cord designs and many firms developed cord tires; 38 of 80 firms listed in Tufford [1920] are denoted as producing cords.

${ }^{20} \mathrm{~A}$ patent on the balloon tire was initially granted to an independent inventor, but the tire was later ruled to be a logical outgrowth of past design changes and the patent was overturned (Warner [1966, p. 103]).
} 
Diamond, which was in the top five producers before it merged with Goodrich. These firms accounted for all the major tire design innovations. With the exception of one innovation on which Lee was given partial credit, they also accounted for every other major product innovation through 1940 that was credited to tire producers. This pattern persisted after 1940 as well, with the big four accounting for all the subsequent major tire product innovations on Warner's list for 1940-1965 that were credited to tire firms.

The rate of diffusion of the major tire design innovations is reflected in Table 7, which reports the annual percentage of tire sales by the clincher and straight-side designs and by fabric, high-pressure cord, and balloon tire construction for 1910-1933. Spurred on by licensing restrictions on the patented clincher tire, Goodyear and Firestone developed the straight-side in $1905 .{ }^{21}$ Straight-sides were subsequently introduced by many tire producers, but as Table 7 indicates clincher tires continued to be used widely for many years, especially on lighter cars such as the popular Model T and Chevy. As noted above, cord tires also diffused gradually for many years until the balloon tire, which was adopted quickly. The other major innovations tended to diffuse rapidly. A separate industry developed to supply and improve carbon black, a chemical added to rubber to increase the life of the tire tread (Warner [1966, pp. 194-209]), thereby facilitating adoption of the latest advances. Patents on accelerators, antioxidants, and other rubber chemical innovations were generally easy to invent around through minor modifications in the new compounds (Warner [1966, p. 220]), and these chemicals were generally available from suppliers and widely used (Warner [1966, pp. 214-218]). ${ }^{22}$ Among the tire cord innovations, long staple cotton was widely used from the outset of the industry, and first order high-twist cotton was part of a continuous stream of improvements whose adoption was not blocked by patents

\footnotetext{
${ }^{21}$ The clincher tire was secured to the wheel by a thick bead of rubber around the inner edge of each side of the tire which fit under the inwardly curved flanges of the clincher rim. The straight-side used wire covered by rubber to form an inextensible bead that provided a more secure way to fix the tire to the rim and made it easier to change. Licensing restrictions on the clincher tire were later nullified by a ruling limiting clincher patents to bicycles.

${ }^{22}$ Accelerators speed up the vulcanization of rubber (the application of heat under pressure to make rubber resilient to temperature changes and other forces), and antioxidants slow the aging of tread and sidewall rubbers. Secrecy rather than patents was the main device for appropriating returns from rubber chemical innovations (Warner [1965, p. 220]).
} 
(Warner [1966, pp. 137-141]).

What does this evidence imply about the causes of the industry's shakeout? The major tire design innovations, in light of their importance, are the likely place to look for a product innovation that might have played the role of the triggering innovation in the innovative gamble theory. Judging from Table 7, none of the design innovations prior to the balloon was quickly adopted, suggesting that none of them could have triggered the shakeout in tires. The balloon seems a viable candidate for the triggering innovation, although by the time it began to be widely adopted the shakeout was at least a few years old. Jovanovic and MacDonald consider but do not nominate the balloon as the innovation in their theory that triggered the shakeout in tires. Perhaps this is because of the timing of the balloon or because the balloon diffused quickly once it became popular, suggesting that it was not terribly challenging to adopt. It may also be because there is no evidence suggesting the balloon increased the minimum efficient size firm, which was quite small relative to the size of the market (Reynolds [1938]).

In terms of the dominant design theory, in light of the slow diffusion of straight-side and cord tires prior to the balloon tire, it does not seem reasonable to talk of a dominant design in tires until the widespread adoption of the balloon starting around 1925. As noted above, this comes at least a few years after the start of the shakeout. Nevertheless, this does not preclude the possibility of a dominant design corresponding to the balloon tire playing an important role in the shakeout.

In terms of the increasing returns theory, the rate of product innovation appears to have peaked soon after the start of the shakeout, consistent with the theory. On the other hand, product innovation was almost entirely concentrated in the leading firms, which the theory predicts for process but not product innovation. Indeed, the concentration of product innovation in the top firms is striking--although over 600 firms produced tires at some point according to the list compiled from Thomas' Register, the leading five firms accounted for nearly all the major product innovations. This is almost as extreme as the concentration of process innovations in the leading auto producers. It may reflect the fundamental character of a number of the product innovations, particularly the design innovations. Although some of these innovations opened new 
submarkets as portrayed in the theory, they also greatly increased tire mileage and the smoothness of the ride, clearly attributes valued by all users. That these innovations were not pursued by smaller firms is perhaps not surprising. For a later era, Warner [1966, p. 246]) notes that at most the top seven firms could have afforded a research program required to stay at the technological frontier.

\subsection{Process Innovation}

In contrast to product innovation, no series has been compiled on tire process innovations. Several studies and articles in the trade press, however, review major process developments and the sources of productivity growth in tire manufacturing. Labor productivity data are also available from 1914, when the tire industry was first distinguished as a separate industry in the Census. Before 1914, labor productivity data are available for the rubber industry and fragmentary productivity data are available for Goodrich, Goodyear, and Firestone. Together, this information is used to analyze the nature of process innovation during the formative decades of the industry.

We begin with the data on labor productivity, presented in Table 8. Indexes are presented for tires per man hour and value added per man hour for various years from 1914 to 1937. Also reported is an index of tires per direct man hour for six leading tire plants in 1914 and 1922-1931. These six plants accounted for $45 \%$ of total tire output in 1922 and 60\% in 1931 (Stern [1933]).

All three series reflect a similar pattern. Tires per man hour in all plants grew by an average annual rate of $12.7 \%$ in $1914-1924$ versus $3.7 \%$ in $1924-1937$. Tires per direct man hour in the six plants grew by $11.9 \%$ in $1914-1924$ versus $7.8 \%$ in 1924-1931. Value added per man hour for all plants similarly registered its biggest growth early, growing by an average annual rate of $8.9 \%$ from 1914-1923 and then slowing to a $1.2 \%$ annual growth from 1923-1935. Kendrick's estimates of labor productivity for the entire rubber industry suggest that the high growth rates beginning in 1914 may have started as early as 1909 , with annual rubber output per man-hour rising by $2.5 \%$ in $1899-1909,7.8 \%$ in $1909-1919,8.4 \%$ in $1919-1929$, and $3.5 \%$ in $1929-1937$ (French [1985, p. 266]). Fragmentary productivity data for Goodyear, Goodrich, and 
Firestone prior to 1914 show a similar pattern, with uneven growth through 1909 and then high growth subsequently. Crude estimates of total factor productivity growth compiled by French [1985, p. 362] similarly show no growth prior to 1909, with annual TFP growth rising from $3.1 \%$ in $1909-1919$ to $12.6 \%$ in $1919-1929$ and then becoming negative in 1929-1937. Together, these series suggest there was little process innovation prior to 1909 and then a surge in process innovation lasting well into the 1920s, if not beyond. This pattern is similar to autos.

These trends agree with the qualitative information available about tire process innovations. Improvements in the production process have come from sources including labor saving machinery, chemical innovations, better quality inputs, and improved labor practices. Perhaps the biggest improvements stemmed from new machinery, with tires following automobiles down the path of mechanization and mass production. Prominent mechanical innovations in the period 1901-1934 are catalogued in Table 9, along with dates for when the innovations were introduced. The list was compiled from studies of technological change in the production process by Wanning [1921], Stern [1933], Carlsmith [1934, pp. 124-147], Gaffey [1940], and French [1985]. Of the innovations in the list, only two were developed before 1909, and one of them reflected a continuous trend extending well beyond 1909. The rest of the innovations were spread over the next twenty years or so, reflecting the continuous efforts to improve the production process. Thus, the timing of prominent mechanical innovations corresponds closely to trends in labor productivity.

The production of tires was organized into departments, which facilitated process innovation and also limited the ramifications of product innovations. The innovations in Table 9 affected nearly every aspect of the production process and typically yielded large savings in labor. ${ }^{23}$ Steps of the production process affected by these innovations included cutting and washing of rubber (affected by plasticators); drying (vacuum dryers); compounding with chemical ingredients (mixing mills, Banbury mixer); sheeting of rubber alone or with fabric or cords (new calenders); preparation of rubber sheets or

\footnotetext{
${ }^{23}$ Stern [1933] provides estimates of the labor saved by many of the innovations in Table 9.
} 
plies for tire building (bias cutting machine); building beads, treads, and rubber sheets into tires (core and drum tire building machines, merry-go-round conveyor); vulcanization (new vulcanizers, pneumatic mold openers); and transportation between steps (conveyors).

The leading producers, most prominently the big four, were in the forefront in developing and adapting new machines used in the production process. While the identity of the innovators has not been determined systematically for all the innovations in Table 9, the three most important innovations in the table illustrate the role of the leading firms in major process innovation. The core tire building machine was patented by Goodyear in 1909. Goodrich, Firestone, and many mechanical engineering firms developed competitive machines (French [1985, p. 233]). The Banbury mixer was patented in 1916 and produced by Birmingham Iron Foundry Company, a supplier of machinery to the industry. Upon the insistence of Goodyear, it was first used in Goodyear's Akron plant during its development and before it was even on the market (Allen [1949, pp. 44-45]). The drum tire machine was financed and patented by Ernest Hopkinson of U.S. Rubber. Firestone developed a competitive machine. Thus, the big four producers were the leaders among tire manufacturers in the development and use of the most important process innovations.

These and other innovations tended to diffuse quickly through licensing and sale by both tire producers and suppliers. Goodyear widely licensed its core tire building machine, with 50 firms licensing it by 1920 , and collected over $\$ 2$ million in royalties from 1909 to 1920. The rival machines developed by Goodrich, Firestone, and equipment supply firms ensured that royalties remained low (French [1985, p. 233]). ${ }^{24}$ The Banbury mixer was sold throughout the industry by Birmingam Iron Foundry, and was widely adopted (Stern [1933, pp. 40-42]). The drum tire machine was widely adopted in the mid 1920s after it was improved and licensed at the modest rate of 2 to 4 cents per casing (French [1985, p. 257]). Firestone's competitive machine again helped

\footnotetext{
${ }^{24}$ Goodyear sued Firestone for infringing its patent on the core tire machine but ultimately lost its case (French [1985, p. 231]).
} 
to keep royalties reasonable. ${ }^{25}$

The natural place to look for a process innovation that could have triggered the shakeout a la the innovative gamble theory is the three innovations just reviewed. The timing is right for two of them, the drum tire building machine and the Banbury mixer. Gaffey [1940, p. 90] singles out the drum tire building machine as the only revolutionary process innovation in 1915-1940, and Jovanovic and MacDonald identify the Banbury mixer as the best candidate for their refinement innovation. It seems doubtful, though, that either innovation could have qualified as the triggering innovation in the innovative gamble theory. The drum tire building machine had limited ramifications beyond tire assembly, was licensed at modest rates, and was widely adopted by the mid-1920s while the shakeout continued long afterward. The Banbury mixer was confined to the compounding stage, which along with calendering involved only $17 \%$ of the direct labor hours used to manufacture tires and tubes, ${ }^{26}$ thereby limiting the savings from adopting it. Indeed, even by the 1930s a number of plants had no Banbury mixers or were using both mixing mills and Banbury mixers (Stern [1933, p. 41]). It was also not a challenging innovation to adopt, with mixers of many different sizes available and its supplier helping firms to adapt their production lines to accommodate the mixer. Moreover, rather than increase the optimum size firm, as conjectured in the innovative gamble theory, Nelson [1982, p. 201] notes that it reduced the minimum efficient size firm, enabling tire producers to locate plants outside the Akron region in the 1930s to escape the rubber workers union.

Consider next the dominant design theory. Process innovation surged starting in 1909, well before the emergence of any kind of dominant design. Indeed, even as late as 1919, Table 7 indicates that the shift to cord tires and later the balloon had not proceeded very far, with cords accounting for only $25 \%$ of the tires produced.

\footnotetext{
${ }^{25}$ The patent for the drum tire machine was later overturned in an infringement suit against Firestone after a 1901 patent purchased by Dunlop was found to incorporate a similar cylindrical drum principle.

${ }^{26}$ This was computed from the average man hours worked in 1922-1931 in the preparation of crude rubber (page 44) versus stock preparation (page 55), curing and finishing (page 63), and inner tubes (page 72).
} 
Furthermore, the shift to process innovation also preceded the start of the shakeout by over ten years, suggesting that the shift did not redefine the basis for competition in such a way as to trigger a shakeout, as envisioned in the dominant design theory. Not only did the shift to process innovation not induce a shakeout, but the bulk of entry into the industry came after the rise in process innovation, which is contrary to the pattern predicted by the dominant design theory.

The history of process innovation in tires is broadly consistent with the increasing returns theory. Process innovation accelerated when the industry's output started to take off. With the exception of one or two innovations, it involved continual, modest innovations that cumulatively were quite significant (Gaffey [1940, p. 90]). All indications are that the leading firms were consistently in the vanguard of process innovation, which is further supported by data from the Census of Manufacturers for 1935 and 1937 indicating that value added per man hour was significantly higher in the larger tire plants. ${ }^{27}$ It is not hard to envision how in such an environment smaller firms might have found it difficult to remain competitive. Indeed, in his analysis of tire innovations, especially process innovations, in the period 1913-1920, Nelson [1988, p. 48] concluded that:

Generally, however, mass production in the tire industry resulted from an inconspicuous process of adjustment and innovation rather than notable inventions. Because of this gradual development, and because it was possible to make money during the war boom with obsolete equipment and labor-intensive methods, the new technology evoked comparatively little comment until the 1920s...By the late 1910s, however, the die was cast. The structure of the industry and the fate of the vast majority of firms that did not embrace mass production and its concomitant, vertical integration, were apparent by 1920 . By that date the new machinery was too expensive, the competition too severe, and the profits too meager for the laggards to catch up.

\footnotetext{
${ }^{27}$ In 1935 , the value added per man hour of plants with 501 to 2,500 employees was $25 \%$ greater than plants with 51 to 500 employees, and plants over 2,500 employees had yet higher value added per man hour. A similar pattern applied in 1937 (U.S. Bureau of Labor Statistics [1938, 1939]).
} 


\section{Televisions}

Television is the only one of the four products that was heavily affected by international competition in its first forty years. The brunt of this competition, though, occurred after the shakeout was largely complete. We focus primarily on the U.S. market before the advent of international competition but also consider the effects of foreign competition in the latter part of the shakeout.

\subsection{Overview ${ }^{28}$}

By 1939, when regularly scheduled experimental TV broadcasts began in the U.S., a few companies were selling TV sets. However, Federal Communications Commission decisions about standards, followed by World War II, delayed substantial market development until after the war. Standards for black and white transmissions were established in 1941, and standards for color transmissions were finalized in 1953. Annual U.S. production of television sets, both in total and divided into black and white and color sets, is reported in Levy [1981, pp. 99, 100, 112] for the years 1947-1978. Total production increased rapidly to over 7 million sets in 1950 and did not rise much above that figure until the popularization of color television sets in the 1960s. Color sets were first sold in 1954, but their high price and low quality limited their appeal, and as late as 1960 the number of color television sets produced was negligible. Subsequently production of color television sets increased rapidly to a peak of over 11 million sets in 1966, and color production surpassed black and white by 1969. Imports of televisions began in the early 1960 s with black and white sets, particularly portables. They rose steadily, surpassing four million sets in 1969 and eight million sets in 1978 when imports nearly equaled U.S. production.

Large numbers of firms entered into television manufacturing during the industry's post-war boom. Figure 5 presents the annual number of U.S.-based firms, entry, and exit in television manufacturing for the period 1947-1989. The combined number of U.S.- and foreign-based firms with at least partial U.S. production is indicated separately

\footnotetext{
28This section draws from Graham [1986], Teitelman [1994], and Willard [1982], with other sources cited where used.
} 
by the curve labelled "all." These data are compiled from issues of Television Factbook and from a predecessor list published separately as Supplement 57 to Television Digest and FM Reports. The initial list of producers in 1947 contained 30 firms. In the next year entry peaked at some 40 firms. It remained high for the next five years, with a total of 71 firms entering from 1949-1953. It then dropped sharply, averaging less than one firm per year through the end of the series in 1989. In the early 1950s, sales sagged after many buyers acquired their first televisions. The number of U.S. producers started to decline from its peak of 89 firms in 1951; hence we date the shakeout as beginning in 1951. In the color era, sales reached new heights, yet the number of producers continued to fall. Then as solid state electronics became common, U.S. firms lagged behind in using integrated circuitry, highly automated production techniques, and plants in low-wage regions, allowing Japanese firms to steadily gain market share. In the 1970s, some of these Japanese firms set up final assembly facilities in the United States, and U.S. firms began selling out to European and Japanese companies. Motorola sold its Quasar line to Matsushita in 1974, and Philips N.V. acquired Magnavox in 1974 and GTE-Sylvania's television business in 1976. In 1988 GE sold its television business, along with the remnants of the RCA television business which it acquired in 1985, to Thomson S.A. of France, leaving three firms based in the U.S. producing televisions. In 1995 the last U.S. stalwart, Zenith, sold out to LG Electronics of South Korea.

Firm market shares for U.S. sales of black and white and color television sets for selected years are presented in Table 10. The early market leader and the leading developer of television technology was RCA. RCA began television research in the mid 1920s and by 1948 had spent $\$ 50$ million for R\&D, equipment, and broadcast facilities for its subsidiary, NBC. It obtained many basic patents which it licensed industry wide. To encourage the growth of the industry and the adoption of its broadcast standards, it held seminars to provide manufacturing know-how to its licensees. It was the leader in developing color television and also licensed its color technology liberally and produced and sold color picture tubes. This leadership gave it an initially high black and white market share, but as other firms entered production, its market share soon declined, dropping below $20 \%$ in 1950 . As Table 10 indicates, its color market share also 
declined over time, falling to $20 \%$ by 1978 . RCA's presence steadily declined after Robert Sarnoff succeeded his father David as head of RCA in 1966. It sold its television business to GE in 1985.

The other U.S. producers listed in Table 10 also were all early radio producers. Zenith conducted television research and manufactured a small number of experimental sets prior to World War II. It began selling televisions in 1948, and Table 10 indicates that it rapidly captured a large share of the black and white market. It committed from the start to be a technological leader in the industry. By 1963 it produced its own color tubes, and in 1969 it developed a superior-contrast color picture tube that was purchased by most firms, including RCA (Herold [1974, 1976]). Table 10 indicates that by 1978 it had attained a comparable share of the color market to RCA. Like many of the U.S. producers, Zenith was slow to adapt to the solid state era and had trouble competing with foreign producers, especially the Japanese, leading to its sale to LG Electronics in 1995. Philco, the leading producer of radios and number two television producer in 1948, had also been involved in early television research and had produced experimental television receivers prior to World War II. By mid 1948, the company employed hundreds of researchers and engineers working on the design, development, and mass production of TV receivers (Tele-Tech [1948]). As Table 10 indicates, its black and white market share settled around 10\% through the 1950s, but it was not profitable in competition with rivals whose R\&D strengths exceeded its own. ${ }^{29}$ It was sold to Ford in 1961 and began producing its own color tubes in 1967, but it was unsuccessful and its assets were sold off and liquidated in 1973 and 1974. Admiral, another early leader, was a small upstart in the radio business when it began producing televisions in 1947. It was primarily a marketing specialist and was successful early with a small model which it advertised heavily. It initiated color tube production in 1965 but its market share declined over time and it was sold to Rockwell in 1973, which sold off its home appliance business four years later. The other firm initially in the top five producers was General Electric, which had started producing television receivers prior

\footnotetext{
${ }^{29}$ In the 1950 s Philco failed in its attempt to develop an alternative to RCA's complex 3-gun shadow mask color tube.
} 
to World War II. It maintained a steady presence in the industry, using its research and marketing skills to keep pace with industry developments without confronting the leaders. It acquired RCA's television business in 1985, which it sold off along with its own interests in 1988 to Thomson S.A. of France.

In terms of the three theories, the pattern of entry is once again consistent with all the theories. Entry was concentrated in a briefer period than for autos and tires, possibly reflecting the delayed start of the industry due to World War II. It then fell off sharply after the start of the shakeout. The number of U.S. producers declined steadily after the start of the shakeout, as predicted only by the increasing returns theory, although the combined number of U.S. and foreign-based producers leveled off about 25 years after the start of the shakeout. All the leading U.S. firms in the industry entered quite early, as predicted only by the increasing returns theory.

\subsection{Product Innovation}

To guide our analysis of television product innovation, we use a list of major TV product innovations compiled by Levy [1981] in his doctoral dissertation on international competition in televisions. The list, which is presented in Table 11, is based primarily on interviews with TV manufacturing executives, including heads of $R \& D$, and a review of the trade press. We counted the number of major innovations in each of the five-year intervals from 1946-1950 to 1976-1980. Where Levy identified innovations as occurring during intervals of time, the count was divided equally over the relevant periods, yielding non-integer counts. For innovations that occurred at different times for black and white versus color TV, the black and white and color innovations were each counted one-half. The resulting index starts with 3.6 innovations during the period 1946-1950, falls to 2.2 and 1.2 innovations in 1950-1955 and 1955-1960, and then rises to 7.3 and 5.0 in 1960-1965 and 1965-1970 and 11.2 and 4.5 in 1970-1975 and 1975-1980. With the shakeout dated as starting in 1951, this suggests that product innovation declined through roughly the first ten years of the shakeout and then increased sharply, remaining at a higher level than at any earlier point.

The rise in product innovation in the 1960s resulted in part from work on color TV. 
After the RCA color broadcast specifications became the industry standard in 1953, RCA tried to promote the color market by selling complete color sets and kits to competitors (Levy [1981, p. 163]). However, factory prices in the 1950s were typically $\$ 400-500$, equivalent to over $\$ 2,000$ in 1990 dollars (Willard [1982, pp. 171-172]), and breakdowns in 1957 required visits by repairmen on average every two months (Harris [1957, p. 115]), so that despite efforts by NBC to spur color sales through prime time color broadcasts, color set sales remained tiny. Only in the early 1960s did color set sales begin to take off, and manufacturers responded with a range of color display improvements (Levy [1981, pp. 35-64]; Herold [1974, 1976]). Other innovations in the 1960s and 1970s improved the displays, tuning, and circuitry of black and white as well as color TVs. After the rise of color set sales, probably the most important change to the product was the growing use of solid state circuitry in the 1970s. Transistors and integrated circuits greatly improved set reliability and, more importantly, eventually changed both TV set design and production techniques (LaFrance [1985, pp. 120, 309], Wooster [1986, pp. 68-75]). Japanese producers took the lead in designing integrated circuits for TVs, and U.S. producers lagged one to two generations behind in their level of component integration (Wooster [1986, pp. 73-74, 118-119, 156-157]).

Table 11 can be used to assess which firms were most involved in TV product innovation. Innovations that were not attributed to specific firms were ignored because they were developed by many firms around the same time, and as before black and white and color versions of an innovation were each counted one-half. Eight U.S. TV set manufacturers appear in the list. The top four, in order, were Magnavox, RCA, Zenith, and GE, with 5, 4, 4, and 3.5 innovations respectively. These four firms accounted for $62 \%$ of the innovations attributed to particular firms. Table 10 indicates that RCA, Zenith, and GE were the top three U.S. producers by 1958, with RCA and Zenith continuing as the industry leaders in the color era and Magnavox displacing GE as the number three color producer. Magnavox's innovations involved tuning and peripherals, plus its light sensor for brightness adjustment which, according to Levy [1981, p. 53], "involved no new technology, but was eminently demonstrable in the showroom." In contrast, the innovations by RCA, Zenith, and GE were concentrated in display innovations and fundamental improvements in circuitry. The next three firms in 
order of number of innovations, Motorola, Sylvania, and CBS, were in the second tier of firms in terms of market share at the times of their innovations. Advent was the only U.S. TV set innovator that was not an industry leader, and its innovation addressed a small niche market, projection television. Thus, TV product innovation was dominated by the leading firms, especially the top four producers. ${ }^{30}$

The product innovations in Table 11 diffused rapidly within the U.S., according to Levy's [1981, p. 46] impressions from interviews. A quarter of the innovations in the table were not even attributed to particular firms because of their development by multiple firms simultaneously. Components including picture tubes, cabinets, tuners, and later semiconductors were available from large numbers of independent suppliers, and many major TV set producers integrated backward into production of these components (Levy [1981, pp. 104-108]; LaFrance [1985, p. 105]; Wooster [1986, p. 379]). ${ }^{31}$ Key patents were held by RCA and to a lesser extent by Hazeltine, but were licensed to any interested firms. RCA's royalties during 1952-1956 were estimated to be $2.26 \%$ of TV set prices (Levy [1981, pp. 154-162]). ${ }^{32}$ And in a 1958 consent decree, all of RCA's TV patents except a block of color TV patents were made available royaltyfree in exchange for other firms allowing RCA to use their patents (even if they had none); Hazeltine's licensing was also constrained. Thus, simultaneous innovation, suppliers, and licensing provided means for rapid diffusion of television product innovations.

\footnotetext{
${ }^{30}$ Consistent with these conclusions, a report by Charles River Associates [1979, pp. 2-4] noted that of fourteen key color TV innovations developed by U.S. firms in the 1970s and 1980s, RCA developed 5 and Zenith 4, versus at most 1 for other U.S. set manufacturers. A U.S. Office of Technology Assessment and Forecast study, cited in the same report [pp. 2-9], found that among U.S. firms in the period 1969-1978, RCA and Zenith had the most color TV patents granted, 183 and 55 respectively.

${ }^{31}$ Picture tube suppliers included Clinton, a specialist in small tube sizes that did not make TVs, RCA and Sylvania, which sold large numbers of tubes, and GE, Sony, and Zenith, which manufactured primarily for their own use. Many picture tube suppliers entered color tube production in the 1960s (LaFrance [1985, p. 105]).

${ }^{32} \mathrm{RCA}$ netted $\$ 96$ million in patent royalties during the period 1952-1956 (Levy [1981, pp. 154-162]). RCA licensed liberally in part to promote its broadcasting standard, upon which its patents were based, and to support the growth of its broadcasting subsidiary, the National Broadcasting Corporation. After its 1958 consent decree, RCA continued to license Japanese firms, which from 1964 through 1970 paid over $\$ 47$ million for black and white and \$87 million for color TV set royalties; as of 1981, RCA still received approximately $\$ 50$ million per year from Japanese firms for color TV licenses (LaFrance [1985, p. 366]).
} 
Could a major product innovation have triggered the industry's shakeout a la the innovative gamble theory? Based on unanimous statements from television engineers and executives, Levy [1981, p. 36] noted that the industry's two key innovations were black and white and color television, with the other innovations described as "evolutionary rather than... revolutionary." This suggests that the only good candidate among product innovations for the triggering innovation in the innovative gamble theory was color television. However, color TV was not a single innovation but a stream of innovations. Indeed, when color was first introduced in the 1950s it flopped, leading Fortune writer William B. Harris [1957, p. 114] to ask, "So what is wrong with color? What mistakes did RCA make?" It was not until a number of subsequent innovations had been developed that color sales began in earnest in the 1960s. By this point, however, the shakeout had progressed quite far, with the number of firms having fallen to 35 by 1959 from the peak of 89 in 1951 . Thus, color TV could not have triggered the shakeout in the innovative gamble theory.

In light of the importance of color TV, a dominant design would have to involve widespread adoption of color television, the only revolutionary change following black and white. Color television was the impetus for large numbers of product innovations, making it difficult to see how television design could have coalesced before the color era. Yet, as noted already, color TV did not become competitively significant until well after the shakeout began, hence it could not have been a key development that triggered the shakeout a la the dominant design theory. In their analysis of televisions, Utterback and Suarez [1993] claim that a dominant design arose around 1952, with the widepsread adoption of the 21 -inch picture tube. This is a strange choice for a dominant design, however, in that it was a temporary phenomenon. Data from the Electronic Industries Association [1968, p. 58; 1971, p. 64; 1975, p. 82] indicate that 18to 21 -inch picture tubes accounted for $73 \%$ of black and white unit sales in 1954 but then declined to $50 \%$ of sales by 1960 and less than $40 \%$ of sales by 1967 . Furthermore, a 1969 sales breakdown indicates that 20- and 21-inch tubes together accounted for only $12 \%$ of black and white sales versus $32 \%$ for 18 - and 19 -inch tubes. For color tubes, size data are available beginning in 1973, when 21-inch tubes accounted for only $5 \%$ of color tube sales. Thus, it is difficult to see how a dominant 
design could have emerged from the 21 -inch picture tube. Moreover, the dominant design theory predicts a fall in product innovation after the emergence of a dominant design, yet as shown earlier, product innovation increased markedly after 1960, especially in key color innovations that drove large increases in sales of color TVs and TVs in general.

The pattern of TV product innovation also departs in significant ways from the increasing returns theory. The theory predicts a decline in product innovation after the start of the shakeout. This occurred initially, but after the shakeout had proceeded for roughly ten years, the rate of product innovation increased markedly. The increase may have resulted from the initial failure of color television, which necessitated further innovations to develop the market for color. Whatever the cause, this pattern of product innovation is not consistent with the theory. The concentration of product innovation among the leading firms is also not in accordance with the theory, which predicts such a concentration primarily for process innovation. Apparently, product innovations may have been subject to the same increasing returns forces as featured in the theory for process innovations. Indeed, such a conclusion would be consistent with the findings of two statistical studies, by Datta [1971] for the black and white era and Willard [1982] for the color era, concerning the determinants of firm survival. Both authors found that TV set quality was a more important determinant of firm survival than any other firm characteristic considered, including price, advertising, firm size, vertical integration, and overall firm profitability. The typical surviving producer of color TV sets, according to Willard [1982, pp. 289-291, 299-301, 318-324], placed strong emphasis on R\&D and achieved high quality sets, whereas nonsurvivors tended to de-emphasize R\&D and to have low quality sets. Industry analysts such as Levy [1981, p. 69] and Wooster [1986, p. 74] have also emphasized that smaller firms had trouble keeping up with the $R \& D$ necessary to improve sets and consequently lagged behind in set quality. This is consistent with the $1975 \mathrm{R} \& \mathrm{D}$ to sales ratio of $2.0 \%$ for radio and TV producers and $4.4 \%$ for cathode ray and picture tube producers in the FTC's Line of Business Program (FTC [1981]), which as in Warner's analysis of tire innovation might have made it prohibitively expensive for smaller TV firms to remain at the technological frontier. 


\subsection{Process Innovation}

To analyze process innovation in televisions, we rely primarily on a list of innovations from 1946 to 1970 . Levy [1981, pp. 64-68] developed a brief list of five major process developments, each involving multiple innovations. We supplemented Levy's list with our own based upon the trade literature. We analyzed articles cited in the Industrial Arts Index (later Applied Science and Technology Index), which comprehensively indexed articles in most substantial journals in electronics and other industrial trades, from the years 1946 through 1971.33 Any new manufacturing techniques described for televisions (but not components) and created at U.S. firms were catalogued, yielding a list of 264 innovations by U.S. firms. The innovations were ranked on a seven-point scale, and as for the automobile innovations in Abernathy et al. [1983], squares of the rankings were used to address the nonlinear relationship between rank and impact. ${ }^{34}$ We recorded the date at which each major (rank 4 or higher) innovation occurred where available, or in other cases a span of years in which the major innovation seems to have occurred given the context of ongoing innovations and of firms' activities.

Table 12 presents all innovations ranked 4 or higher, grouped into six categories. Categories of innovations and specific innovations corresponding to Levy's major developments are denoted by asterisks. ${ }^{35}$ The innovations in Table 12 are not attributed to particular firms because in most cases they were developed by multiple firms. To supplement the table of innovations, labor productivity data available beginning in 1958 for radios and TVs together are presented in Table 13.

We summed the impact ratings of the major process innovations presented in

\footnotetext{
${ }^{33}$ Of approximately 210 relevant articles, 198 were obtained and analyzed. A search of key journals with television-related articles uncovered a handful of additional articles of relevance, and those articles were included in the analysis.

${ }^{34}$ Rankings of the innovations were estimated subjectively on the basis of the potential for cost savings in the adopting plants.

${ }^{35}$ The use of transistors and integrated circuits is mentioned by Levy as a single development, but integrated circuits had the greater impact on manufacturing processes and accordingly are designated by an asterisk in Table 12.
} 
Table 12 according to their dates of innovation. In the years 1946-1950, major innovations had an average total impact (squared rank) of 56 per year, versus 25 per year in the years 1951-1960 and 5 per year in 1961-1970. Thus, the trend in major innovations indicates that the most process innovation occurred in the industry's earliest years, with process innovation slowing thereafter, dropping off particularly in the 1960s. ${ }^{36}$ The productivity data for TV and radio manufacturing combined, shown in Table 13, begin in 1958, once the number of innovations had already dropped off. They show a roughly constant productivity increase of $5.1 \%$ per annum from 1958 to 1980, yielding a tripling in productivity over those years, and hence indicate that strong productivity advance continued even in the period when both Levy's and our own lists catalogue fewer innovations. Indeed, Zenith Vice President Leonard Dietch, in an interview with Levy [1981, p. 71], estimated an even greater productivity improvement for TV sets alone than is reflected in Table 13, with labor hours per set falling from 8-10 in the early 1960s to 2 in the late 1970s.

The earliest television process innovations were mainly variants on radio manufacturing techniques and represent adoption rather than invention. Indeed, radio producers brought in their radio production supervisors and engineers to assist in setting up television manufacturing lines. In contrast, beginning in 1948 innovations were developed contemporaneously for use in TVs as well as in radios and other products. In the 1950s, attention turned from developing streamlined assembly lines and equipment for operators toward more automated production. TV manufacturers began to use printed circuit boards, dip soldering to solder multiple components simultaneously, and automated component insertion. These techniques were adapted to TV set production based on approaches used by the electronics industry at large. In

\footnotetext{
${ }^{36}$ For the minor innovations, the timing of the innovations has not been catalogued, and the availability of information is affected by trends in publication, but some idea of the number of innovations can be gained by counting the impact of the innovations according to their publication times. For minor innovations discussed in articles during the period 1946-1950, minor innovations had an average total impact of 34 per year, versus 88 per year in 1951-1960 and 4 per year in 1961-1970. Breaking down further the minor innovations in the 1950s, there was an average total impact of 127 per year during 1951-1953, 118 per year in 1954-1956, and 35 per year during 1957-1960. Given the delay between innovation and publication, the innovations described in 1951-1953 may have occurred before the shakeout in the number of producers began in 1951.
} 
the 1960s, the small number of process innovations reflects the fact that color television did not fundamentally alter the production process. Color television sets involved a larger number of components that had to be assembled than black and white sets, and they required additional test and adjustment procedures relating to their use of color (McClane [1954]), but otherwise relied on the same production techniques as for black and white sets. ${ }^{37}$ The productivity advances in the 1960s and 1970s in part reflect changes in product design, making it difficult to disentangle product and process innovation. Continual redesign of the television chassis reduced the number of parts that needed to be assembled, increasing labor productivity as well as reducing component costs (e.g., Levy [1981, p. 72]).

The trade articles from which the list of innovations was compiled discuss innovations in the context of particular firms, and they provide a means to assess the relative amounts of innovation according to firm size. For innovations ranked 4 and higher, all the firms mentioned at some time had market shares exceeding $3 \%$. Of the six U.S. firms that sometime during 1945-1970 achieved a market share exceeding $10 \%$, five were mentioned in the context of these major innovations, and the remaining firm, Motorola, was mentioned in the context of innovations ranked 3. Among all the innovations, only 7 of 264 innovations were mentioned in the context of firms that never exceeded a $1 \%$ market share or that were too small to appear in market share surveys. ${ }^{38}$ The tiny firms mentioned in the context of those 7 innovations constituted only 5 of 147 such firms. In contrast, of the 15 firms known to have achieved market shares exceeding 1\%, 13 firms were mentioned in the trade and technical articles. Thus, process innovation, and particularly major innovation, was dominated by the industry's largest firms.

\footnotetext{
${ }^{37}$ Automated assembly equipment, while used by many of the major manufacturers for black and white sets starting in the 1950s, was not generally used for color television set manufacture until 1972 (Willard [1982, pp. 181-182]). Perhaps process innovation and the use of automated color TV set production techniques awaited the growth of the color market.

${ }^{38}$ Of the 7 innovations created by such tiny firms, three involved cabinet manufacture and finishing, two involved testing equipment for sale to other manufacturers, one involved placing chassis into cabinets, and one involved manual pass-along assembly lines. This distribution of types of innovations by the tiny firms contrasts sharply with that of big firms, for which assembly- and automation-related innovations predominated.
} 
Process innovations diffused quickly, particularly given the simultaneous development of similar innovations at multiple firms, which is why the table of innovations does not attribute innovations to specific firms. Equipment such as conveyors, soldering devices, automatic insertion machines, and circuit board printers was available from third-party suppliers, and descriptions of useful production methods were published in trade journals such as Electronics and were a source of prestige for industrial engineers. The quick diffusion also reflects the application of approaches used for radios and other electronics products.

What do these process innovation patterns reveal about the determinants of the shakeout in TVs? In terms of the innovative gamble theory, Table 12 provides a means of establishing which major process innovations occurred around the time of the shakeout. The most important innovations were dip soldering, printed circuits, and automated assembly. Printed circuits were based on military developments, and all three innovations were developed for the electronics industry at large, not just for TVs, fitting Jovanovic and MacDonald's [1994] characterization of a radical innovation that originates outside the industry. Yet throughout the 1950s these innovations were resisted by Zenith and other firms, in part because of concerns about effects on TV set quality. Despite not adopting these innovations, Zenith led the industry in profits and in the growth of market share. Moreover, there is no evidence of process innovations that contributed to a significant rise in the optimal size firm, which is a requisite characteristic of the triggering innovation in the innovative gamble theory. Indeed, based on his interviews with TV executives, Levy [1981, p. 69] found that the conventional sources of production scale economies were not significant for televisions.

According to the dominant design theory, process innovation increases substantially around the time of the dominant design and the start of the shakeout. Yet the amount of process innovation in TVs was greatest initially as radio production knowledge was transferred to television production, and the amount of process innovation fell soon after the start of the shakeout in the 1950s. Judging from the innovative efforts that accompanied the fierce international competition of the 1970s, process innovation may have risen in the 1970s, but such innovation did not occur until 
two decades after the shakeout began. Furthermore, the innovative trends in the 1970 s were largely driven by novel integrated circuitry made possible by the semiconductor industry and involved redesign rather than standardization of the product.

In terms of the hypothesis of increasing returns to R\&D, the television industry exhibited substantial innovative challenges that continued over time, rising substantially in the eras of transistors and especially integrated circuits. The firms with the largest market shares were in the vanguard of innovation, consistent with the hypothesis. The pattern is perhaps less pronounced for process than for product innovation, in that before the 1970s Zenith was reluctant to adopt the more automated production techniques. But by the 1970s, the stakes for R\&D had increased, and the dependence on technology emphasized by the increasing returns hypothesis became plainly apparent. Japanese firms led in the use of integrated circuits, ${ }^{39}$ and by 1978 automatically inserted $65-85 \%$ of their components, versus $40 \%$ or less for U.S. producers (Wooster [1986, pp. 140-142]). ${ }^{40}$ The U.S. firms, pressured by declining profits, tightened their R\&D budgets at a time when Japanese R\&D budgets, already large compared to those of U.S. firms, expanded (Wooster [1986, pp. 251-253, 401-402]). ${ }^{41}$ These changes coincided with Japanese firms' gains in output. By 1977, Matsushita had $17 \%$ of the world market, and Sony's $9 \%$ share equaled those of RCA and Zenith (Wooster [1986, p. 152]). The increasing R\&D pressures, which through the 1950s and 1960s affected most U.S. firms, by the 1980s and 1990s caught up to the

\footnotetext{
${ }^{39}$ Integrated circuits required design principles new to electronic engineers, and Japanese engineers had greater experience with the circuits. Also, the backward integration of Japanese set manufacturers into integrated circuitry may have given them increased flexibility to develop proprietary circuitry. The potential for integrated circuits was not obvious to U.S. manufacturers. A noted example is RCA's 1971 plant to manufacture thick-film ceramic circuit modules. After spending over $\$ 5$ million to build the plant, RCA scuttled the plan because advances in integrated circuits made the ceramic circuits obsolete (Wooster [1986, pp. 74-75]). Besides aiding in the use of automatic insertion, Japanese firms' lead in integrated circuitry helped to push their color TV defect rate down to $0.4 \%$ by 1979 , versus $5.0 \%$ in the same year for U.S. producers (Wooster [1986, p. 435]).

${ }^{40}$ Zenith in 1971 had still not adopted automatic component insertion and was forced into a crash program to develop automatic component insertion methods (HBS [1977]).

${ }^{41}$ U.S. firms' R\&D budgets were by no means small. One project, a failed joint venture of Zenith and Corning Glass to develop and put into production a low-cost Able picture tube, cost \$70-100 million (Wooster [1986, p. 252]).
} 
last of the U.S. manufacturers and RCA and then Zenith sold out to their foreign competitors.

While the nature of process innovation in the era of international competition is consistent with the increasing returns hypothesis, the time trend in TV process innovation is not. There was not a steady early growth in process innovation as expected under the theory and as occurred in autos and tires. The departure from the theory may be attributable to outside influences. The heavy early process innovation in the industry was driven largely by radio production techniques that could be usefully adapted to TVs. Developments in the semiconductor industry may have played a similar role in many of the later reductions in production costs.

\section{Penicillin}

For our final product, we turn to penicillin. As with the other products, U.S. firms were leaders in developing this manufacturing industry, and exports far exceeded imports well through the period of the shakeout.

\subsection{Industry Evolution}

Penicillin was in its laboratory stages until World War II, when it was developed in a massive wartime effort. Production of penicillin from 1945 through 1987 is reported in the U.S. Tariff Commission's annual reports Synthetic Organic Chemicals for selected years. ${ }^{42}$ Once the war ended, firms continued to increase their production capacities greatly. Production rose from 11,000 pounds in 1945 to $10,200,000$ pounds in 1987 as the price of bulk penicillin plummeted by orders of magnitude. From 1945 to 1948, output grew by $145 \%$ per year. The rate of growth gradually slowed, dropping to $25 \%$ per year during 1948-1954, 16\% per year during 1954-1971, and 1.6\% per year during 1971-1987.

Most penicillin manufacturers entered production during World War II, with further entry after wartime restrictions were removed. Figure 6 shows the annual number of

\footnotetext{
${ }^{42}$ Figures for 1945-1947 were converted from billions of Oxford units to thousands of pounds by assuming 0.7 billion units per pound on the basis of figures presented by the FTC [1958, p. 355].
} 
firms, entry, and exit. The data are compiled from annual issues of Thomas' Register and Synthetic Organic Chemicals, with wartime information from a FTC [1958] report and from Elder [1970]. After the entry of the wartime producers, 21 new manufacturers entered from 1947 to 1955 . Thereafter, entry fell to an average of only 0.3 firms per year during the years 1956-1982. In the 1980s, entry increased again as entirely new semisynthetic penicillins were developed. The number of firms reached a peak of 29 firms in 1952-1954; hence we date the shakeout as beginning in 1954. The number of firms continued to fall for three decades, reaching a low of five firms in 1991.

The companies most centrally involved in the wartime push for penicillin production were "the Big Three," Merck, Squibb, and Pfizer. All three began early experiments with penicillin production even before the British researcher Howard W. Florey arrived in the U.S. to encourage a penicillin program (Sheehan [1982, p. 69]). Other important wartime producers included Commercial Solvents, Cutter, Lilly, and Wyeth. Many more pharmaceutical firms asked to join the wartime penicillin program but were denied entry. ${ }^{43}$ While additional firms entered the industry shortly after wartime restrictions were removed, these firms remained relatively obscure. Around 1958, Bristol, which had helped in the synthesis of penicillin by MIT Professor John C. Sheehan, and the British company Beecham Laboratories led in the development of new "semisynthetic" types of penicillins. These varieties of the drug were patented and tightly controlled, yielding lucrative new markets for their developers. The value of newer forms of penicillin can be seen from Table 14, which reports market shares of dollar sales for leading penicillin producers in 1960 and 1973 (comparable data were not available for earlier years). The two leading producers in 1960, Lilly and Wyeth, were the developers of what became their two most profitable forms of penicillin, penicillin $\mathrm{V}$ and benzathine penicillin (FTC [1958, pp. 3, 25], Schwartzman [1976, pp. 124-127]). By 1973 Bristol had become the number one U.S. producer, capitalizing on its prowess in the new

\footnotetext{
${ }^{43}$ Applications from Hoffman-LaRoche and CIBA were turned down in 1943 because of concerns related to their foreign ownership and management (Sheehan [1982, p. 57]). Other firms were rejected because they were unwilling to promise a substantial enough contribution to the penicillin program, or to avoid wasteful overbuilding. In all, Elder [1970, p. 10] stated that over one hundred firms were discouraged from submitting penicillin production projects to the War Production Board.
} 
semisynthetic penicillins to increase its market share from 8\% in 1960 to $22.6 \%$ in 1973 . In terms of the theories, the pattern of entry is again consistent with all three theories, with entry falling off sharply after the start of the shakeout. Penicillin is the only one of the products, though, in which there was modest rise in entry after many years of negligible entry. None of the theories predicts such a rise. The number of firms declined steadily after the start of the shakeout, as predicted only by the increasing returns theory. Also consistent with the theory, the earliest firms to exit the industry were all relatively small antibiotics producers (FTC [1958, p. 82]). In contrast to the other products, especially autos and tires, there was apparently considerable flux in the market shares of the leading firms after the shakeout had proceeded for a number of years. This is not consistent with the increasing returns theory, and is not predicted by the other theories.

\subsection{Product Innovation}

To analyze product innovation in penicillin, we developed a list of new forms of penicillin, the innovator and date of innovation where available, and for each form the years it was produced by each producer. The producers of each form of penicillin and the years of production are compiled from annual editions of Synthetic Organic Chemicals (SOC). ${ }^{44}$ The identity of the innovating firm and the date of innovation are drawn from the report of the FTC [1958] and Achilladelis [1993] for forms of penicillin that they discussed. Table 15 presents the list of innovations, with asterisks indicating innovating firms and daggers indicating major innovations according to Achilladelis.

The trend over time in the rate of penicillin product innovation can be seen from the table. After penicillin was first developed, only 1 major and 1 minor new form were developed in the sixteen years 1943-1958. Thereafter the number of innovations jumped to 3 major and 8 minor new forms in the 16 year period 1959-1974, and 3 major and 5 minor new forms during the 16 year period 1975-1990. This pattern is consistent

\footnotetext{
${ }^{44} \mathrm{SOC}$ does not reflect some of the smaller firms listed in Thomas' Register. The FTC [1958] report, however, provides another listing of producers by type of penicillin for the years 1950 and 1956 which basically accords with the listing from SOC, suggesting it is doubtful that many, if any, of the firms excluded from SOC produced the more innovative forms of penicillin.
} 
with trends in annual numbers of penicillin-related patents, papers, and incremental innovations shown by Achilladelis [1993]. Patenting grew after World War II, reaching an average of about 100 patents per year before the advent of semisynthetics, and then rose immediately to about 1,500 per year after 1958 . Papers published gradually rose to a high of nearly 500 per year before 1958 and then climbed to over 2,000 per year after 1958. Three incremental innovations occurred in the 15-year period before 1958 and 29 occurred in the roughly 30 -year period following.

To understand the reasons for these patterns, it is important to understand the nature of product innovation in penicillin. Before 1958, new forms of penicillin were developed by experimentally adding chemicals to a production broth and testing to see whether Penicillium mold produced varieties of the drug with improved properties. In 1957, Sheehan achieved a chemical synthesis in which 6-aminopenicillanic acid (6APA) was formed and treated to yield penicillin, and Beecham independently discovered 6-APA in the broth used to produce penicillin biologically. This made it possible to introduce variations into the side-chain of penicillin using synthetic methods, which gave rise to a plethora of new forms of penicillin. These new forms were not substitutes for the old, but attacked different diseases, and rarely took away markets for existing forms. Indeed, the production data of Table 16 show that outputs of older forms continued to grow despite the advent of new penicillins. ${ }^{45}$

Table 15 lists the firms that developed each of the major new forms of penicillin and it indicates the first producers of the minor forms. The first major new form, penicillin V, was developed by Lilly (and Glaxo in the UK). In the semisynthetic era, the first three major new forms involved the British firm Beecham, with Bristol sharing credit for the first form and Pfizer for the third. The other three major semisynthetics were developed by the European firms Bayer and Roche and by Pfizer. Among the twelve

\footnotetext{
${ }^{45}$ To construct Table 16, data from FTC [1958, p. 73] for 1948 to 1956 were converted to estimated metric tons to yield the same values as in Scholz [1992] for the year 1956. For penicillin V, data were converted using a ratio of 0.767 billion units per pound based on FTC [1958, p. 355]. The 1970 figures for procaine and other natural penicillins were not available and were estimated by averaging 1969 and 1971 figures. The "other" figures for natural penicillins include all types for which information was not available in a given year.
} 
minor forms starting with the first minor semisynthetic, methicillin, Bristol was the first U.S. producer for six and Beecham for three. ${ }^{46}$ Thus, among the U.S. firms the leading innovators were Bristol, Pfizer, and Lilly. Table 14 indicates that these three firms were among the industry leaders at the time of their innovations. The European innovators were also very major drug firms. Thus, innovation in penicillin was dominated by major firms, although two of the Big Three wartime producers, Merck and Squibb, did not play major roles in penicillin product innovation.

The basic forms of penicillin developed during World War II were not patented and were freely produced by any firm (FTC [1958, pp. 228-229]). However, later forms including the procaine and benzathine salts of penicillin, penicillin $\mathrm{V}$, and the semisynthetic penicillins were patented. Given the small number of firms that produced them during the 17-year period of patent protection, as seen in Table 15, new forms of penicillin were apparently rarely licensed for production.

Tables 15 and 16 can be used to assess the extent to which product innovation in penicillin conformed to the three theories. Consider first the innovative gamble theory, which posits a unique innovation around the start of the shakeout that induces a large number of firms to exit. Table 15 indicates that the first major new form of penicillin, penicillin $\mathrm{V}$, was developed around the start of the shakeout. Yet penicillin $\mathrm{V}$ opened new submarkets for penicillin without displacing older forms of penicillin, as indicated in Table 16 by the continued growth in output of the older forms long after the introduction of penicillin V. This suggests that it did not directly cause the exit of producers of older forms of penicillin. Furthermore, many of the industry's producers had exited prior to the initial production of penicillin $\mathrm{V}$ according to Table 15. And moreover, the rate of product innovation increased markedly later with the development of the semisynthetics, and the semisynthetics appear to have had a significant effect on firm survival. Among producers listed in SOC in 1965, shortly after the semisynthetics became common, the four nonproducers of the semisynthetics, Abbott, Lilly, Merck, and Upjohn, exited the

\footnotetext{
${ }^{46}$ Penicillin $\mathrm{O}$ was excluded from the tally because the first producer/innovator was kept confidential and NEP penicillin was excluded because it was an obscure penicillin of unknown status produced for only one year.
} 
industry in 1975, 1991, 1987, and 1967 respectively. In contrast, three of the four semisynthetic producers in 1965, Bristol, Pfizer, and Wyeth, were still producing penicillin at the end of 1991, with the fourth, Squibb, having exited in 1983. Thus, if penicillin $\mathrm{V}$ affected firm survival, the effects were hardly unique, suggesting that it alone could not have caused the shakeout a la the innovative gamble theory.

In terms of the dominant design theory, the trend in product innovation is opposite to that predicted by the theory. The rate of introduction of new forms of penicillin was relatively modest before the start of the shakeout and accelerated greatly a half-decade later. Product variety increased over time, particularly with the advent of the semisynthetics. The number of forms of penicillin in Table 15 that were manufactured in each five-year period from 1946-1950 through 1986-1990 increased from 1 in the first period to $3,4,10,11,13,14,15$, and 15 in the subsequent periods. Hence, far from coalescing around a dominant design, the product grew less standardized with time.

In terms of the increasing returns theory, product innovations opened up new submarkets for penicillin, as portrayed in the theory, yet the rate of product innovation increased after the start of the shakeout, contrary to the predicted pattern. This increase appears to have been driven by the technical breakthrough in synthetic methods pioneered by Sheehan. The theory also predicts that process rather than product innovation will be concentrated in the industry leaders and will be the key determinant of firm survival. However, the leading U.S. product innovators were among the industry leaders and product innovation, particularly in the semisynthetic era, appears to have played an important role in firm survival. Similar to tires and televisions, it appears that increasing returns forces may have played a prominent role in product innovation in penicillin. This role is consistent with the large amount of resources devoted to $R \& D$ by antibiotics manufacturers, with $8 \%$ to $9 \%$ of the employees of antibiotics manufacturers devoted to R\&D in 1956 (FTC [1958, p. 10]). ${ }^{47}$

\footnotetext{
${ }^{47}$ These figures pertain to all antibiotics manufactured, with no breakdown reported by type of antibiotic.
} 


\subsection{Process Innovation}

The nature of penicillin manufacturing processes and much about process innovation can be reconstructed from a range of sources, including FTC [1958], Elder [1970], Calam [1987], and various trade articles. Penicillin firms normally kept their manufacturing processes highly secret, however, which prevented us from assembling a fully comprehensive list of major process innovations as in the other products. Therefore, to analyze quantitatively the extent of process innovation over time, we use data on price and production yield which are reported in Table 17.

The price of penicillin fell enormously after World War II. Table 17 shows the price per pound of bulk penicillin, in 1967 dollars, every five years from 1945 through 1980. Between 1945 and 1950, the price plummeted from $\$ 5291$ to $\$ 266$, an average decrease of $45 \%$ per year. Thereafter, the price continued to fall, but at a less dramatic rate. From 1950 to 1955 , the price fell from $\$ 266$ to $\$ 89$, or $20 \%$ per year. In later years, expensive new forms of penicillin took up a more meaningful share of the market, but even so the average price across all forms of penicillin continued to fall, dropping $19 \%$ per year to $\$ 11$ in 1965 , then 3\% per year to an eventual low of $\$ 8$ per pound by $1975 .{ }^{48}$

Increased production yields were not the only means of reducing production costs, but they did reduce costs per unit at most steps in the manufacturing process. Table 17 presents data for available years on yields of penicillin per unit of the production broth used to grow the Penicillium mold. Between 1950 and 1958, yields grew from 2 to 7 grams per liter of production broth, an annual increase of 17\%. Between 1958 and any of the other dates at which information is available, yields grew at a slower pace; from 1958 to 1986 , yields grew from 7 to 65 grams per liter, an annual increase of $8 \%$.

Improvements in pencillin manufacturing methods, categorized in Table 18, can be classified into three periods: World War II, the post-war years, and the semisynthetic

\footnotetext{
${ }^{48}$ Prices for strictly comparable forms of penicillin during the years 1948 to 1956 were examined in FTC [1958, p. 168]). The figures for four companies show a roughly $90 \%$ (or $25 \%$ per year) decrease in prices over this eight-year period, the same pattern as reflected in the figures in Table 17 from Synthetic Organic Chemicals.
} 
era. In 1941, with the drug still far from commercialization, penicillin researcher Howard W. Florey arrived in the U.S. from war-wracked Britain to enlist aid from government agencies and pharmaceutical houses. The ensuing clinical trials brought spectacular results and soon made penicillin a government priority. Penicillium mold was then grown in surface cultures, and enormous surface areas had to be grown to yield even enough of the drug for clinical trials. A better method had to be found.

In response, the U.S. government's penicillin program took two paths. In the synthetic path, the Office of Scientific Research and Development's Committee on Medical Research, headed by A. N. Richards, focused on developing a method to synthesize penicillin (Elder [1970, p. 4]). According to the director of the government's penicillin program some $200-400$ chemists were working to crystallize, identify, and synthesize the penicillin molecule (Elder [1970, p. 4]). Synthesis was viewed at the time as promising the most economic means of production.

The biological production path of the government's penicillin program was overseen by the War Production Board. In all, at least 21 companies, 6 laboratories, and 7 government agencies became involved (Elder [1970, p. 9]). Soil samples from around the world were flown in to search for improved strains of Penicillium, and pharmaceutical firms and the government's Northern Regional Research Laboratory (NRRL) were charged with developing more efficient submerged production in fermentors. The Fermentation Division of the NRRL discovered that corn steep liquor, a surplus farm commodity that was a by-product of wet corn milling, formed the basis for an excellent growth medium for Penicillium. The group also collected and bred many strains of the mold, some of which produced much larger quantities of penicillin and thrived submerged in a growth medium instead of only on the surface. Yields at the laboratory rose from an initial 2-4 Oxford units of penicillin per milliliter to an eventual 1,500 Oxford units per milliliter. ${ }^{49}$ Several of the NRRL's key production methods were patented, and the patents were freely licensed to all applicants (FTC [1958, pp.

\footnotetext{
${ }^{49}$ Some 500,000 Oxford units were needed to treat a serious medical case, so that at the time of Florey's visit, 125 gallons of fermentation broth were required to treat one patient for one day.
} 
228-229]).

Other early advances were also financed by the government, either directly through contracts (FTC [1958, pp. 47-50]) or indirectly through government purchases of penicillin from manufacturers. The manufacturers had to overcome an array of technical challenges. Fermentation tanks with mechanical stirrers were developed to be larger and more powerful than those used previously for chemical processes (Lyons [1970]), and they needed sterilization systems and highly effective, high-volume air filtration systems to keep out penicillinase-producing bacteria that could destroy a production batch (Coghill [1970, p. 19]). More productive strains of Penicillium mold were sought, as well as suitable compositions of the fermentation medium (Coghill and Koch [1945], Perlman [1970]). Techniques also were developed for extraction and purification of penicillin (Souders et al. [1970], Podbelniak et al. [1970], Brockmann [1970], Brown et al. [1946]). The government also directly financed almost $\$ 8$ million of the $\$ 30$ million cost of buildings and equipment, gave firms tax breaks totaling over $\$ 14$ million by allowing equipment to be amortized over periods of less than five years rather than the usual 12-15 years, and sold government-financed penicillin plants and other surplus war plants to penicillin manufacturers after the war at less than half of cost (FTC [1958, pp. 51-57]). ${ }^{50}$ Thus, government involvement helped to overcome uncertainties inhibiting firms, including fear of obsolescence by synthetic production processes.

After World War II, process innovation occurred in all the categories listed in Table 18. Companies built large pilot plants to help develop new fermentation methods, which represented "a continuing challenge to remain competitive," according to Lilly engineers Fortune et al. [1950, p. 197]. Fermentation tanks were initially purchased from the General American Transportation Company, but after the industry's first decade newer fermentors were obtained from other specialist firms (Lyons [1970, p. 36], Calam [1987,

\footnotetext{
${ }^{50}$ Rapid amortization was again allowed during the Korean War to encourage growth in output.
} 
p. 159]). ${ }^{51}$ Other improvements involved the strains of mold used, fermentation ingredients, continuous control and feeding, waste treatment, air sterilization, extraction, and packaging.

Semisynthetic penicillins required the same production techniques as natural penicillins, but added additional steps. A core ingredient, 6-APA, was either filtered directly from the production broth or created from penicillin $G$ using an enzyme (Lein [1970, p. 67], Lee [1974, p. 401]). The 6-APA was then reacted synthetically, using any of several acylation methods, to attach a desired side chain, then extracted using solvents (Lein [1970, p. 67]). Conditions of acylation and solvent extraction methods had to be developed to suit each different form of semisynthetic penicillin (Industrial Chemist [1963, pp. 517-518]). The enzymatic production method was developed independently by Bristol, Beecham, Pfizer, and Bayer, all major firms, in 1960 (Lein [1970, p. 67]).

How do these patterns of process innovation reflect on the determinants of the shakeout? Consider whether a major process innovation might have triggered the shakeout as in the innovative gamble theory. First, innovative progress clearly was made on many fronts through a large number of incremental advances. The individual advances that were emphasized as most outstanding did not come at the time of the shakeout but were pioneered during World War II and were freely licensed. Fermentation tanks, perhaps the mostly likely candidate around when the shakeout began in 1954, diffused rapidly through purchase from third-party suppliers, contrary to the notion that they required in-house development. Second, and again contrary to the theory, production scale economies do not seem to have been significant in penicillin (Schwartzman [1976, p. 308]). In the case of fermentors, plants operated large numbers of fermentation tanks, remaining well above any scale requirements related to this equipment.

\footnotetext{
${ }^{51}$ Fermentors were developed under conditions which fermentation researcher Elmer Gaden [1956, p. 168] called an "extreme atmosphere of competitive secrecy," and by the mid-1950s had improved to achieve higher aeration, thorough agitation of production media using powerful stirring blades, complete elimination of contaminants, and close control of process variables.
} 
In terms of the dominant design theory, the marked rise in process innovation anticipated to occur when the shakeout begins does not seem to have occurred. The government played a strong role in encouraging early process innovation, initiating a trajectory of heavy innovation that predated the shakeout by almost a decade. Large productivity improvements did continue after the shakeout began, but the price and yields data suggest a continuation or decrease in the rate of process improvement rather than an increase in process innovation.

In terms of the increasing returns theory, the simultaneous development of production methods by multiple firms is consistent with the theory, as are scattered references in trade articles to major penicillin producers and equipment suppliers, rather than smaller producers of penicillin, as sources of process innovation. Also consistent with the theory, key equipment innovations diffused rapidly through sale by third-party firms. In contrast to the theory, however, process innovation seemingly did not rise over time as anticipated under the increasing returns theory. The large role played by the government in accelerating the exploration of process techniques no doubt distorted the pattern that would have arisen if penicillin manufacturing processes had developed solely at corporate expense. Indeed, the fact that firms were reluctant to invest heavily in manufacturing processes when synthetic production techniques seemed imminent, as documented by Elder [1970, p. 4], suggests that process innovation was much higher than it would have been initially given firms' own perceptions of their payoffs from R\&D.

\section{Synthesis}

In this section, we bring together our key empirical findings and use them to proceed in three ways. First, we focus on empirical patterns common to all four products, asking how they fit with the theories. Second, we focus on the theories and ask what the empirical evidence says about them. Third, we focus on those aspects of each theory that seem to fit the evidence, using them to build a composite story about the role of technological change in shakeouts.

Seven key findings from the four products are particularly pertinent to understanding shakeouts. Of these findings, the first four transcend all four products. 
In contrast, the latter three describe innovative patterns that vary over time and among the products.

1. Entry was concentrated early in all four products. An initial buildup in the number of firms lasted roughly ten to twenty-five years. Once the number of firms reached a peak, however, entry declined sharply and soon became negligible. With the exception of a modest late rise in entry in penicillin, entry remained negligible after it declined sharply, with virtually no entry after roughly ten years into the shakeouts of the products.

2. All four products experienced prolonged shakeouts. The decline in the number of producers continued for over thirty years, to at or near the end of our data series. The number of U.S.-based producers declined in autos from a peak of 274 firms in 1909 to a low of 7 in the mid-1950s, in tires from the same peak of 274 firms in 1922 to a low of 23 in 1970, in televisions from a peak of 89 firms in 1951 to 3 (U.S.-owned) firms by the end of our series in 1989, and in penicillin from 29 firms in 1953 to a low of 5 firms in 1991. These long-term declines occurred despite continued growth in output of the products.

3. Early entrants generally came to dominate each of the four products. The firms with the largest market shares by the times the shakeouts had begun nearly always attained their leading positions substantially before the onset of the shakeouts. Ford and GM were the early leaders in autos and maintained their leadership after the start of the shakeout. Goodrich, Goodyear, Firestone, and U.S. Rubber early on constituted the big four tire producers and maintained their dominant positions after the start of the shakeout. RCA, Zenith, and GE were the early market leaders in televisions and maintained their leadership until challenged by foreign competitors. Lilly, Wyeth, Squibb, and Bristol, all wartime penicillin producers, were the leaders of the industry early in its shakeout. With the exception of Squibb, which was displaced by another wartime producer, Pfizer, they all maintained their leadership for many subsequent years. Not only were the industries dominated by early entrants, but with the exception of Chryslers in autos, no firm that entered after the start of the shakeouts remained for long a major player, and in fact even Chrysler's heritage dated back to an early entrant. 
4. Industry leaders dominated product and process innovation in the four products, with the exception of product innovation in automobiles. Most and sometimes nearly all of the major product and process innovations developed by producers of the products came from the largest four or five firms. These firms' share of innovations was not only the largest, but in fact substantially exceeded their market share. Firms outside the top eight played a negligible role in technological advance. The one exception was automobile product innovation. Smaller automobile producers contributed a substantially larger share of product innovations than their market share, although smaller producers still achieved far fewer innovations per firm than their larger competitors.

5. Individual innovations rarely stood out above the overall ongoing technical advance in each product, and the few that did stand out were not concentrated around the start of the shakeouts. Important innovations usually diffused rapidly, through imitation, licensing, and sale by third-party producers. Trajectories of related innovations occurring over extended periods sometimes had more potent effects, and two competitively significant trajectories, the Ford automobile manufacturing processes and the cord/balloon tire, occurred around the start of the shakeouts in autos and tires.

6. Product innovation started to decline around the start of the shakeouts in autos and tires but increased after the start of the shakeouts in television and penicillin. In autos, product innovation reached its highest peak in 1901 to 1904, gained a second and lesser peak when the shakeout began in 1910-1914, and peaked yet again in the mid-1920s. In tires, product innovation occurred most in the first decade of the 1900s, fell in the 1910s, and rose to a high level again when the shakeout began in the 1920s, after which it declined. In televisions, the rate of product innovation fell when the shakeout began in the 1950s, but the absolute number of innovations -- though perhaps not the importance of the innovations -- rose to its highest level beginning in the 1960s. In penicillin, product innovation increased dramatically after the advent of semisynthetic methods in 1958, a few years after the shakeout began. 
7. Process innovation rose for many years beginning at or prior to the start of the shakeouts in autos and tires, whereas process innovation in televisions and penicillin was greatest initially and then declined over time. In autos, the number and summed importance of process innovations increased steadily from the 1890 s to the early 1930 s. In tires, process improvement surged in the 1910s and, according to some indicators, remained high through the 1920s after the shakeout began. In televisions, process improvement apparently occurred most importantly in the late 1940s, with improvement dropping somewhat through the 1950s as the shakeout began, and perhaps rising again in the early 1970s. In penicillin, the greatest process improvement occurred during World War II as part of the government's effort to make the drug available and then declined subsequently.

Consider first only those findings common to all four products. What do these findings suggest about common evolutionary processes at work over their disparate histories? In each product, an initial period of entry was followed by a virtual cessation of entry, exit occurred continually and contributed to a shakeout lasting for decades, some early-entering firms established leading market positions that they retained as long as any U.S.-based producers remained, and the leading firms dominated product and process innovation. The latter two findings are suggestive of a significant advantage experienced by early entrants, manifested especially in innovation. An R\&Drelated process of increasing returns would generate just this sort of early-mover advantage. Such an interpretation would also explain the first two findings, since the growing advantages of the leading firms would eventually preclude profitable entry and would steadily drive out less fortunate incumbents through growing pressures on profit margins. Such pressures were noted explicitly in autos, where the manufacturing expert Walter Flanders remarked how the cost of a research program required to remain competitive had gone up so much that later entrants had to spend more initially on research than earlier entrants had spent on factories, and in tires, where Warner noted that the cost of an R\&D program required to stay at the technological frontier during the later evolution of the industry was prohibitively expensive for all but the leading firms. In televisions, the statistical studies of firm survival by Datta and Willard highlighted links between firm size, R\&D commitment, TV set quality, and survival, 
suggestive of the high cost to small firms of keeping up with the technological frontier. And in penicillin, the very high percentage of employees devoted to R\&D by antiobiotics producers is suggestive of the burden on small firms of staying at the technological frontier.

Alternative explanations could be constructed to fit this evidence, but it is difficult to formulate an alternative explanation that simultaneously fits with other historical facts about these products. If the dominance of early entrants did not result from an increasing returns dynamic, an obvious alternative would be some kind of early lock-in of firms to established positions. Yet plausible bases for early lock-in, such as patents, consumer reliance on a proprietary product, or government-sponsored monopolization, clearly did not generally operate in these products. The dynamics of market shares, entry, and exit also point to some continuous process that lock-in of itself does not explain.

A second alternative would be an increasing-returns dynamic that stems primarily from sources other than R\&D. Perhaps the leading alternative candidates are economies of scale in production and economies in distribution/service/marketing, two factors stressed by Chandler [1990] in his account of the emergence of large dominant firms in modern industrialized economies. While this study has focused on technological change, some evidence was assembled regarding the importance of production scale and marketing-related economies for early mover advantages in the four products. Regarding production scale economies, Reynolds [1938] found that the minimum efficient level of output in tires was quite small relative to the size of the market. Interviews of television executives by Levy [1981, p. 69] indicated that conventional sources of production scale economies were not significant in televisions. Schwartzman [1976, p. 308] concluded that production scale economies were not significant in penicillin. Only in automobiles were production scale economies significant. Regarding marketing-related economies, they were not the exclusive domain of the largest manufacturers. In tires, large mail order chains such as Sears Roebuck and Montgomery Ward and the oil companies entered on a large scale into wholesaling and retailing, marketing private label brands purchased from the 
manufacturers. The fact that their entry in the 1920s did not alter the structure of the market nor affect the shakeout in tires and that they eventually gravitated to buying from the largest firms suggests that the advantages of the largest tire manufacturers transcended distributional economies. ${ }^{52}$ Private label sales were also significant in televisions, and statistical analyses by Datta [1971] and Willard [1982] indicate that marketing-related advantages had little impact on firms' survival. Thus, the limited evidence available about nontechnological factors suggests that they did not play a key role in the shakeouts of the four products.

An alternative way to evaluate the three theories is to ask how well each accords with all seven of the highlighted findings. Readers may wish to refer to Section II as necessary regarding the basis for and predictions of the theories.

The innovative gamble theory features a radical technical development that triggers a shakeout. This development comes from outside the industry and involves difficult technical challenges that firms must overcome to remain competitive. Firms unable to adapt to the development exit the industry, while successful innovators expand because the new technology raises the minimum efficient size of firm. Finding 5 indicates, however, that major technical advances with singularly potent competitive effects were rare, and the times when they did occur were not generally around the start of the shakeouts. Furthermore, such advances did not seem to increase the minimum efficient firm size. A case in point is the Banbury Mixer, the innovation singled out by Jovanovic and MacDonald as the cause of the shakeout in tires. The Mixer was readily available through a third-party supplier, and besides diffusing widely, it had quite limited effects on the production process. Moreover, it was judged to reduce, not increase, the minimum efficient size of firm (Nelson [1982]). Given such conclusions, it is not surprising that finding 2 also did not match the theory's predictions; rather than leveling off as firms unable to adapt to the new technology exited, the number of firms continued to decline for decades after the start of the shakeouts. As for all the theories, finding 1, the cessation of entry, did match the innovative gamble theory's predictions. Findings

\footnotetext{
${ }^{52}$ Warner [1966, p. 65] makes a similar point regarding distributional economies in tires.
} 
3-4 and 6-7 were not directly addressed by the theory. Overall, the evidence suggests that individual radical innovations were not responsible for the shakeouts.

Given the enormous technical improvement that occurred in the four products, the innovative gamble theory begs the question of why so few technical advances had sufficient competitive significance to cause sustained exit. With the exception of new types of penicillin, the answer seems to lie in the rapid diffusion of the most important innovations among producers. This diffusion resulted from many factors, three of which seem most salient. First, many significant innovations could be (and were) readily imitated. Some of these innovations were not protected by patents, either because they were not patentable or because patents would reveal valuable knowledge that would facilitate imitation. Others were patented, but the scope of the patents was (eventually) so narrowly defined as to afford little protection from imitation. Major innovations in this first category include the Selden patent on the automobile, the three major advances in tire design, the clincher, straight-side, and balloon tire (and for that matter the pneumatic automobile tire itself), many rubber chemical innovations, penicillin $G$ (the original form of penicillin), and most major process improvements, including the moving assembly line in autos, the core and drum tire building machines, dip soldering and printed circuit boards in televisions, and most of the major advances in the fermentation of penicillin. Second, many significant innovations were developed by suppliers or were developed simultaneously by multiple firms and were subject to competition, which in both instances led to them being widely available through sale. Supplier-developed innovations available for sale include the DELCO electrical system for autos, the Banbury mixer in tires, and fermentation equipment in penicillin, and producerdeveloped innovations available through sale include the core tire building machine and color television picture tubes. Third, even when significant innovations were effectively protected by patents, with the exception of new forms of penicillin they were generally widely licensed. In autos, the patent agreement in force as of 1915 virtually guaranteed royalty-free licensing. ${ }^{53}$ In tires, the two biggest patented advances, the core and drum

\footnotetext{
${ }^{53}$ The automobiles patent agreement had an escape clause for major advances, but no advance ever qualified.
} 
tire building machines, were both licensed widely. In televisions, RCA not only licensed widely its key black and white patents but also provided technical assistance and later was forced to make most of its patents freely available. ${ }^{54}$

The dominant design theory features a coalescence of product standards around a particular design. Before the emergence of the dominant design, new firms often break into the market by developing novel product features, and firms limit their process improvement efforts lest changes in the product require new manufacturing processes. Product innovation is relatively frequent and process innovation relatively infrequent. After the emergence of the dominant design, efforts shift to producing the standardized product at the lowest possible cost, with a consequent decrease in the importance of product innovation and increase in the importance of process innovation. This shift in innovative patterns causes the shakeout. Entry slows because novel product features no longer provide a basis to break into the market, and a shakeout ensues as those firms that are less able process innovators exit. Can this tale of shifting innovative demands explain the shakeouts in the four products? Findings 6 and 7 indicate that it cannot. Only in automobiles and tires was there a lasting shift in importance from product to process innovation. In automobiles the Model $\mathrm{T}$ and the advent of mass production techniques coincided roughly with the beginning of the shakeout, but the Model T was hardly a lasting design standard for the industry. Indeed, Utterback and Suarez [1993] identify the inexpensive closed-body developed one and a half decades after the shakeout began as essential to the industry's dominant design. ${ }^{55}$ In tires the decrease in product innovation and rise in process innovation preceded the shakeout by a full decade. And televisions and penicillin had patterns directly opposite that predicted

\footnotetext{
${ }^{54}$ Although licensing has been estimated to enable innovators to appropriate only about one-third of the value of their innovations (Caves et al. [1983]), it may often be the lesser of the evils. It may forestall the kind of competition that ensued when the clincher tire patents were restrictively licensed and Goodyear and Firestone developed the straight-side tire, it may help the innovator establish its product as an industry standard, as in RCA's case, and it may reduce the legal challenges to a patent that can often be prolonged and costly to defend, as occurred in a number of instances. Indeed, one reason major new forms of penicillin may not have been widely licensed is that they did not directly challenge older forms but opened up new submarkets, thereby limiting their competitive implications.

55Utterback and Suarez mistakenly dated the shakeout in autos as beginning after 1923, apparently failing to notice that their source for data on the number of firms, Fabris [1966, p. 27], excluded all earlier exitors from his list of automobile makes.
} 
by the theory, with the greatest process innovation in each industry's earliest years, and the greatest product innovation after the shakeout was well underway. Given these conclusions, it is again hardly surprising that the theory is unable to explain finding 2 , in which the number of firms fell for decades rather than leveling off once only the most able process innovators survived, or finding 3 , in which some of the earliest entrants came to dominate their industry rather than entrants just prior to the shakeouts. As for all the theories, finding 1 , the cessation of entry, matched the dominant design theory's predictions. Findings 4 and 5 were not directly addressed by the theory. Overall, the evidence suggests that the emergence of dominant designs did not trigger the shakeouts.

These conclusions beg the question of why firms did not delay process improvement as described in the theory. Why did process innovation generally not await the resolution of uncertainty about the configuration of the product or other factors that could render previous production processes obsolete? No doubt one reason was competition. Auto producers might have liked to delay investments in machine tools and factories until their rate of obsolescence declined, but being in the forefront of process innovation was key to the success of a number of firms, most prominently Ford. Similarly, penicillin producers might have liked to delay their process investments until efforts to synthesize penicillin in the laboratory had ceased, but failure to lower costs during the early years of the industry would have been competitively catastrophic given the sharp reductions in prices that occurred. A second reason for the early commitment to process innovation is that, in contrast to the dominant design theory, major product innovations often had limited ramifications for the production process and thus did not render process investments obsolete. Cord tires, for example, contributed to new methods to construct the plies of the tire, but the rest of the steps in tire construction do not appear to have been greatly affected. Color television resulted in many more parts and may have initially slowed efforts to automate the production process, but it does not seem to have fundamentally altered the nature of the production process for TV sets. Even the synthesis of penicillin in the laboratory did not ultimately undermine the use of fermentation methods in the production of penicillin, as was feared during the early years of the industry. 
The increasing returns theory features a rich-get-richer dynamic in which some of the earliest entrants capture an R\&D-related advantage that propels them to positions of lasting dominance in the industry. These firms grow large and, by spreading the costs of their R\&D over greater amounts of output, achieve lower costs per unit of quality than their competitors. The close fit of this theory with findings $1-4$, the common findings across all four products, has already been noted. Finding 5, the lack of singularly important technological changes and instead the presence of large numbers of ongoing changes, also accords with the theory. However, two interrelated aspects of the theory did not fare so well. The theory portrays product innovation as opening new submarkets, which eliminates any link between firm size and incentives to conduct product $R \& D$, whereas process innovation is structured so that the incentives to conduct process $R \& D$ are directly related to firm size. This implies that process innovation will be dominated by the largest firms but product innovation will not. However, finding 4 indicates that both product and process innovation were dominated by the industry leaders. Only in automobiles was the leading firms' share of product innovation less than their market shares, and even there the absolute amount of innovation carried out by the average leading firm was far greater than carried out by the average small firm. The theory also implies that process R\&D will be exploited more fully as firms grow and hence, if technological opportunities remain constant, the amount of process innovation will increase over time. In contrast, assuming constant technological opportunities the theory implies that product innovation will rise and fall with the number of firms. However, findings 6-7 indicate that these patterns held only in two of the four products. While automobiles and tires fit very roughly with the predicted patterns of rising process innovation and rising and falling product innovation, in televisions and penicillin the bulk of process innovation occurred early and the rise in product innovation occurred surprisingly late. Overall, the evidence is supportive of an R\&D-related dynamic of increasing returns but suggests that the increasing returns dynamic pertained to product as well as process innovation and was not consistently the driving force behind patterns of product and process innovation.

These conclusions raise issues about why product innovation was subject to increasing returns and what drove patterns of product and process innovation. The 
theory's characterization that product innovations open up new markets and process innovations do not was overdrawn for all of the products except penicillin. Innovations such as improved automobile engines and bodies, longer-lasting tires, and clearer television reception had broad appeal, and to some extent process innovation fueled price decreases that attracted new customers as well as servicing existing customers. The predicted patterns of product and process innovation over time hinge both on the relative incentives for product and process $R \& D$ and on notions of diversity versus duplication. In the theory, a diversity of firms are assumed to generate a diversity of product innovations, but process innovation is assumed to be duplicative so that the rate of process innovation depends only on the largest firm's size. This distinction may also be overdrawn. Many firms carried out duplicative research on product innovations such as straight-side tires and larger-screen TVs, just as they did for process innovations such as automated insertion equipment for TV components and the enzymatic production of 6-APA for semisynthetic penicillins. Changes in technological opportunity over time and external influences may also account for some of the departures from the increasing returns theory. The exploitation of key technological opportunities for automobiles in the early 1900s may explain why automobile product innovation reached its highest peak as early as 1905. In televisions and penicillin, technological imperatives clearly affected the trajectory of innovation over time; in televisions product innovation rose after the initial failure of color TV and process improvement occurred early through the adaptation of manufacturing techniques from the radio industry, and in penicillin the rise in product innovation came after a major technical breakthrough and the early focus on process innovation stemmed from the U.S. government's efforts to build up war-time capabilities in penicillin production.

Consider finally the composite story about technological change and industry evolution that can be assembled from those aspects of each theory that do seem to fit the evidence. The continued decline in the number of firms for decades after the start of the shakeouts, the negligible amount of entry soon after the start of the shakeouts, and the long-term dominance of the markets for the four products by early entrants suggest that the shakeouts in the four products were not triggered by sudden technological or non-technological developments, but were part of a broader 
evolutionary process. The rapid rate of technical change in the four products, coupled with the dominance of innovation by the largest firms, nearly all of which entered early, suggests technical change played a key role in the shakeouts by imparting an advantage to some of the earliest entrants. In particular, a technology-related process of increasing returns seems to have propelled some early entrants to large market shares. These leading firms retained or improved their market shares with the help of their large outputs, which lowered per-unit R\&D costs. ${ }^{56}$ The dynamic of increasing returns explains the eventual drying up of entry and the long-term decline in the number of producers that occurred in all four products. Rising competition from the leading firms put pressure on prices and product quality, eventually making entry untenable and steadily forcing out smaller and less capable firms with relatively high costs and low quality.

The continual processes of technological advance that fueled competition often involved trajectories of related innovations. At times, these trajectories of innovations had a substantial impact on the competitive process, as noted in finding 5 . The innovations involved were both technically challenging and costly to adopt. In automobiles, Ford led the industry in implementing efficient mass production techniques which were put into use in the 1910s and 1920s. In tires, a series of innovations related to cord tires beginning in the 1910s led eventually to the development of balloon tires which took over the market in the 1920s. In televisions, color TV development led initially by RCA in the 1950s and 1960s eventually opened up the color television market. To some extent, the decision to pursue these trajectories of innovations amounted to gambles, and the idea of the innovative gamble helps to capture the competitive dangers experienced by firms participating in major, as yet untried, trajectories. Firms choosing to pursue these trajectories established sustained and very expensive programs of R\&D, ranging from applied research in laboratories to plant-floor engineering.

\footnotetext{
${ }^{56}$ Alternatively, progressive cost reduction and the progressive accumulation of technology might be thought to generate R\&D-related increasing returns. However, the rapid diffusion of technologies suggests that contemporary improvements, rather than those developed many years in the past, were most competitively relevant.
} 
The gradual path of product innovation, for all the products except pencillin, eventually led to the establishment of various de facto and de jure product standards. Thus, the products tended to become increasingly defined over time, eventually developing a number of lasting characteristics that might be termed a dominant design. Automobiles perhaps conforms most to this pattern. Major innovations such as bigger engines, electric starters, sliding gear transmissions, four wheel brakes, and inexpensive closed bodies diffused rapidly, and by roughly the late 1920s, product innovation had slowed and become more incremental. In tires, the shape and size of tires, methods of attachment to wheel rims, types of fabric or cords used to build the tires, and chemical additives went through a number of types and phases until finally coalescing around standard designs after the widespread adoption of balloon tires in the late 1920s. In televisions, the working out of basic black-and-white electronics and transmission standards by the 1940s and the spread of color television in the 1960s helped to define a basic design for televisions; other features of televisions, though, continued to change for decades, with degaussing, tuning, and tracking systems pioneered in the mid-1960s through the 1970s and various picture tube innovations ongoing through at least the 1970s. The principal exception to convergence toward a dominant design was penicillin, which experienced a proliferation of designs over time. This is consistent with Utterback's [1994] restriction of dominant designs to complex assembled products. Thus, for the three complex assembled products, the gradual standardization on a dominant design seems a useful way to characterize technical change over the long run.

\section{Conclusion}

To probe the role of technological change in industry shakeouts, we investigated whether four diverse products that experienced severe shakeouts, automobiles, tires, televisions, and penicillin, experienced common patterns in the way they evolved. Using three theoretical perspectives on how technological change could lead to industry shakeouts, we focused on how entry, the number of firms, the market shares of the leading firms, and various characteristics of product and process innovation evolved over time in the four products. Common features in how the products evolved were 
identified. Entry was concentrated early and became negligible soon after the start of the shakeouts, the number of firms declined for over thirty years after the start of the shakeouts, and the leading firms were nearly all early entrants and generally dominated both product and process innovation. Coupled with other patterns concerning trends in product and process innovation and the diffusion of innovations, these patterns suggested that industry shakeouts were not triggered by particular innovations nor by dominant designs but were part of a broader evolutionary process driven by continual technological change. Shakeouts appear to result from an evolutionary process in which technological innovation contributes to mounting dominance by some earlyentering firms. Falling prices and rising quality standards eventually make entry so difficult as to deter further entry, and smaller firms with relatively high cost and low quality steadily exit production as they become unprofitable.

The four products studied were selected because of the severity of the shakeouts they experienced. Such a sample is clearly not a random collection of products. It was chosen to facilitate the identification of factors that consistently contribute to shakeouts. It may well be that the four products are not representative of products experiencing less severe shakeouts (including ones experiencing no shakeouts at all). None of the four products experienced the kinds of innovations that in other industries provided opportunities for new firms to displace the industry leaders (Tushman and Anderson [1986], Henderson and Clark [1990], Christensen and Rosenbloom [1995]). Products subject to such innovations may experience periods of new entry that limit the severity of their shakeouts. ${ }^{57}$ Consequently, our sampling strategy may be biased toward industries which are characterized by strong first-mover advantages and long-term domination of innovation by the leading firms.

Although technological trends and early-mover advantages surely differ between industries with extreme shakeouts and those with periodic technical changes that bring in new firms, a single cause could nonetheless be at the root of both types of evolution. Various theories have been proposed concerning the kinds of innovations that can

\footnotetext{
${ }^{57}$ Rigid disk drives may be an example (Christensen et al. [1996]).
} 
undermine industry leaders. One developed by Christensen and Rosenbloom [1995] provides a possible link to the increasing returns hypothesis and thus to a more general theory of industry evolution. Christensen and Rosenbloom argue that innovations that open opportunities for new firms and sometimes lead to the decline of dominant firms often have the characteristic that they create new uses for a product that appeal to new classes of buyers. They stress that incumbent firms' innovations are shaped by their existing buyers, which often causes incumbent firms to be slow to develop innovations that appeal to new buyers. Consequently, such innovations provide opportunities for new firms to compete with incumbents. The notion of R\&D cost spreading that drives the increasing returns theory provides an alternative explanation for this same phenomenon. Since incumbents sell no prior output to new buyers, R\&D cost spreading implies that in the absence of R\&D or other scope economies incumbents have no greater incentive than new firms to develop innovations that appeal to new buyers. Consequently, industries which systematically experience innovations that attract new users might be expected to experience more entry and hence to undergo less severe shakeouts, ceteris paribus. A sensible next step to explore these ideas would be to analyze samples of products with less severe shakeouts. Indeed, a study of products that experienced no shakeouts at all as well as those experiencing moderate shakeouts might be especially revealing of the factors conditioning whether and how severely industries undergo shakeouts. A unified theory of shakeouts and more generally industry evolution must be able to account for both ends of the spectrum. In this respect, our findings may serve as both guide and goal for theorizing about shakeouts and industry evolution. 


\section{References}

Abernathy, William J. The Productivity Dilemma: Roadblock to Innovation in the Automobile Industry. Baltimore: Johns Hopkins University Press, 1978.

Abernathy, William J., and James M. Utterback. "Patterns of Industrial Innovation." Technology Review, June/July 1978, pp. 40-47.

Abernathy, William J., Kim B. Clark, and Alan M. Kantrow. Industrial Renaissance: Producing a Competitive Future for America. New York: Basic Books, 1983.

Achilladelis, Basil. "The Dynamics of Technological Innovation: The Sector of Antibacterial Medicines." Research Policy, 22, 1993, pp. 279-308.

Allen, Hugh. The House of Goodyear: Fifty Years of Men and Industry. Cleveland: Corday and Gross, 1949.

Anderson, Philip and Michael L. Tushman. "Technological Discontinuities and Dominant Designs: A Cyclical Model of Technological Change." Administrative Science Quarterly, 35, 1990, pp. 604-633.

Babcock, Glenn D. History of the United States Rubber Company. Bloomington: University of Indiana Press, 1966.

Baum, J.A.C., H.J. Korn, and S. Kotha. "Dominant Designs and Population Dynamics in Telecommunications Services: Founding and Failure of Facsimile Transmission Service Organizations, 1965-1992." Social Science Research, 24, 1995, pp. 97-135.

Bomstein, Joseph, and William G. Evans. "Automated Colorimetric Determination of 6-Aminopenicillanic Acid in Fermentation Media." Analytical Chemistry, 37, April 1965, pp. 576-578.

Bradley, James J. and Richard M. Langworth. "Calendar Year Production: 1896 to Date." In L. Scott Bailey, ed., The American Car Since 1775, Kutztown, PA: Kutztown Publishing Company, 1971, pp. 138-143. 
Briggs, Tedford C. "Medicinal Chemicals: Important Developments in Medicinal Chemicals in 1978, and a Case Study of the Penicillins." In Synthetic Organic Chemicals: United States Production and Sales, 1978, U.S. International Trade Commission publication 1001, Washington, D.C.: U.S. Government Printing Office, 1979, pp. 143-148.

Brockmann, Maxwell C. "Freeze Drying." In Elder, Albert L., ed., The History of Penicillin Production, New York: American Institute of Chemical Engineers, 1970, pp. 51-61.

Brown, George H., R.A. Bierwirth, and Cyril N. Hoyler. "Radio-Frequency Dehydration of Penicillin Solution." Proceedings of the I.R.E., Waves and Electrons section, 1, Feb. 1946, pp. 58W-56W.

Business Week. "TV Goes to Automation." Business Week, 18 June 1955, pp. 58-65.

Calam, C. T. Process Development in Antibiotic Fermentations. Cambridge: Cambridge University Press, 1987.

Carlsmith, Leonard E. The Economic Characteristics of Rubber Tire Production. New York: Criterion Linotyping and Printing, 1935.

Carroll, Glen R. and Michael T. Hannan. "Automobile Manufacturers." in Carroll, Glenn R. and Michael T. Hannan, eds., Organizations in Industry, New York: Oxford University Press, 1995, pp. 195-214.

Caves, Richard E., Harold Crookell, and J. Peter Killing. "The Imperfect Market for Technology Licensing." Oxford Bulletin of Economics and Statistics, August, 1983, pp. 249-267.

Chandler, Alfred D., Jr. Scale and Scope. Cambridge, MA: Harvard University Press, 1990.

Charles River Associates. International Technology Competitiveness: Television 
Receivers and Semiconductors, Phase I. Boston: Charles River Associates, July 1979.

Chemical Engineering. "Penicillin." Chemical Engineering, 58, April 1951, pp. 174-177.

Cherry, G.B., E.P. McCann, and Alan Parker. "The Removal of Bacteria from Air by Filtration: Application to Industrial-Scale Fermentations." Journal of Applied Chemistry, 1, Sept. 1951, pp. S103-S107.

Chisholm, Bradley Francis. The CBS Color Television Venture: A Study of Failed Innovation in the Broadcasting Industry. PhD dissertation, University of Wisconsin at Madison, 1987.

Christensen, Clayton M., and Richard S. Rosenbloom. "Explaining the Attacker's Advantage: Technological Paradigms, Organizational Dynamics, and the Value Network." Research Policy, 24, 1995, pp. 233-257.

Christensen, Clayton M., Fernando F. Suarez, and James M. Utterback. "Strategies for Survival in Fast-Changing Industries." Working paper, MIT Sloan School, July 1996.

Chrysler, Walter P., in collaboration with Boyden Sparks. Life of an American Workman. New York: Dodd, Mead, and Company, 1937.

Coghill, Robert D. "The Development of Penicillin Strains." In Elder, Albert L., ed., The History of Penicillin Production, New York: American Institute of Chemical Engineers, 1970, pp. 13-21.

Coghill, Robert D., and Roy S. Koch. "Penicillin: A Wartime Accomplishment." Chemical and Engineering News, 23, 25 Dec. 1945, pp. 2310-2316.

Colvin, Fred H. "Continuous Assembling in Modern Automobile Shops." American Machinist, August 26, 1915, pp. 365-370.

Consumers' Research. Consumer Bulletin - Annual, vol. 37. Washington, N.J.: Consumers' Research, Inc., September 1962. 
Darney, Arsen J. Market Share Reporter: An Annual Compilation of Reported Market Share Data on Companies, Products, and Services. Detroit: Gale Research, 1991.

Dasgupta, Partha and Joseph Stiglitz. "Industrial Structure and the Nature of Innovative Activity." Economic Journal, 40, 1980, pp. 266-293.

Datta, Yudhishter. Competitive Strategy and Performance of Firms in the US Television Set Industry: 1950-60. PhD dissertation, State University of New York at Buffalo, 1971.

David, Paul. "Clio and the Economics of QWERTY." American Economic Association Papers and Proceedings, 75, 1985, pp. 332-337.

Dick, J.S. "How Technological Innovations Have Affected the Tire Industry's Structure: Part 5." Elastomerics, January 1981, pp. 25-30.

Doolittle, James R. The Romance of the Automobile Industry. New York: The Klebold Press, 1916.

Dosi, Giovanni. "Technological Paradigms and Technological Trajectories." Research Policy, 11, 1982, pp. 147-162.

Elder, Albert L. "The Role of the Government in the Penicillin Program." In Elder, Albert L., ed., The History of Penicillin Production, New York: American Institute of Chemical Engineers, 1970, pp. 1-11.

Electronic Industries Association. Electronic Industries Yearbook, 1968. Washington: Electronic Industries Association, 1968.

Electronic Industries Association. Electronic Market Data Book, 1971. Washington: Electronic Industries Association, 1971.

Electronic Industries Association. Electronic Market Data Book, 1975. Washington: Electronic Industries Association, 1975. 
Epstein, Ralph C. The Automotive Industry. A. W. Shaw, 1928. Reprinted in New York: Arno Press, 1972.

Fabris, Richard H. A Study of Product Innovation in the Automobile Industry During the Period 1919-1962. PhD dissertation, University of Illinois, 1966.

Federal Trade Commission (FTC). Economic Report on Antibiotics Manufacture. Washington, D.C.: US Government Printing Office, 1958.

Federal Trade Commission (FTC). Report on the Motor Vehicle Industry. Washington, D.C.: US Government Printing Office, 1939.

Federal Trade Commission (FTC). Statistical Report: Annual Line of Business Report 1975. Washington D.C., 1981.

Ferrari, Andres, Frank M. Russo-Alesi, and Jacques M. Kelly. "A Completely Automated System for the Chemical Determination of Streptomycin and Penicillin in Fermentation Media." Analytical Chemistry, 31, Oct. 1959, pp. 1710-1717.

Flaherty, Therese. "Industry Structure and Cost-Reducing Investment." Econometrica, 48, 1980, pp. 1187-1209.

Fortune, W.B., S.L. McCormick, H.W. Rhodehamel, Jr., and J.J. Stefaniak. "Antibiotics Development." Industrial and Engineering Chemistry, 42, Jan. 1950, pp. 191-198.

French, Michael J. The American Rubber Products Industry, 1890-1937: Technical Change, Productivity and Concentration in Tyre Manufacture. PhD dissertation, Birkbeck College, University of London, 1985.

French, Michael J. "Structural Change and Competition in the United States Tire Industry, 1920-1937." Business History Review, 60 (Spring), 1986, pp. 28-54.

French, Michael J. The U.S. Tire Industry. Boston: Twayne Publishers, 1991.

Futia, Carl A. "Schumpeterian Competition." Quarterly Journal of Economics, 94, 
1980, pp. 675-695.

Gaden, Elmer. "Chemical Technology of Fermentation." Chemical Engineering, 63, April 1956, pp. 159-174.

Gaffey, John D. The Productivity of Labor in the Rubber Tire Manufacturing Industry. New York: Columbia University Press, 1940.

Gort, Michael, and Steven Klepper. "Time Paths in the Diffusion of Product Innovations." The Economic Journal, 92, Sept. 1982, pp. 630-653.

Graham, Margaret B. W. RCA and the Videodisc: The Business of Research. New York: Cambridge University Press, 1986.

Harris, William B. "R.C.A. Organizes for Profit." Fortune, 56, August 1957, pp. 110-115 and 228-234.

Harvard Business School (HBS). "Zenith Radio Corporation (C)." Case study 9-674-095 (revised), Harvard Business School, 1977.

Hatch, Darwin S. "Production the Genie of 1916." Motor Age, December 20, 1915, pp. 5-7.

Henderson, Rebecca M. and Kim B. Clark. "Architectural Innovation: The Reconfiguration of Existing Product Technologies and the Failure of Established Firms." Administrative Science Quarterly, 35, 1990, pp. 9-30.

Herold, Edward W. "History and Development of the Color Picture Tube." Proceeding of the Society for Information Display, 14, Fourth quarter 1974, pp. 141-149.

Herold, Edward W. "A History of Color Television Displays." Proceedings of the IEEE, 64, September 1976, pp. 1331-1338.

Hockenhull, J.D. "Lessons from Penicillin Production." Manufacturing Chemist, Aug. 1961, pp. 355-356.

Hopenhayn, Hugo A. "The Shakeout." Economics working paper 33, Universitat 
Pompeu Fabra, 1993.

Hounshell, David A. From the American System to Mass Production, 1800-1932. Baltimore: Johns Hopkins University Press, 1984.

lansiti, Marco and Tarun Khanna. "Technological Evolution, System Architecture and the Obsolescence of Firm Capabilities." Industrial and Corporate Change, 4, 1995, pp. 333-361.

Industrial Chemist. "Production of Semisynthetic Penicillins at Worthing." Industrial Chemist, 39, Oct. 1963, pp. 513-518.

Jovanovic, Boyan, and Glenn M. MacDonald. "The Life Cycle of a Competitive Industry." Journal of Political Economy, 102, 1994, pp. 322-347.

Katz, Harold. The Decline of Competition in the Automobile Industry, 1920-1940. PhD dissertation, Columbia University, 1970. Also published as New York: Arno Press, 1977.

Kimes, Beverly R. and Henry A. Clark, Jr. Standard Catalog of American Automobiles, 1805-1942. Iola, Wis: Krause Publications, 1985.

Klepper, Steven. "Entry, Exit, Growth, and Innovation over the Product Life Cycle." American Economic Review, 86, 1996, pp. 562-583.

Klepper, Steven, and Elizabeth Graddy. "The Evolution of New Industries and the Determinants of Market Structure." Rand Journal of Economics, 21, 1990, pp. 27-44.

LaFever, Mortier W. "Workers, Machinery, and Production in the Automobile Industry." Monthly Labor Review, October, 1924, pp. 1-26.

LaFrance, Vincent A. The United States Television Receiver Industry: United States versus Japan, 1960-1980. PhD dissertation, Pennsylvania State University, 1985.

Langlois, Richard N. and Paul L. Robertson. "Explaining Vertical Integration: 
Lessons from the American Automobile Industry." Journal of Economic History, 49, 1989, pp. 361-375.

Lee, Michael A. "Development of a Process for the Manufacture of Phenethicillin." Chemistry and Industry, 18 May 1974, pp. 399-403.

Lein, Joseph. "The New Semisynthetic Penicillins." In Elder, Albert L., ed., The History of Penicillin Production, New York: American Institute of Chemical Engineers, 1970, pp. 64-72.

Levy, Jonathan D. Diffusion of Technology and Patterns of International Trade: The Case of Television Receivers. PhD dissertation, Yale University, 1981.

Lief, Alfred. The Firestone Story. New York: Whittlesey House, 1951.

Look. Look National Appliance Survey: Volume One, Major Household Appliances. New York: Cowles Magazines, 1959.

Lyons, Emerson J. "Deep Tank Fermentation." In Elder, Albert L., ed., The History of Penicillin Production, New York: American Institute of Chemical Engineers, 1970, pp. 31-36.

Markus, John. "Mechanized Production of Electronic Equipment." Electronics, 28, Sept. 1955, pp. 137-160.

McClane, Charles T. "Adjustment Procedures for Color TV Production." Electronics, 27, Aug. 1954, pp. 140-143.

Metcalfe, J. S., and M. Gibbons. "Technology, Variety and Organisation: A Systematic Perspective on the Competitive Process." In Rosenbloom, Richard S. and Robert A. Burgelman, eds., Research on Technological Innovation, Management, and Policy, vol. 4, Greenwich, Conn.: JAI Press, 1988.

Modern Packaging. "Sterile-Filling Machine." Modern Packaging, 22, April 1949, pp. $150-151$. 
Modern Packaging. "Parts by the Reel." Modern Packaging, 28, Aug. 1955, pp. 100-101, 186-188.

Murmann, Johann Peter and Michael L. Tushman. "New Directions in Dominant Design Research: Hierarchy of Technology Cycles as an Integrating Concept for the Study of Technical Change and Organizational Dynamics." Manuscript, Columbia University, June 1996.

Muss, David L. "The Treatment of Penicillin Wastes." Sewage and Industrial Wastes, 23, April 1951, pp. 486-496.

Nelson, Daniel. "Origins of the Sit-Down Era: Worker Militancy and Innovation in the Rubber Industry, 1934-1938." Labor History, 23, 1982, pp. 198-225.

Nelson, Daniel. American Rubber Workers \& Organized Labor, 1900-1941. Princeton: Princeton University Press, 1988.

Nelson, Richard R. and Sidney G. Winter. "In Search of a Useful Theory of Innovation." Research Policy, 5, 1977, pp. 36-76.

Nelson, Richard R. and Sidney G. Winter. "Forces Generating and Limiting Concentration under Schumpeterian Competition." Bell Journal of Economics, 9, 1978, pp. 524-548.

Nevins, Allan, with the collaboration of Frank E. Hill. Ford, the Times, the Man, the Company. New York: Charles Scribner's and Sons, 1954.

O'Reilly, Maurice. The Goodyear Story. Elmsford, NY: The Benjamin Company, Inc., 1983.

Oxenfeldt, Alfred R. Marketing Practices in the TV Set Industry. New York: Columbia University Press, 1964.

Perlman, David. "The Evolution of Penicillin Manufacturing Processes." In Elder, Albert L., ed., The History of Penicillin Production, New York: American Institute of Chemical Engineers, 1970, pp. 23-30. 
Phillips, Almarin. Technology and Market Structure: A Study of the Aircraft Industry. Lexington, Mass.: D.C. Heath and Company, 1971.

Podbelniak, Walter J., Herbert R. Kaiser, and George J. Ziegenhorn. "Centifugal Solvent Extraction." In Elder, Albert L., ed., The History of Penicillin Production, New York: American Institute of Chemical Engineers, 1970, pp. 43-50.

Pound, Arthur. The Turning Wheel. New York: Doubleday, Doran \& Company, Inc., 1934.

Rae, John B. American Automobile Manufacturers. Philadelphia: Chilton Company.

Raff, Daniel. "Making Cars and Making Money in the Interwar Automobile Industry: Economies of Scale and Scope and the Manufacturing Behind the Marketing." Business History Review, 65, 1991, pp. 721-753.

Renner, Gail K. The Hudson Years: A History of an American Automobile Manufacturer. PhD dissertation, University of Missouri-Columbia, 1973.

Reynolds, Lloyd G. "Competition in the Rubber-Tire Industry." American Economic Review, 3, 1938, pp. 459-468.

Romer, Paul M. "Increasing Returns and Long-run Growth." Journal of Political Economy, 94, 1986, pp. 1002-1037.

Ryu, Dewey D.Y., and Arthur E. Humphrey. "Examples of Computer-Aided Fermentation Systems." Journal of Applied Chemistry and Biotechnology, 23, April 1973, pp. 283-295.

Sahal, Devendra. Patterns of Technological Innovation. Reading, Mass.: AddisonWesley, 1981.

Scholz, Anne. "Penicillins -- United States." Chemical Economics Handbook data summary, antiinfectives section 551.0150, April 1992. 
Schumpeter, Joseph A. The Theory of Economic Development. Oxford: Oxford University Press, 1974. Originally published in German, 1911.

Schumpeter, Joseph A. Capitalism, Socialism, and Democracy, 3rd ed. New York: Harper, 1950.

Schusteff, Sandy and Marinell Landa. "Bristol-Myers Squibb Company." In Kepos, Paula, ed., International Directory of Company Histories, vol. 9, Detroit: Saint James Press, 1994, pp. 88-91.

Schwartzman, David. Innovation in the Pharmaceutical Industry. Baltimore: Johns Hopkins University Press, 1976.

Shaked, Avner and John Sutton. "Product Differentiation and Industry Structure." Journal of Industrial Economics, 36, 1987, pp. 131-146.

Sheehan, John C. The Enchanted Ring: The Untold Story of Penicillin. Cambridge, Mass.: MIT Press, 1982.

Smallzreid, Kathleen A. and Dorothy J. Roberts. More Than You Promise. New York: Harper and Brothers, 1942.

Smith, Philip H. Wheels within Wheels: A Short History of American Motor Car Manufacturing. New York: Funk and Wagnalls, 1968.

Sorensen, Charles E., with Samuel T. Williamson. My Forty Years with Ford. New York: Collier Books, 1956.

Souders, Mott, G.J. Pierotti, and C.L. Dunn. "The Recovery of Penicillin by Extraction with a $p \mathrm{H}$ Gradient." In Elder, Albert L., ed., The History of Penicillin Production, New York: American Institute of Chemical Engineers, 1970, pp. 37-42.

Spencer, L.V. "Metamorphosis of the Motor Car." Motor Age, March 9, 1916, pp. 5-11.

Stern, Boris. Labor Productivity in the Automobile Tire Industry. Bureau of Labor 
Statistics Bulletin 585, Washington, D.C., US Government Printing Office, 1933.

Suarez, Fernando F. and James M. Utterback. "Dominant Designs and the Survival of Firms." Strategic Management Journal, 16, 1995, pp. 415-430.

Sutton, John. Sunk Costs and Market Structure: Price Competition, Advertising, and the Evolution of Concentration. Cambridge, Mass.: MIT Press, 1991.

Teitelman, Robert. Profits of Science. New York: Basic Books, 1994.

Tele-Tech. "Television Engineering and Manufacturing at Philco." Tele-Tech, 7, Nov. 1948, pp. 61-94.

Television Factbook (or Television and Cable Factbook), vols. 5 to 59. Washington, D.C.: Warren Publishing, 1948 to 1991.

Thomas' Register of American Manufacturers. New York: Thomas Publishing Co., 1905 to 1994.

Thomas, Robert Paul. An Analysis of the Pattern of Growth of the Automobile Industry, 1895-1929. PhD dissertation, Northwestern University, 1965.

Tire Business. "Evolution of Today's Pneumatic Tire." Tire Business, August 1988, pp. 26-29.

Tufford, Henry H. Tires and Vulcanizing. Chicago: Frederick J. Drake \& Co.

Tushman, Michael L., and Philip Anderson. "Technological Discontinuities and Organizational Environments." Administrative Science Quarterly, 31, 1986, pp. 439-465.

U.S. Bureau of Labor Statistics. "Census of Manufactures: 1935; Man-Hour Statistics for 59 Selected Industries." Washington, D.C.; US Government Printing Office, 1938.

U.S. Bureau of Labor Statistics. "Census of Manufactures: 1937; Man-Hour Statistics for 105 Selected Industries." Washington, D.C.; US Government Printing 
Office, 1939.

U.S. Bureau of Labor Statistics. "Case Study Data on Productivity and Factory Performance: Radio and Television Manufacturing." Report prepared for the Mutual Security Agency, Productivity and Technical Assistance Division, February 1952.

U.S. Bureau of Labor Statistics. "Productivity Measures for Selected Industries, 1954-82." Bulletin 2189, December 1983.

U.S. Tariff Commission, later US International Trade Commission. Synthetic Organic Chemicals. Washington, D.C.; US Government Printing Office, 1945 to 1993.

Utterback, James M. Mastering the Dynamics of Innovation. Cambridge, Mass.: Harvard Business School Press, 1994.

Utterback, James M, and William J Abernathy. "A Dynamic Model of Process and Product Innovation." Omega, 3, 1975, pp. 639-656.

Utterback, James M., and Fernando F. Suarez. "Innovation, Competition, and Industry Structure." Research Policy, 22, 1993, pp. 1-21.

Wanning, F.D. "Changes in Rubber Mill Machinery, 1901 to 1921." India Rubber Review, November 1921, pp. 1027-1034.

Warner, Stanley L. Innovation and Research in the Automobile Tire and TireSupporting Industries. PhD dissertation, Harvard University, 1966.

Willard, Gary E. A Comparison of Survivors and Non-survivors under Conditions of Large-scale Withdrawal in the U.S. Color Television Set Industry. PhD dissertation, Purdue University, 1982.

Wooster, James Howard. Industrial Policy and International Competitiveness: A Case Study of U.S.-Japanese Competition in the Television Receiver Manufacturing Industry. PhD dissertation, University of Massachusetts, 1986.

Wyatt, Horace. The Motor Industry. London: Sir Isaac Pitman \& Sons, Ltd., 1917. 


\section{Automobile Producers}

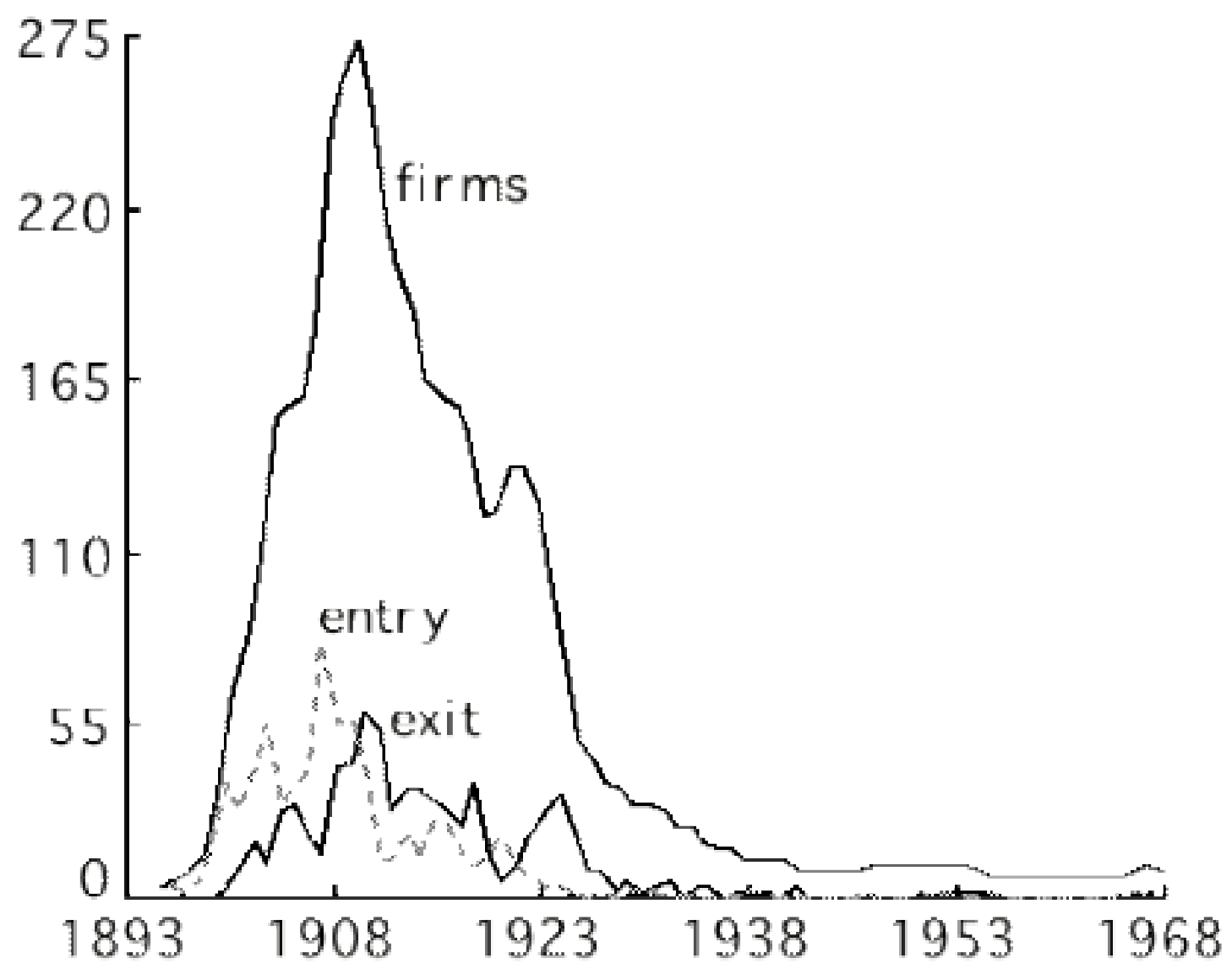

Figure 1. 


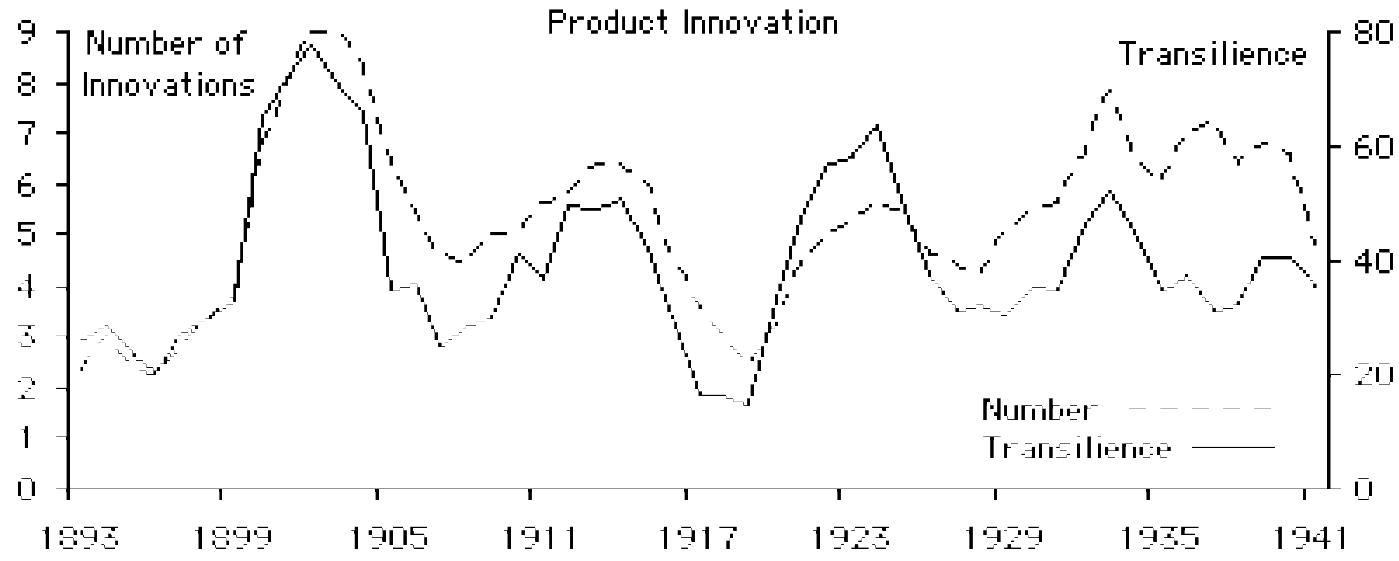

Figure 2. 


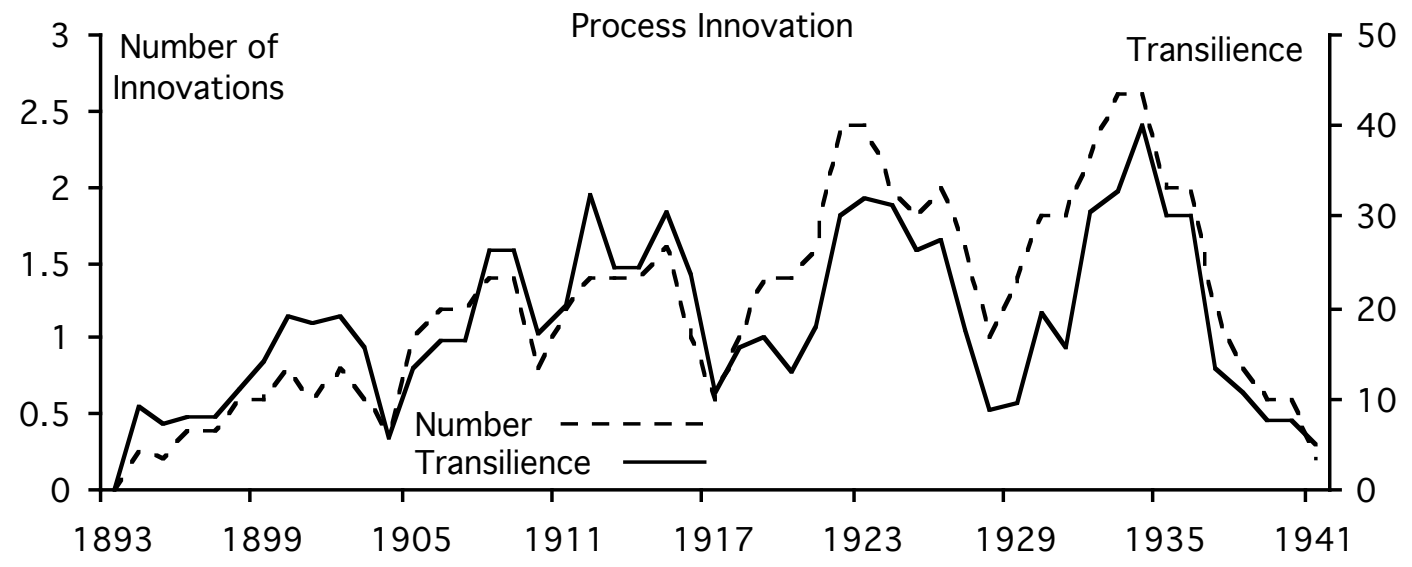

Figure 3. 
Tire Producers

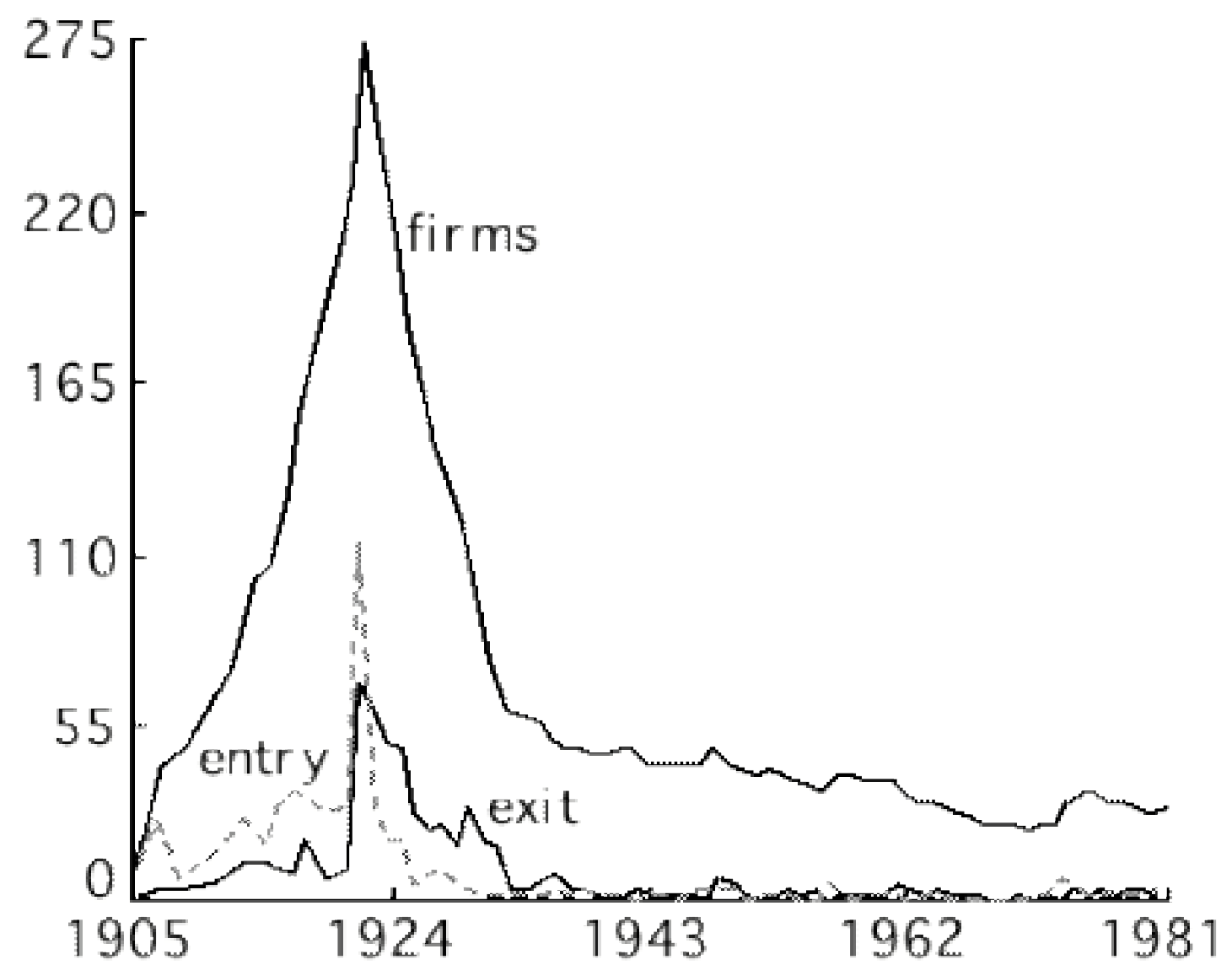

Figure 4. 


\section{Television Set Producers}

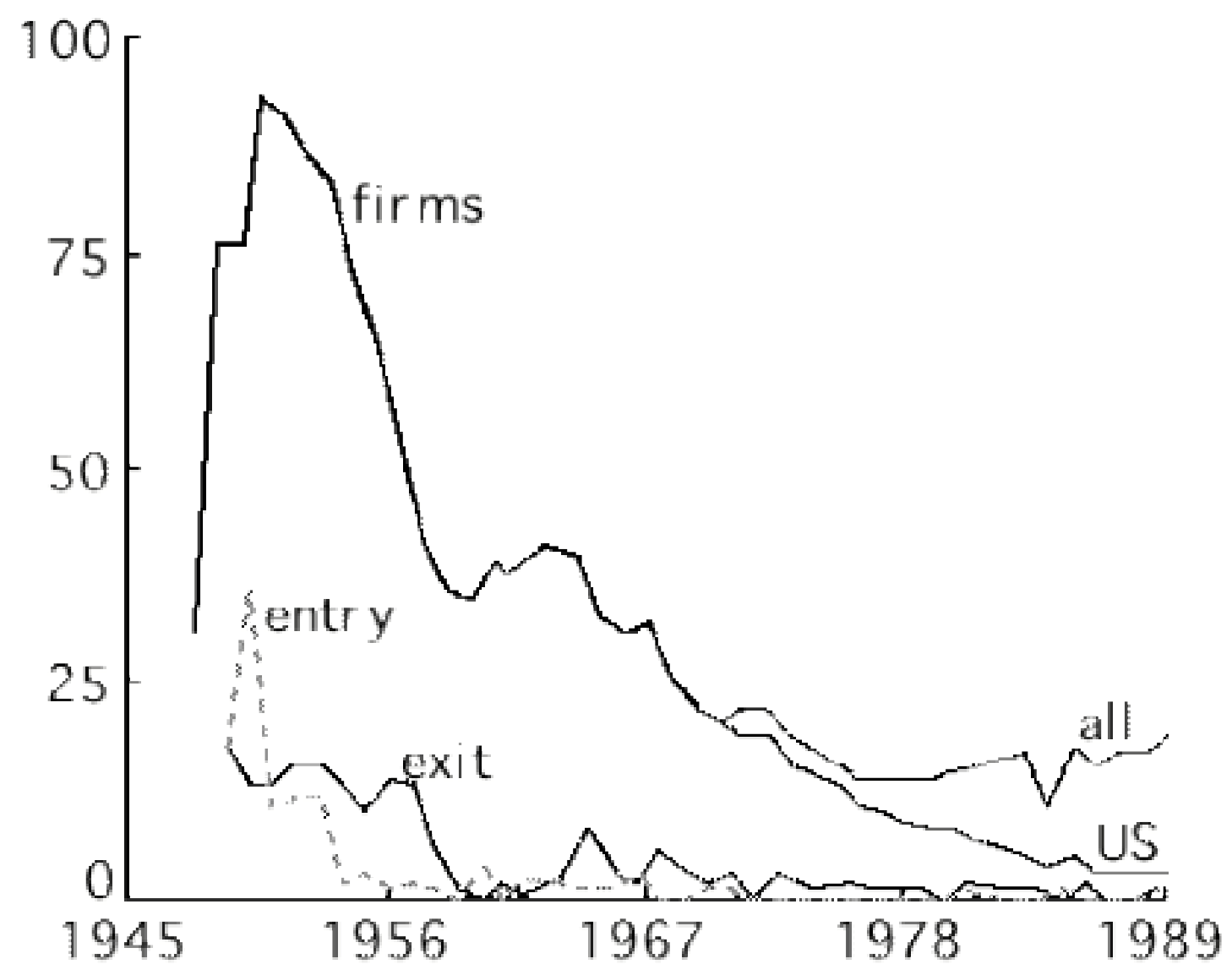

Figure 5. 


\section{Penicillin Producers}

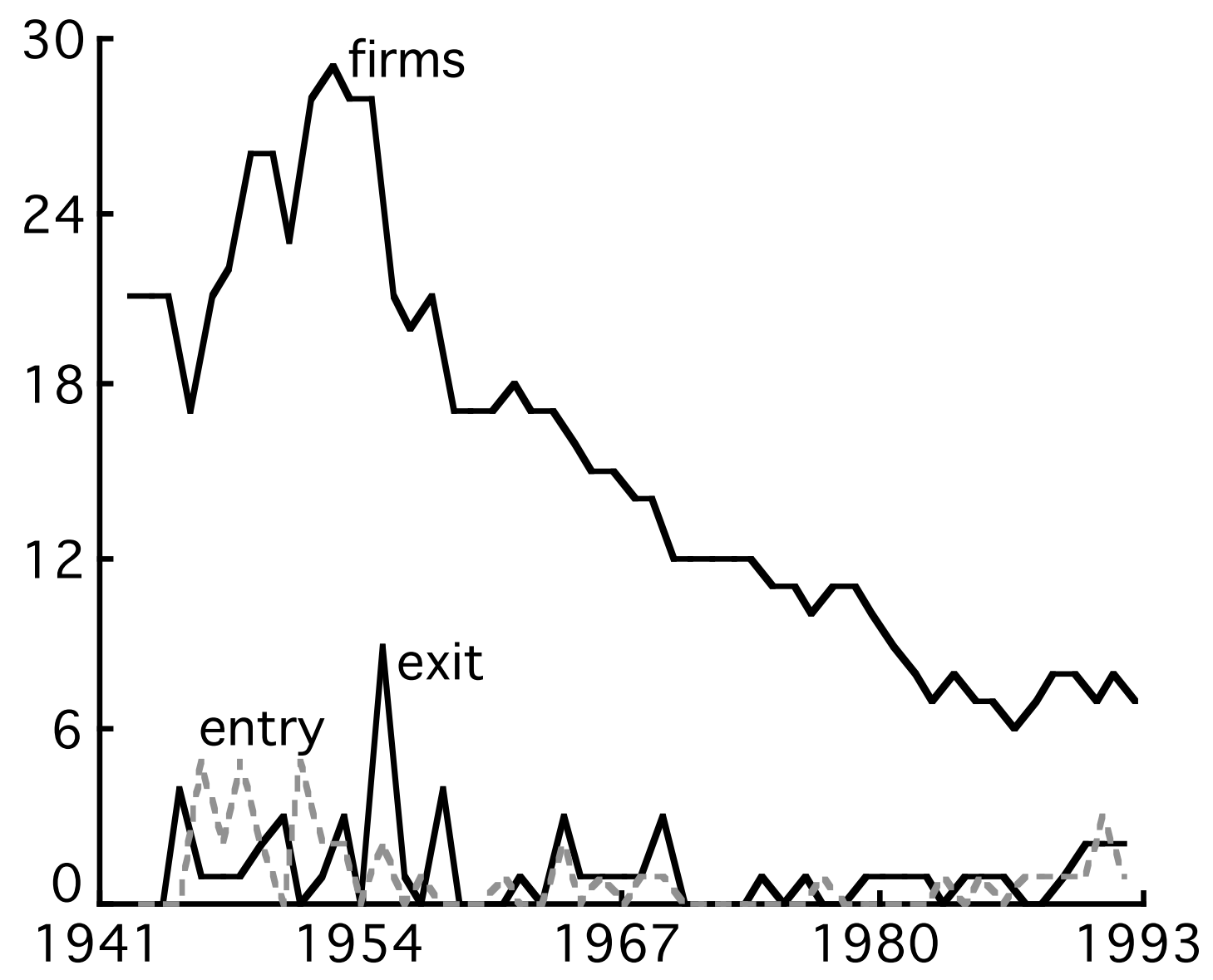

Figure 6. 
Table 1

Annual Production of Top Ten Automobile Makes,

Selected Years

1904

1908

1916

$\begin{array}{lrlrlr}\text { Oldsmobile } & 5,508 & \text { Ford } & 10,202 & \text { Ford } & 734,811 \\ \text { Cadillac } & 2,457 & \text { Buick } & 8,820 & \text { Willys-Overland } & 140,111 \\ \text { Rambler } & 2,342 & \text { Studebaker } & 8,132 & \text { Buick } & 124,834 \\ \text { Ford } & 1,695 & \text { Maxwell } & 4,455 & \text { Dodge } & 71,400 \\ \text { Franklin } & 712 & \text { Reo } & 4,105 & \text { Maxwell } & 69,000 \\ \text { White } & 710 & \text { Rambler } & 3,597 & \text { Studebaker } & 65,536 \\ \text { Stanley } & 550 & \text { Cadillac } & 2,377 & \text { Chevrolet } & 62,898 \\ \text { Packard } & 250 & \text { Franklin } & 1,895 & \text { Saxon } & 27,800 \\ \text { Overland } & 25 & \text { Packard } & 1,803 & \text { Hudson } & 25,772 \\ \text { Maxwell } & 10 & \text { Hupmobile } & 1,618 & \text { Oakland } & 25,675\end{array}$

1925

1936

$\begin{array}{lrlr}\text { Ford } & 1,643,295 & \text { Chevrolet } & 975,238 \\ \text { Chevrolet } & 444,671 & \text { Ford } & 791,812 \\ \text { Hudson-Essex } & 269,474 & \text { Plymouth } & 527,177 \\ \text { Willys-Overland } & 215,000 & \text { Dodge } & 274,904 \\ \text { Dodge } & 201,000 & \text { Oldsmobile } & 187,638 \\ \text { Buick } & 192,100 & \text { Buick } & 179,533 \\ \text { Studebaker } & 133,104 & \text { Pontiac } & 178,496 \\ \text { Chrysler-Maxwell } & 132,343 & \text { Hudson-Terraplane } & 123,266 \\ \text { Hupmobile } & 129,020 & \text { Studebaker } & 85,026 \\ \text { Durant lines } & 127,000 & \text { Packard } & 80,699\end{array}$

Source: Bradley and Langworth [1971, pp. 138-141] 
Table 2

Major Automobile Product Innovations Through 1940

\begin{tabular}{|c|c|c|c|}
\hline Year & Firm(s) & Innovation & ience \\
\hline & & Engines & \\
\hline 1895 & Haynes- & Aluminum Engine & 5 \\
\hline 1896 & King & En-Bloc Engine & 5 \\
\hline 1902 & Locomobile & 4-Cylinder, Front Mounted Engine & 4 \\
\hline 1902 & Northern & Three Point Suspension of Power Unit & 5 \\
\hline 1908 & Ford & Detachable Cylinder Heads & 6 \\
\hline 1913 & Studebaker & $\begin{array}{l}\text { First Production Six Cylinder Engine } \\
\text { Cast in a Single Block of Gray Cast Iron }\end{array}$ & 4 \\
\hline 1914 & Cadillac (GM) & First Large Scale Production V-8 Engine & 7 \\
\hline 1916 & Hudson & $\begin{array}{l}\text { Counter-Balancing of Crankshaft in Multiple- } \\
\text { Cylinder (6) Engine }\end{array}$ & 4 \\
\hline 1920 & Packard & Lanchester Vibration Dampener & 4 \\
\hline 1921 & $\begin{array}{l}\text { Duesenberg, } \\
\text { Kenworthy }\end{array}$ & Straight-Eight (or in-line) Engine & 4 \\
\hline 1922 & Duesenberg & Overhead Camshaft Engine & 4 \\
\hline & Nash & Rubber Engine Mounts & 5 \\
\hline 1924 & Cadillac (GM) & Balanced V-Type 8 Cylinder Engine & 5 \\
\hline 1924 & Cadillac (GM) & Crankcase Ventilation & 5 \\
\hline 1925 & Chrysler & High Compression L-Head Engine & 4 \\
\hline 1926 & Oakland (GM) & L-6 Engine (Begins Low Stroke-to-Bore Ratio Trend) & 5 \\
\hline & Chrysler & Valve-Šeat İnserts in Cast-Iron Cylinder Blocks & 4 \\
\hline & & $\underline{\text { Carburetion/Fuel }}$ & \\
\hline 1910 & Adams-Farwell & Early Fuel Injection System & 4 \\
\hline 1917 & Studebaker & Internal Manifold "Hot Spot" on the Intake Manifold & 4 \\
\hline 1923 & Cadillac (GM) & Thermostatic Carburetion Control & 4 \\
\hline 1930 & Chrysler & Stromberg-Supplied Downdraft Carburetor & 4 \\
\hline & & Ignition & \\
\hline 89 & Packard & Automatic Spark Advance & 4 \\
\hline
\end{tabular}


Table 2 (continued)

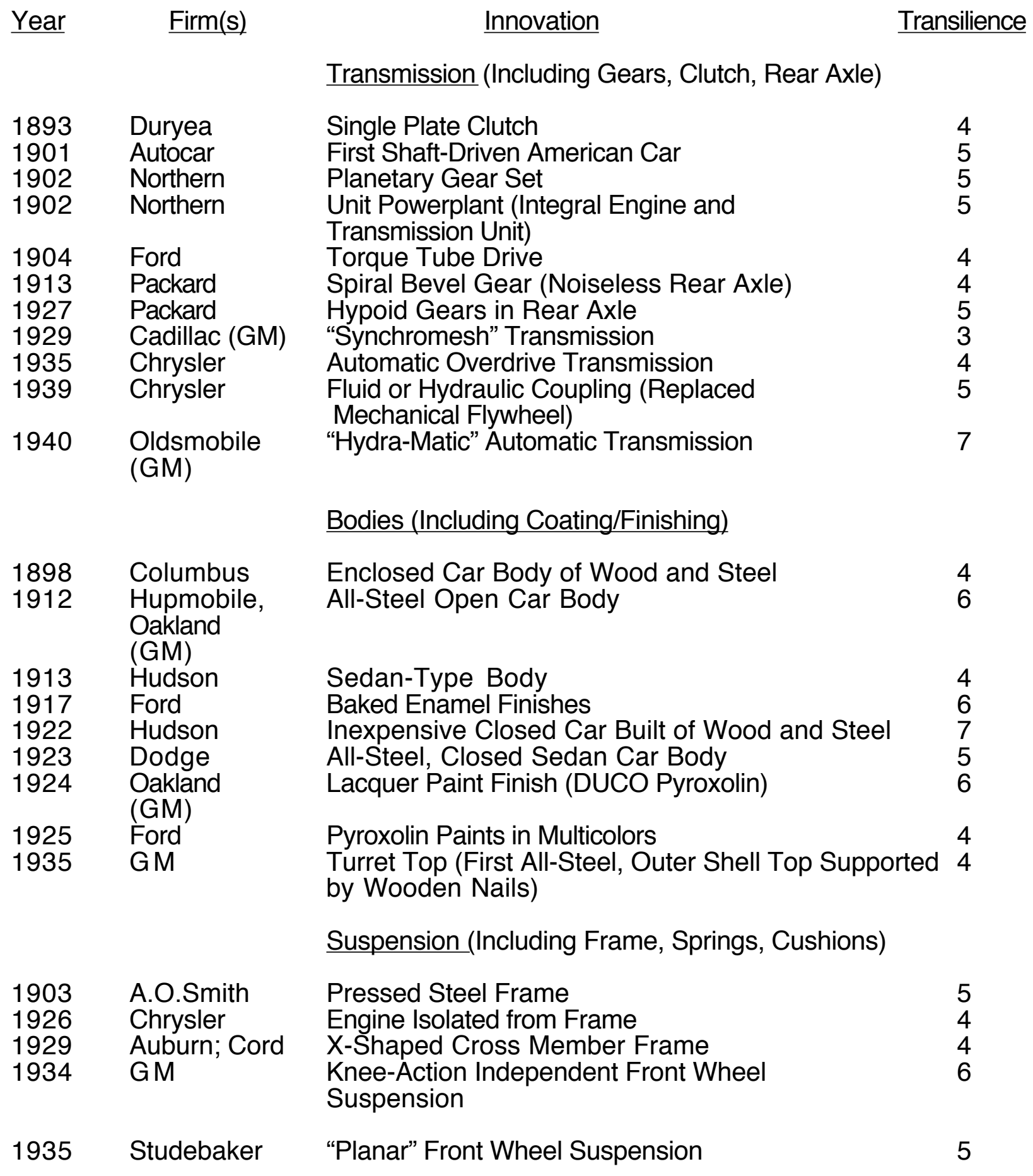


Table 2 (continued)

\begin{tabular}{cllc} 
Year & \multicolumn{1}{c}{ Firm(s) } & \multicolumn{1}{c}{ Innovation } & Transilience \\
& & Electrical System & \\
1906 & Ford & Wiring Harness for Electrical System & 4 \\
1908 & Ford & Magneto Integrated into Flywheel & 6 \\
1912 & Cadillac (GM) & Electric Starter & 4 \\
& & Braking & \\
& & Internal-Expanding Brakes & 4 \\
1898 & Duryea & Duesenberg & Four-Wheel Hydraulic Brakes
\end{tabular}

Source: Abernathy et al. [1983, pp. 155-167] 
Table 3

Labor Productivity and Capital in the Automobile Industry

$\begin{array}{lclr} & \begin{array}{l}\text { Number of } \\ \text { Automobiles/Wage } \\ \text { Earner }\end{array} & \begin{array}{l}\text { Value Added/ } \\ \text { Wage Earner }\end{array} & \text { Capital/Wage Earner } \\ 1899 & 1.66 & \$ 1314 & \\ 1904 & 1.89 & 1401 & \$ 2,007 \\ 1909 & 1.68 & 1552 & 2,624 \\ 1914 & 4.51 & 2176 & 3,945 \\ 1919 & 4.90 & 3320 & 6,223 \\ 1921 & 7.52 & 3564 & 9,909 \\ 1923 & 9.66 & 3618 & 6,508 \\ 1925 & 9.80 & 4108 & 9,549 \\ 1927 & 9.09 & 3977 & 11,073 \\ 1929 & 11.84 & 4475 & \\ 1931 & 8.05 & 3333 & \\ 1933 & 7.60 & 2660 & \\ 1935 & 10.14 & 2900 & \\ 1937 & 9.88 & 3144 & \\ & & & \end{array}$

Source: The series on number of automobiles per wage earner and value added per wage earner are from the Census of Manufacturers as reported in FTC [1939, p. 7]. The data on capital per wage earner are from the Census of Manufacturers for 1904-1919 and from Facts and Figures in the Automobile Industry 1921-1927, as reported in Katz [1921, p. 247] 
Table 4

Major Automobile Process Innovations Through 1940

\begin{tabular}{|c|c|c|c|}
\hline Year & Firm(s) & Innovation & ransilience \\
\hline 1896 & Duryea & $\begin{array}{l}\text { First Multiple Production of One Car Design } \\
\text { (13 vehicles) }\end{array}$ & 6 \\
\hline 1900 & $\begin{array}{l}\text { Most } \\
\text { producers }\end{array}$ & Gasoline Engine Mounted in Front of Car & 4 \\
\hline 1901 & Oldsmobile & First Mass Produced Auto & 7 \\
\hline 1902 & Marmon & First All-Metal Body (aluminum casting) & 5 \\
\hline 1907 & Ford & $\begin{array}{l}\text { Multiple Simultaneous Machining Operations on Cast } \\
\text { Parts }\end{array}$ & 5 \\
\hline 1907 & Ford & Integrally Cast Cylinder Block and Crankcase & 5 \\
\hline 1908 & Ford & Vanadium Steel Components & 4 \\
\hline 1910 & Ford & First Branch Assembly Plant & 7 \\
\hline 1912 & Budd & Electric Spot Welding & 4 \\
\hline $191 \overline{3}$ & Ford & Moving Flywheel-Magneto Assembly Line & 5 \\
\hline 1914 & Dodge & Mass Production of All Steel Open Body & 4 \\
\hline 1914 & Ford & Elevated Moving Chassis Assembly Line & 7 \\
\hline 1917 & Ford & Baked Enamel Finishes & 6 \\
\hline 1920 & Ford & Continuous Pouring of Molten Iron & 4 \\
\hline 1922 & $\begin{array}{l}\text { A.O. Smith } \\
\text { for GM }\end{array}$ & Mechanical Transfer in Building Automobile Frames & 5 \\
\hline 1923 & $\begin{array}{l}\text { Oldsmobile } \\
\text { (GM) }\end{array}$ & Sectionalized Body Production & 5 \\
\hline 1924 & $\mathrm{GM}$ & Harmonic Crankshaft Balancer & 4 \\
\hline 1924 & $\begin{array}{l}\text { Oakland } \\
\text { (GM) }\end{array}$ & Lacquer Paint Finish (DUCO-Pyroxolin) & 6 \\
\hline 1925 & $\begin{array}{l}\text { Budd } \\
\text { (supplier) }\end{array}$ & Automatic Welding Equipment & 5 \\
\hline 1928 & Ford & Seam Welding Method & 4 \\
\hline 1928 & GM & 1st Use of Tungsten Carbide Cutting Tools & 4 \\
\hline 1932 & Ford & $\begin{array}{l}\text { Hydraulic Transfer Machine (To Connect } 2 \text { Boring } \\
\text { Operations on a V-8 Engine) }\end{array}$ & 5 \\
\hline 1932 & Ford & Mass Produced, Low-Cost V-8 Engine & 5 \\
\hline 1934 & Ford & Cast Alloy Steel Crankshaft & 4 \\
\hline 1934 & Ford & Continuous V-8 Engine Casting Line & 7 \\
\hline 1936 & Ford & Transfer Machine for Drive Train Parts & 4 \\
\hline 193 & Ford & Semi-Unit Construction Body & 5 \\
\hline
\end{tabular}

Source: Abernathy et al. [1983, pp. 155-167] 
Table 5

Market Shares of Unit Tire Sales, Big Four Companies,

1921-1933

$\begin{array}{cccccc}\text { Year } & \text { Goodyear } & \text { Firestone } & \text { U.S. Rubber } & \text { B.F. Goodrich } & \text { Total } \\ 1921 & 16.1 \% & 8.2 \% & 8.5 \% & \text { n.a. } & \\ 1926 & 21.8 & 14.1 & 7.4 & 10.0 & 53.3 \\ 1929 & 29.2 & 19.0 & 6.6 & 7.2 & 62.0 \\ 1933 & 30.1 & 15.4 & 18.9 & 7.7 & 72.1\end{array}$

Source: French [1991, p. 47] 
Table 6

Tire Product Innovations, 1895-1940

Year(s) Tire Design Innovation

$1895 \quad$ Clincher tire (and rim)

1905

1906

1910

1923

1927

1899-1905

1923, 1936

1931

1935

1937

1938

1939

1905

1912

1922

1906

1912-23

1922

1924

1924

1926, 1937

1928-40 Improved accelerators

Synthetic Rubber

\section{Carbon Black}

Gas blacks

Furnace blacks

Rubber Chemicals

Organic accelerators

Improved accelerators

Ultra accelerators
Firms

Innovator not determined

Firestone/Goodyear

Firestone

Diamond

Firestone

Innovator not determined

Innovator not determined

Goodyear; Lee-Goodrich

Rayon Co.

duPont

Goodrich/Goodyear

$\mathrm{N}$-type synthetic rubber

S-type synthetic rubber

Goodrich/Goodyear

Goodrich

High carbon black treads

Diamond

Columbian

Aldehyde arrives (antioxidant)

Aromatic arrives (antioxidant)

Crack resistant antioxidants

Diamond

Goodrich/American Cyanamid

U.S. Rubber

Goodyear

Goodrich/duPont

duPont

(partial credit to American Cyanamid and Vanderbilt)

Vanderbilt/Monsanto/U.S. Rubber

Source: Warner [1966, pp. 268-270] 
Table 7

Estimated Production of Automobile Tire Casings by Types 1910-1933

(Percentages)

Construction

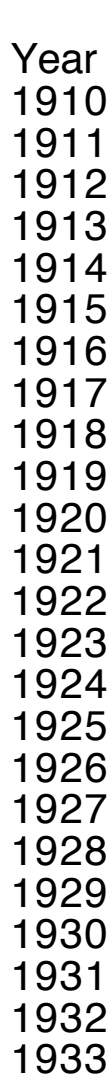

$$
\text { High }
$$

Fabric

100

100

99

98

97

95

92

90

85

75

65

60

51.4

42.6

29.7

14.1

5.3

1.5

0.6

0

0

0

0

0

Cord

2

3

5

8

10

15

25

35

40
Pressure

$\begin{array}{rr}0 & 0 \\ 0 & 0\end{array}$

$1 \quad 0$

48.6

55.4

58.8

51.8

47.2

44.6

33.0

25.2

16.9

14.2

12.2

10.8
Balloon
Cord
0
0
0
0

0

0

0

0

0

0

0

2.0

11.5

34.1

47.5

53.9

66.4

74.8

83.1

85.8

87.8

89.2
Rims

$\begin{array}{rr}\text { Clincher } & \begin{array}{r}\text { Straight } \\ \text { Side }\end{array} \\ 98.0 & 2.0 \\ 96.7 & 3.3 \\ 93.0 & 6.0 \\ 91.0 & 9.0 \\ 90.0 & 10.0 \\ 89.0 & 11.0 \\ 87.5 & 12.5 \\ 85.0 & 15.0 \\ 80.0 & 20.0 \\ 75.0 & 25.0 \\ 70.0 & 30.0 \\ 65.0 & 35.0 \\ 58.8 & 41.2 \\ 61.0 & 39.0 \\ 57.2 & 42.8 \\ 50.8 & 49.2 \\ 40.7 & 59.3 \\ 28.6 & 71.4 \\ 19.6 & 80.4 \\ 12.7 & 87.3 \\ 6.3 & 93.7 \\ 2.0 & 98.0 \\ 0.5 & 99.5 \\ 0 & 100.0\end{array}$

Source: Gaffey [1940, p. 43] 
Table 8

Indexes of Tire Labor Productivity

$(1925=100)$

$\begin{array}{lll}\text { Tires per man-hour } & \begin{array}{l}\text { Value Added per } \\ \text { man-hour }\end{array} & \begin{array}{l}\text { Tires per direct } \\ \text { man-hour in six } \\ \text { large plants }\end{array}\end{array}$

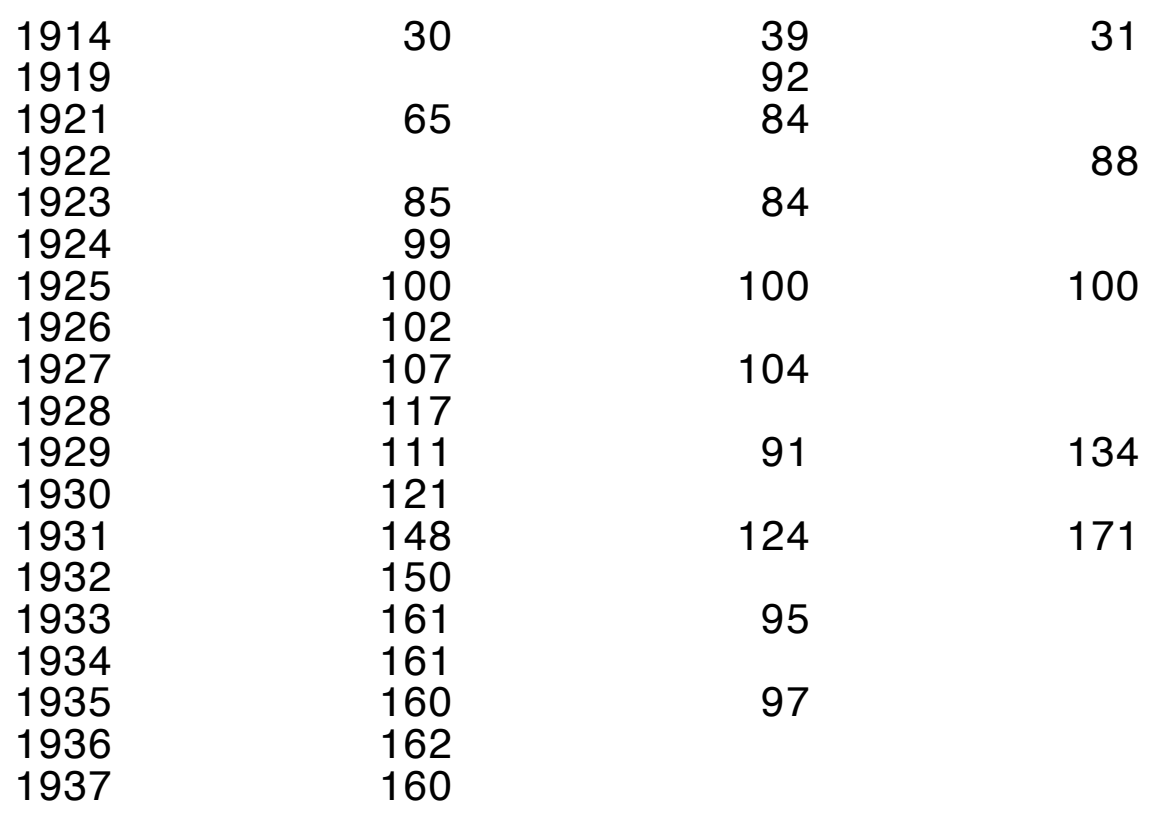

Source: Gaffey [1940, p. 69] for tires per man-hour and value added per man-hour, Stern [1933, p. 72] for tires per direct man-hour in six large plants 
Table 9

Prominent Mechanical Process Innovations

1901-1934

\begin{tabular}{|c|c|c|}
\hline$\underline{\text { Innovation }}$ & Date & Major Stages Affected \\
\hline Enlarged calenders and mixing mills & 1902 on & $\begin{array}{l}\text { Compounding, preparation of the } \\
\text { plies and rubber sheets }\end{array}$ \\
\hline Bias cutting machine & 1906-09 & $\begin{array}{l}\text { Preparation of the plies and rubber } \\
\text { sheets }\end{array}$ \\
\hline Core tire builidng machine & 1909 & Assembly \\
\hline Vacuum dryer & circa 1910 & Preparation of rubber \\
\hline Faster calenders and mixing mills & 1912 on & $\begin{array}{l}\text { Compounding, preparation of the } \\
\text { plies and rubber sheets }\end{array}$ \\
\hline $\begin{array}{l}\text { New machines for forming cord plies, } \\
\text { impregnating cords with rubber }\end{array}$ & 1915-1925 & $\begin{array}{l}\text { Preparation of the plies and rubber } \\
\text { sheets }\end{array}$ \\
\hline Banbury mixer & 1916 & Compounding \\
\hline Drum tire building machine & 1919 & Assembly \\
\hline $\begin{array}{l}\text { Pneumatic devices for opening molds } \\
\text { after vulcanization }\end{array}$ & $1920 \mathrm{~s}$ & Curing \\
\hline Molded type process & mid 1920s & Inner tubes \\
\hline Mechanical conveyors & $\begin{array}{l}\text { especially } \\
1920 \text { s }\end{array}$ & Multiple stages \\
\hline Plasticator & circa 1930 & Preparation of rubber \\
\hline Watch case vulcanizer & circa 1930 & Curing \\
\hline $\begin{array}{l}\text { Merry-go-round conveyor for tire } \\
\text { building }\end{array}$ & circa 1930 & Assembly \\
\hline
\end{tabular}


Table 10

Market Shares of Leading U.S. Producers of Television Sets,

$\begin{array}{lcrrr}\text { Firm } & 1948 & \underline{1958} & \underline{1968} & \underline{1978} \\ \text { Zenith } & 0 & 13.9 & 22.0 & 17.4 \\ \text { RCA } & 42.6 & 17.8 & 17.0 & 14.0 \\ \text { GE } & 1.9 & 13.9 & 11.0 & 9.5 \\ \text { Motorola } & 6.2 \dagger & 8.4 & 6.5 & 5.5 \\ \text { (Quasar) } & 16.6 & 9.9 & 6.0 & \\ \text { Philco } & 1.9 & 11.9 & 8.0 & 3.4^{*} \\ \text { Admiral } & 2 \dagger \dagger & 4.0 & 4.5 & 1.5 \\ \text { Magnavox } & & & & \end{array}$

Color

$\begin{array}{lllll}\text { Firm } & \underline{1960} & \underline{1968} & \underline{1978} & \underline{1989}\end{array}$

Zenith

RCA

GE

Motorola

(Quasar)

Philco

Admiral

Magnavox

95

20.0

30.0

21.2

20.0

6.5

$5.3^{\star \star * *}$

12.0

5.3

7.0

0

6.0

2.4

0

9.0

$7.0^{* * *}$

$6.4^{* \star *}$

†Estimate for he years 1950 and earlier combined.

††Estimate for 1950.

${ }^{\star}$ As part of Sylvania.

${ }^{* *}$ As part of Thomson.

${ }^{* * *}$ As part of Philips.

${ }^{* * * \star}$ As part of Matsushita.

Source: Levy [1981, pp. 84-88] for most figures, Oxenfeldt [1964, p. 13] for 1948 black and white, Darney [1991, p. 297] for 1989 color, Television Digest with AMFM Reports 25 Feb. 1950 for the 1948 Magnavox estimate, Look [1959, p. 201] for the 1950 and earlier Motorola estimate 
Table 11

Major Television

Product Innovations
Innovation

intercarrier sound system electromagnetic deflection portable receivers (b\&w/c) solid state (b\&w/c)

modular construction surface wave filters

shadow mask picture tube curved shadow mask light sensor for automatic brightness adjustment (b\&w/c) rectangular color picture tube

automatic degaussing rare earth phosphors in-line picture tube, small screen trinitron picture tube black surround (black matrix) picture tube in-line picture tube, large screen picture within a picture tinted phosphors tripotential electron gun projection television (b\&w/c) wide-angle tubes (b\&w/c)

very large size tubes bonded safety glass \& barefaced picture tubes (implosion protection) 
Table 11 (cont.)

\begin{tabular}{|c|c|c|}
\hline Year & Firms(s) & $\underline{\text { Innovation }}$ \\
\hline & Tuning & \\
\hline pre-1965 / 1965 & - / Magnavox & $\begin{array}{l}\text { automatic fine tuning (automatic } \\
\text { frequency control) (B\&W/C) }\end{array}$ \\
\hline 1950s-70s & Zenith \&c & remote control \\
\hline late 1960s & European firms & $\begin{array}{l}\text { electronic tuning (using varactors; } \\
\text { Sylvania first in U.S. in 1970) }\end{array}$ \\
\hline 1974 & Magnavox & $\begin{array}{l}\text { "STAR" system, digitally addressed } \\
\text { electronic remote control }\end{array}$ \\
\hline $\begin{array}{l}1971 \\
1973,76 \\
1974 \\
1976\end{array}$ & $\begin{array}{l}\text { Motorola } \\
\text { Sylvania \&c. } \\
\text { Magnavox } \\
\text { GE }\end{array}$ & $\begin{array}{l}\text { one-button tuning } \\
\text { automatic tuning and tracking circuitry } \\
\text { random access tuning } \\
\text { vertical interval reference signal used for } \\
\text { picture adjustment }\end{array}$ \\
\hline & Cabinetry & \\
\hline continuous & - & $\begin{array}{l}\text { new shock, temperature, and fire- } \\
\text { resistant materials, including phenolic }\end{array}$ \\
\hline & Peripheral & \\
\hline $\begin{array}{l}1972 \\
1975 \\
1978,1979\end{array}$ & $\begin{array}{l}\text { Magnavox } \\
\text { Sony } \\
\text { Philips, Magnavox }\end{array}$ & $\begin{array}{l}\text { video games } \\
\text { video tape recorder } \\
\text { video disc player }\end{array}$ \\
\hline & ? & \\
\hline
\end{tabular}




\section{Table 12}

Major Television Process Innovations

Year

Innovation

Rank

\section{Assembly Lines}

1946

assembly lines with

7

1946

conveyor belts

overhead conveyors for

4

chassis and materials

1946

trunnion supports for

4

inverted chassis for

1946-47

working positions

1952-55

pass-along assembly line

with rolling cradles in tracks

conveyor sped up 14\%

to fit 24-inch chassis on a

line usually used for 21-

inch sets

Jigs, Component Preparation, and Riveting

$1946-50$

1948-49

1948-50

1950-53

1946

1946

1946

$1949-50$

1951-56

1953-54

multiple part-holding

subassembly soldering

4

4

jigs, of many types

automatic lead cutting

4

machines

automatic positioning

devices for riveting, \&

automatic tripping

multiple riveting machine

for riveting of pin plates

and terminal

\section{Testing and Alignment}

continuity tests

setups for i-f, r-f, and

5

deflection tests

4

4

central test signal source

improved, lower-cost test

equipment

intensity marker electronic

equipment for i-f alignment

new adjustment and test

procedures for color TVs

4

5

5

4

4 
Table12 (cont.)

Year

Innovation

$\underline{\text { Rank }}$

Dip Soldering

1949

dip soldering for TV

6

1949-53

chassis and boards

automatic conveying and

4

feeding machines for

fluxing and soldering

\section{Printed Circuits}

1951-52

use of printed wiring

6

boards for TVs

1953-56

i-f transformer windings

5

covered with leakage-

preventing dielectric

sheets

1951-55

redesign of components

5

for use in printed wiring

boards

1953-56

board processing

machinery

1966

1970-71

use of integrated circuits

ceramic substrate printed

circuit production

\section{Component Insertion}

1953-54

automatic insertion

machines for resistors and jumpers

1953-55

automatic air-operated

4

cutting and clinching of

4

7

5

1954-55

component leads

component-belting

machines

Source: Authors' analysis (see text) 


\section{Table 13}

\begin{tabular}{lc}
\multicolumn{2}{c}{ Labor Productivity Index for Radio and Television Manufacturing } \\
Year & Index \\
1958 & 40.8 \\
1959 & 42.5 \\
1960 & 44.5 \\
1961 & 46.3 \\
1962 & 50.0 \\
1963 & 54.1 \\
1964 & 53.7 \\
1965 & 58.1 \\
1967 & 59.1 \\
1968 & 61.6 \\
1969 & 66.7 \\
1970 & 65.2 \\
1971 & 71.2 \\
1972 & 73.2 \\
1973 & 83.7 \\
1974 & 83.2 \\
1975 & 85.9 \\
1977 & 91.6 \\
1978 & 103.4 \\
1979 & 100.0 \\
1980 & 116.7 \\
\hline
\end{tabular}

Source: U.S. Bureau of Labor Statistics [1983, p. 217] 


\section{Table 14}

\section{Dollar Shares of Penicillin Sales}

Firm

Lilly

American Home Prods. (Wyeth)

Squibb

Bristol

Abbott

Pfizer/Roerig
1960 Share

21.0

17.0

13.8

8.0

6.7

2.4
1973 Share

13.1

20.6

13.0

22.6

1.8

13.4

Source: Schwartzman [1976, pp. 131-132] 
Table 15

Penicillin Types and Their Manufacturers, 1948-1993

Penicillin G†

Penicillin O

Penicillin V†

Phenethicillin†

Ampicillin†

NEP penicillin

Methicillin

Oxacillin

Cloxacillin

[Innovation dated as 1942 by Achilladelis]

Abbott 1948-1964

Baker 1948-1952

Bristol 1948-1959, 1961, 1974, 1977, 19811983

Commercial Solvents 1948-1959

Cutter 1948-1954

Heyden 1948-1953

Hoffman LaRoche 1948-1949

Lederle 1948-1949, 1954-1955

Lilly 1948-1969, 1972, 1976-1981

Merck 1948-1986

Pfizer 1948-1992

Schenley 1948-1953

Squibb 1948-1982

X 1948-1953, Upjohn 1954-1957

Wyeth 1948-1993

U.S. Rubber 1949

Monsanto 1954

Penick, S.B. 1954-1955

X 1951-1953, Upjohn 1954-1964, 1966

Pfizer 1968-1975

*Lilly 1955-1990

Abbott 1956-1974

Wyeth 1956-1976, 1983-1985

Bristol 1958, 1970-1985, 1987, 1989-1993

Squibb 1968-1976

Pfizer 1976-1988

[*Also developed by Glaxo (UK).]

${ }^{*}$ Bristol 1959-1975

Pfizer 1960-1965, 1967-1971

Squibb 1960-1961, 1963-1964

Wyeth 1962-1966

[ ${ }^{\star}$ Also developed by Beecham (UK).]

Bristol 1963-1993

Wyeth 1966-1993

*Beecham 1968-1990

Squibb 1968-1976

Trade Enterprises 1971-1981

Biocraft 1972-1993

Kanasco 1986-1992

Merck 1963

Bristol 1961-1985

Beecham 1972-1982

Wyeth 1991

Table 15 (contined)

Bristol 1961-1985

Beecham 1969-1992

Biocraft 1979-1992

Bristol 1964-1985

Beecham 1968-1993

Biocraft 1980-1988, 1990-1993

Kanasco 1991-1992 
Nafcillin

Dicloxacillin

Hetacillin

Carbenicillin†

Amoxicillin

Ticarcillin

Azlocillin†

Cyclacillin

Epicillin

Piperacillin

Amdinocillin†

Sulbactam†

Floxacillin
Wyeth 1964-1990

Beecham 1975-1976, 1984-1988, 1990-1991

Bristol 1975-1977, 1979-1985, 1987

Bristol 1966-1979, 1981-1985

Beecham 1968-1992

Wyeth 1968, 1970-1975, 1977-1989

Biocraft 1983-1993

Kanasco 1990, 1992

Bristol 1966-1979, 1981-1991

[Innovation dated as 1969 by Achilladelis]

*Beecham 1970-1985, 1987, 1989††

*Pfizer 1972-1986, 1988

Biocraft 1986

Beecham 1973-1993

Biocraft 1976-1993

Bristol 1977-1993

Trade Enterprises 1978-1979

Wyeth 1980-1985

Kanasco 1986-1992

Beecham 1976-1993

[ ${ }^{\star}$ Developed 1978 by Bayer (Germany)]

Wyeth 1978-1985

Bristol 1984-1985

Biocraft 1986, 1988

Trade Enterprises 1978-1982

Kanasco 1986

Bristol 1982-1993

[Developed 1984 by Roche (Switzerland)]

[`Developed 1986 by Pfizer]

Beecham 1989††

*Innovating firm.

†Major innovation according to Achilladelis [1993].

$X$ Identity of producer kept confidential in Synthetic Organic Chemicals.

††Beecham may have continued production of carbenicillin and floxacillin after 1989.

After 1987, Synthetic Organic Chemicals does not specify all of the semisynthetic penicillins produced solely by Beecham.

Sources: Synthetic Organic Chemicals, FTC [1958], and Achilladelis [1993]. 
Table 16

U.S. Production by Type of Penicillin (Metric Tons), 1948-1980

\begin{tabular}{|c|c|c|c|c|c|c|c|}
\hline \multirow[b]{2}{*}{ Year } & \multicolumn{4}{|c|}{ Natural } & \multicolumn{2}{|c|}{ Semisynthetic } & \multirow{2}{*}{ Total } \\
\hline & G Pot. & G Proc. & $\underline{\mathrm{V}}$ & Other & Ampic. & Other & \\
\hline$\overline{1948}$ & 14 & 17 & $\overline{0}$ & 34 & 0 & 0 & 48 \\
\hline 1949 & 28 & 35 & 0 & 13 & 0 & 0 & 69 \\
\hline 1950 & 42 & 60 & 0 & 19 & 0 & 0 & 112 \\
\hline 1951 & 61 & 96 & 0 & 25 & 0 & 0 & 171 \\
\hline 1952 & 73 & 93 & 0 & 37 & 0 & 0 & 185 \\
\hline 1953 & 57 & 120 & 0 & 45 & 0 & 0 & 204 \\
\hline 1954 & 84 & 144 & 0 & 54 & 0 & 0 & 258 \\
\hline 1955 & 46 & 108 & 10 & 57 & 0 & 0 & 196 \\
\hline 1956 & 54 & 165 & 42 & 43 & 0 & 0 & 286 \\
\hline 1957 & 81 & 174 & - & 60 & 0 & 0 & 315 \\
\hline 1958 & 44 & 123 & - & 68 & 0 & 0 & 234 \\
\hline 1959 & 89 & 139 & - & 30 & 0 & & 257 \\
\hline 1960 & 123 & 227 & - & 40 & 0 & & 390 \\
\hline & 240 & 227 & - & 191 & - & - & 1114 \\
\hline 1970 & 983 & 990 & - & 610 & 310 & 90 & 3097 \\
\hline 1 & 990 & - & - & 1687 & 321 & 131 & 3129 \\
\hline 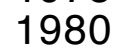 & 1247 & - & - & 1707 & 437 & 365 & 3757 \\
\hline
\end{tabular}




\section{Table 17}

Real Average Price of Penicillin, 1945-1980

Year

1945

1950

1955

1960

1965

1970

1975

1980
Price per Pound

$\$ 5291$ 266

89

69

11

18

8

8

Source: Synthetic Organic Chemicals, various years. 


\section{Table 18}

Categories of Penicillin Process Innovation

Penicillium Strains \& Media

Development of higher-yield cultures by mutation and testing

Investigation of mold life cycles and effects of seed pellet form

New chemicals for fermentation medium

More efficient antifoams

Fermentation \& Control

Higher-power agitators in fermentation vessels

Improved air sterilization filters

Automated monitoring of acidity, carbon dioxide output, dissolved oxygen, nutrients, and antifoam

Automated pumps to control $\mathrm{pH}$ and add fermentation ingredients, precursors, and antifoam when necessary

Continuous sterilization of medium

Computer control of fermentation

Semisynthetics

Production means for 6-APA, through direct fermentation or via penicillin $G$

Product-specific synthetic methods from 6-APA

Filtration, Extraction, and Packaging of Penicillin

New methods of filtration

New methods of extraction (Podbelniak extractors, solvent-only extractors)

Solvent recovery systems

New methods of drying (radio frequency dehydration)

More efficent sterile packaging machines

Waste Treatment

Rationalization of waste treatment using trickling filters \& other equipment

Source: Authors' review of literature (see text) 